\author{
University of Szeged \\ Doctoral School in Linguistics \\ Theoretical Linguistics PhD Programme
}

\title{
Four repair operations in Hungarian conversations in the light of cross-linguistic examinations
}

Zsuzsanna Németh

Supervisor:

Dr. Enikő Németh T. CSc

Szeged

2015 


\section{Table of contents}

1 Introduction: the aim and structure of the thesis. 4

2 The metatheoretical background of the thesis: Kertész and Rákosi's (2012, 2014) $\mathbf{p}$-model of plausible argumentation.............................. 11

2.1 The main issues of the model............................................. 11

2.2 The notion of plausibility: the uncertainty of linguistic data.......................... 12

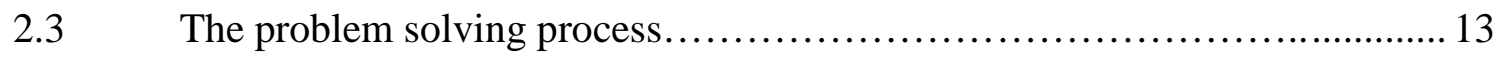

2.3.1 The cyclic and prismatic nature of linguistic theorizing - plausible

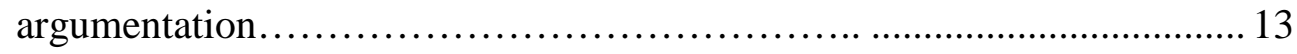

2.3.2 Problem-solving strategies.......................................... 14

3 The object theoretical background of the thesis: conversation analysis...... 15

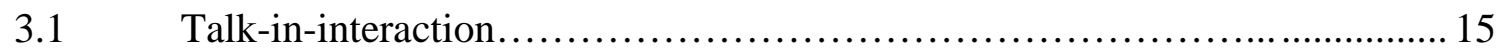

3.2 The organization of conversational repair - Defining the domain of repair, self-repair, and repair operation................................................ 19

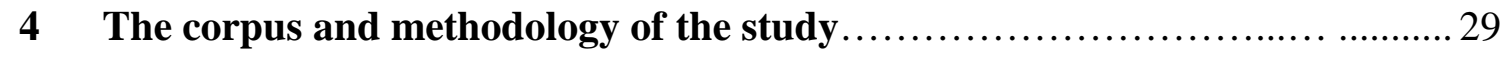

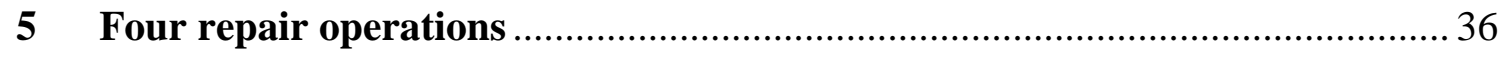

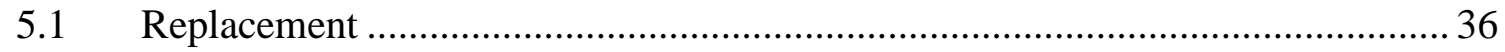

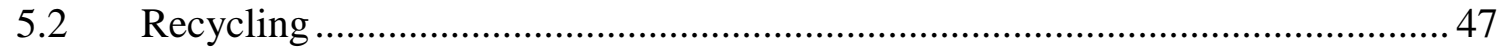

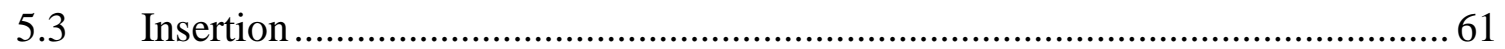

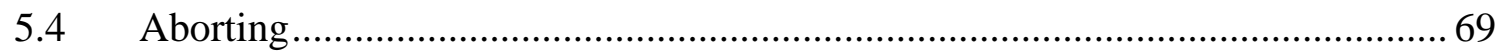

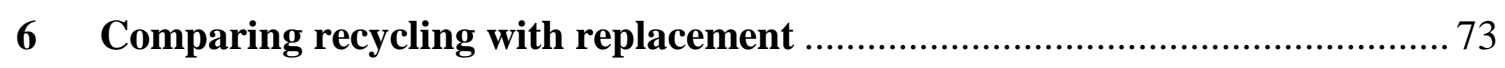

6.1 Recycling and replacement in the languages examined so far............... 73

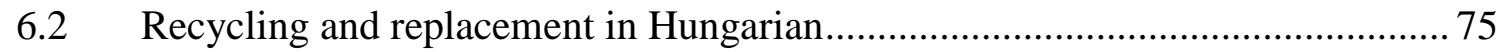

6.2.1 Recycling repair - syntactic category and word length in Hungarian............. 75

6.2.2 Replacement repair - syntactic category and word length in Hungarian ........ 83

6.2.3 Repair type, word length, syntactic class, and the site of repair initiation in

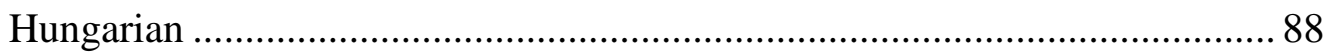

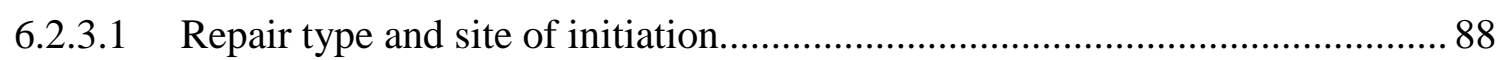

6.2.3.2 Word length, syntactic class, and the site of repair initiation......................... 91

6.2.3.3 Bisyllabic words and restarting repair in Hungarian ................................... 95

6.3 Recycling initiated after recognizable completion, restarting, and replacement. 98

6.4 Sub-conclusion - Comparing recycling with replacement............................... 107 
7 Hypothesis on the preference hierarchy of repair operations ......................... 109

7.1 The notion of preference in conversation analysis .......................................... 109

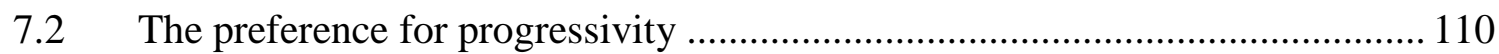

7.2.1 Halting the progressivity of the turn by employing recycling ...................... 112

7.2.2 Halting the progressivity of the turn by employing replacement .................. 116

7.2.3 Halting the progressivity of the turn by employing insertion........................ 117

7.2.4 Halting the progressivity of the turn by employing aborting ….................... 118

7.3 The preference hierarchy of repair operations................................................ 119

7.4 Testing the preference hierarchy hypothesis …............................................. 122

7.5 Sub-conclusion - Hypothesis on the preference hierarchy of repair operations 135

8 Conclusion - The results of the research and future directions................136

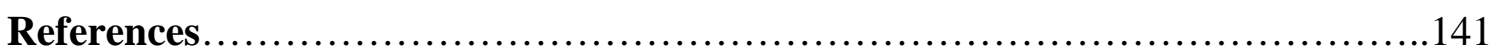

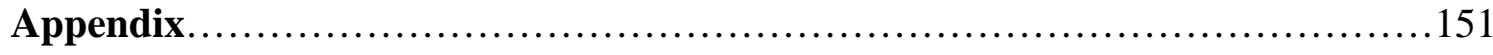

Transcription conventions........................................... 151

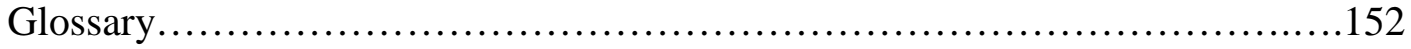

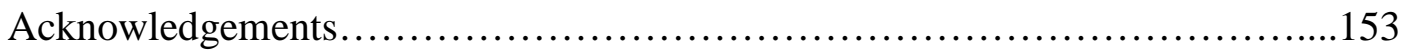




\section{Introduction: The aim and structure of the thesis}

In conversations, speakers may encounter problems which make them stop their talk-inprogress. The treatment of such problems triggering speech disfluencies has been intensively studied in various linguistic disciplines. In the framework of conversation analysis (CA), which studies human social interaction across sociology, linguistics, and communication (Stivers-Sidnell 2013: 1), "the set of practices whereby a co-interactant interrupts the ongoing course of action to attend to possible trouble in speaking, hearing or understanding the talk" constitutes the domain of repair (Kitzinger 2013: 229), and is regarded as one of the fundamental structures of conversation (Sidnell-Stivers 2013: v). While conversation analysis examines repair from an interactional point of view, psycholinguistics and phonetics regard repair as the correction of speech disfluencies (Gósy 2004: 15), and focus on the cognitive and phonetic aspects of the phenomenon. ${ }^{1}$ As the main focus of my research is on the interactional aspects of the repair mechanism, the starting framework of my study is conversation analysis.

Repair is composed of three parts in the conversation analytic framework (Schegloff et al. 1977; Schegloff 1997a, 2000) (see Extract $\left.(1)^{2}\right)$. The "possible disjunction with the immediately preceding talk" is repair initiation (Schegloff 2000: 207) (in Extract (1) - $\ddot{o}$ ' - uh'). The segment of talk to which repair initiation is addressed is the troublesource or repairable ${ }^{3}$ (Schegloff et al. 1977: 363) (in Extract (1) fölál 'sacri'). Finally, repair outcome is the solution or abandonment of the problem (Schegloff 2000: 207; cf. Schegloff et al. 1977: 364) (in Extract (1) kockára teszed 'risk'). The term repair refers to the success of the repair procedure (Schegloff et al. 1977: 363).

\footnotetext{
${ }^{1}$ See, for example, Boomer-Laver 1968; Fromkin 1973; Nooteboom 1980, 2005; Levelt 1983, 1989; Cutler 1988; Postma-Kolk-Povel 1990; Blackmer-Mitton 1991; Kolk-Postma 1997; Clark-Wasow 1998; Poulisse 1999; Postma 2000; Shriberg 2001; Pérez-Palma-O'Seaghdha 2007; Gósy 2003, 2004, 2005, 2008, 2012; Markó 2004, 2006; Huszár 2005; Bóna 2006; Horváth 2004, 2007; Fabulya 2007; Gyarmathy 2006, 2007, 2009, 2012a, b; Gyarmathy-Gósy 2014).

${ }^{2}$ The corpus is described in Chapter 4. Transcription conventions can be found in the Appendix. Since the punctuation in the extracts does not indicate syntactic but intonational boundaries, I do not use capital letters at the syntactic boundaries. The glosses are not intended to capture all morphological properties of Hungarian words but indicate only the necessary ones for the present purposes. The abbreviations used in the glosses can also be found in the Appendix. For the sake of convenience, I repeat the English translation of the longer examples at the end of the extracts.

${ }^{3}$ The term trouble-source thus refers to the particular segment of talk judged problematic by the speaker who initiates repair, and should be distinguished from the basis of the problem (e.g., noise).
} 
(1) (SZTEPSZI2: 953)

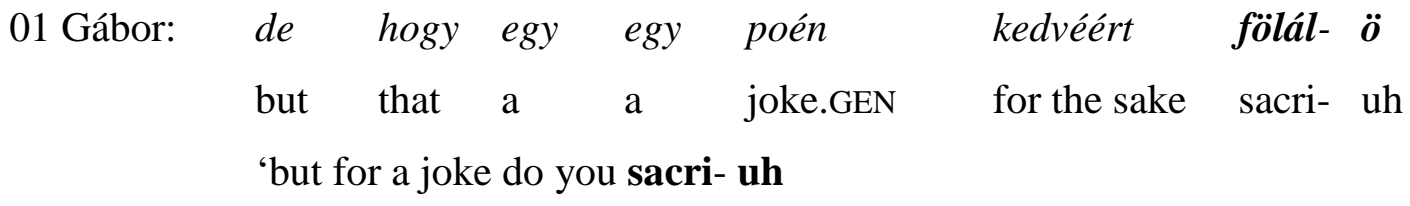

02

$\begin{array}{llll}\text { kockára } & \text { teszed } & \text { egyébként } a: ? \\ & \text { risk.DEF.2SG by the way the }\end{array}$

risk, by the way, your (place at the university)?'

While self-repair (self-initiated repair) is initiated by the speaker producing the trouble-source (Kitzinger 2013: 230) (Extract (1)), other-repair (other-initiated repair) is initiated by someone other than the speaker of the repairable (Kitzinger 2013: 231) (Example (2)).

(2) (DB2 Angela)

$1 \quad$ Clt: $\quad$.hhhhh But it nourished him (.) in utero

$2 \quad$ well did it.

$3 \quad$ (.)

4 Ang: Pardon?

5 Clt: It nour- The placenta nourished him

6 .hhh in utero

$7 \quad$ Ang: Yeah

(Kitzinger 2013: 232)

The previous studies in the conversation analytic literature have paid a great deal of attention to self- and other-initiated repair (see, e.g., Schegloff-Jefferson-Sacks 1977; C. Goodwin 1980, 1981; M. H. Goodwin 1983; Heritage 1984; Jefferson 1972, 1974, 1987; Fox-Hayashi-Jasperson 1996; Drew 1997; Stivers 2005; Robinson 2006; WilkinsonWeatherall 2011; Schegloff 1979, 1987, 1992, 1997a, b, 2000, 2008a, b, 2013). Apart from English, repair has been studied across a range of other languages. Kitzinger (2013: 229) mentions Brazilian Portuguese (Guimaraes 2007), East Caribbean English Creoles (Sidnell 2008), Finnish (Laakso-Sorjonen 2010), French (Maheux-Pelletier-Golato 2008), German (Egbert 1996, 2004), Indonesian (Wouk 2005), Japanese (Fox et al. 1996; Hayashi 2003), Korean (Kim 1993, 2001), Mandarin (Wu 2006; Luke-Zhang 2010), Norwegian 
(Svennevig 2008), Russian (Bolden-Mandelbaum-Wilkinson 2012), and Thai (Moerman 1977). While Fox and her seven colleagues (2009) have carried out a comparative study on English, Bikol, Sochiapam Chinantec, Finnish, Indonesian, Japanese, and Mandarin (see Section 6.3, 101), Fox, Maschler, and Uhmann (2010) have examined self-repair in English, Hebrew, and German. We can add Hungarian to this list. While Lerch (2007) and Németh $(2012 a, b, c, 2013,2014)$ have focused solely on self-repair in Hungarian, Szabó (2012) has examined other-initiated repair as well when applying conversation analysis to language ideology studies. Self-repair is preferable to other-repair (Schegloff et al. 1977), and the most common type of repair is self-repair in the turn containing the repairable, i.e., same-turn self-repair (Kitzinger 2013: 232). The focus of the present thesis is on this repair type.

Schegloff (2013) describes ten main same-turn self-repair strategies, which speakers employ "to deal with some putative trouble-source in an ongoing turn-at-talk in conversation or to alter it in some interactionally consequential way" (Schegloff 2013: 43). These repair operations are recycling, replacing, deleting, searching, parenthesizing, sequence-jumping, reformatting, reordering, inserting, and aborting. Replacing involves a speaker's substituting for a wholly or partially articulated element another, different element (Schegloff 2013: 43) (Example 3).

(3) (Debbie and Shelley, 3)

Shl: that's why he can't go:, .hh an I said b- to be

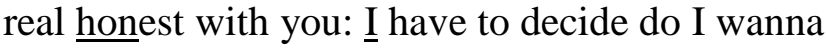
spend this money becuz if Mark was goin .hh he was gonna pay fer- fer m- a lot of it, cause he won money playing footba:1l.

(Schegloff 2013: 44)

Inserting is a self-repair strategy whereby the speaker inserts one or more new elements into the turn (Schegloff 2013: 45) (Example 4).

(4) (Joyce \& Stan, 4)

Stan: And fer the ha:t, I'm lookin fer somethi:ng uh a little different. Na- uh:f: not f:: exactly funky (Schegloff 2013: 46) 
The speaker can abandon what s/he has said altogether and start the same action in a different form. That is the repair operation of aborting (Schegloff 2013: 52) (Example 5).

(5) $(\mathrm{SN}-4,08)$

Mrk: She's jus' that girl thet: uh:, (0.2)

· hh I met her through uh:m::, (0.1)

I met "er in Westwood.

(Schegloff 2013: 53)

When the speaker says again some stretch of talk, s/he employs the repair operation of recycling (Schegloff 2013: 59) (Example 6).

(6) $(\mathrm{KC}-4,07)$

\section{Kay: I don think they grow a I don think}

they -grow a culture to do a biopsy.

(Schegloff 2013: 59)

When the speaker employs deleting, s/he deletes one or more elements which s/he has already articulated (Example (7)).

(7) $(\mathrm{TG}, 9)$

Bee: tuh go en try the:re. Because I als- I tried Barnes

'n Nobles 'n, (0.6) they didn' have any'ing they don'

have any art books she tol' me,

Ava: Mmm

(Schegloff 2013: 48)

The target of searching can be a name or a place, but it can also happen that the source of the problem is unclear and the target is not "precise" (Schegloff 2013: 50) (Example 8).

(8) $(\mathrm{TG}, 17-18)$

Ava: A:nd uh:m,

Ava: ${ }^{\circ}$ Wuhwz I gonnuh say. 
$(0.7)$

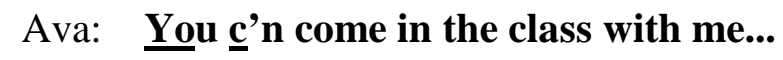

(Schegloff 2013: 50)

Parenthesizing is the interpolation of a clausal unit into the turn (Schegloff 2013: 51)

(Example (9)). ${ }^{4}$

(9) (Auto Discussion, 7)

Mik: So, boy when Keeg'n come in he- yihknow how he's gotta

temper anyway, he js::: ${ }^{\circ}$ wa:::.::h screamed iz damn

e:ngine yihknow

(Schegloff 2013: 52)

When the speaker employs sequence-jumping, s/he turns to something unrelated to the turn and sequence in progress (Schegloff 2013: 56) (Example (10)).

(10) $(\mathrm{KC}-4,14)$

Fre: $\quad$ You know what we're gonna- in fact I'm- she I

haven't seen her since I spoke to you but I'm going to

talk to=what a you making?

(Schegloff 2013: 56)

Reformatting is the grammatical transformation of the turn (Example (11)). ${ }^{5}$

(11) (Virginia, 22)

Vir: You want me to write you a: a little list every

$\mathrm{w}[\mathrm{eek}$ ?

Mom: [I: would- (.) that would be great.

(Schegloff 2013: 63)

Reordering re-orders the elements of the turn-constructional unit (Example (12)). ${ }^{6}$

\footnotetext{
${ }^{4}$ Since the exact definition of insertion given in Section 5.3 includes the phenomenon of parenthesizing, I will analyze the cases of parenthesizing as insertions in the thesis.

${ }^{5}$ Since the exact definition of aborting given in Section 5.4 includes the phenomenon of reformatting, I will analyze the cases of reformatting as abortings in the thesis.
} 
(12) (SBL 1:1:10:R)

Bea: Ah hah end yih never jus' (.) eh yih js' never saw

such devotion in your li:fe

(Schegloff 2013: 65)

Apart from Schegloff's (2013) study on the ten repair operations introduced above, we can say that relatively few of the previous conversation analytic studies have focused on repair operations in their own right. Among the exceptions, see Fox et al. 2009 and Fox et al. 2010 on recycling and replacement (see the languages above); Luke and Zhang 2010 on insertion in Mandarin Chinese; and Wilkinson-Weatherall 2011 on insertion in British, New Zealand, and U.S. English. As far as the investigation of repair operations in Hungarian is concerned, apart from the previously published findings of the present thesis (Németh 2012a, b, c, 2013, 2014), Lerch (2007) has explored the lexical category of the target word in repetition (recycling). The list also shows that even fewer studies in the conversation analytic literature have examined repair operations relative to each other, i.e., contrasting them in the repair mechanism from a certain perspective or perspectives (among the exceptions, see Fox et al. 2009; Fox et al. 2010; and Németh 2012a, b, c, 2013, 2014), and as far as the author of the present thesis knows, the only cross-linguistic studies comparing two repair operations with each other are Fox et al. 2009 and Fox et al. 2010.

On the basis of the research of Fox et al. (2009) and Fox et al. (2010) involving a total of nine languages in their examinations, it can be suggested that recycling is a more frequent repair operation than replacement in all the languages examined. This generalization prompts us to ask the following research questions: Is there such a difference between the frequency of recycling and replacement in Hungarian? That is, does the distribution of recycling and replacement in Hungarian conversations support Fox's et al. (2009) and Fox's et al. (2010) results? If yes, how could we explain the cross-linguistic difference between the frequencies of the two repair operations?

The general aims of the thesis are therefore as follows: 1) to examine recycling and replacement repairs relative to each other in Hungarian conversations, and make a comparison with the languages so far investigated in this respect, and 2) to propose a model able to describe repair operations relative to each other. Setting up the model requires the extension of the research to further repair operations. Insertion and aborting

\footnotetext{
${ }^{6}$ Since the exact definition of aborting given in Section 5.4 includes the phenomenon of reordering, I will analyze the cases of reorderings as abortings in the thesis.
} 
have received relatively greater attention in the conversation analytic literature than the other repair operations (except for recycling and replacement). Apart from these four repair operations, there are six operation types described in the conversation analytic literature (see above) (Schegloff 2013), but as Schegloff (2013: 68) suggests, there may be others which await recognition and invite description. However, the techniques employed in accomplishing deleting, searching, parenthesizing, sequence-jumping, reformatting, and reordering, and their interactional import have not been examined so far (cf. Schegloff 2013: 41). For this reason, in my study I will explore recycling, replacement, insertion, and aborting in Hungarian, and compare my findings with the previous results.

Conversation analysis grounds its empirical analyses in audio and film recordings of naturally occurring interactions collected in familiar, everyday settings as well as in institutional settings, and regards data as these recordings (Mondada 2013). The purposes of the present thesis require a wider spectrum of sources. Apart from semi-spontaneous speech recorded in a corpus consisting of Hungarian, casual face-to-face conversations, I build my argumentation on previous research, as well as on my intuition. The combination of these sources should be carried out in a careful way. Therefore, I also offer a metatheoretical reflection on my study using Kertész and Rákosi’s $(2012,2014)$ p-model of plausible argumentation, which regards data as plausible statements originating from direct sources (e.g., corpus, linguistic intuition, and experiment) (Kertész-Rákosi 2012: 169), and makes the conscious integration of the data from these various data sources possible. In my thesis, following the terminology of the p-model, by the term data I mean plausible statements originating from direct sources, and not the recordings which CA researchers produce as data by collecting them for the purpose of studying them, and not the recordings which can be done by participants for their practical purposes and turned into data by researchers (Mondada 2013: 38). The p-model as a metatheoretical model of linguistic argumentation and data handling helps me to reflect consciously and metatheoretically on various subphases of my research, including the clarification of the most important concepts I work with during my study and the treatment of problems I encounter during my argumentation. Illuminating these metatheoretical issues during my object theoretical discussion, I aim to make my object theoretical results more reliable.

The thesis is organized as follows. I first provide the metatheoretical background of the research, i.e., I introduce the p-model in Chapter 2, then I also provide the object theoretical, conversation analytical background of my thesis in Chapter 3. In Chapter 4, I describe the corpus and methodology of the study. In Chapter 5, using examples from the 
previous literature and the Hungarian corpus, I characterize the repair operations of recycling, replacement, insertion, and aborting. In Chapter 6, I examine recycling and replacement in Hungarian conversations relative to each other, and compare my results with the previous findings concerning the other languages so far examined in this respect. In Chapter 7, I extend the comparative analysis to insertion and aborting, and propose a model which describes repair operations relative to each other. In Chapter 8, I summarize the results and conclude the thesis.

\section{The metatheoretical background of the thesis: Kertész and Rákosi's $(2012,2014)$ p- model of plausible argumentation}

\subsection{The main issues of the model}

The p-model of plausible argumentation has been elaborated by Kertész and Rákosi (2012, 2014) in order to solve a central methodological problem in linguistics, namely, what types of data/evidence can be used and how these types of data/evidence work in linguistic theories (Kertész-Rákosi 2012: 1). The model also aims to reveal the relationship between the argumentation structure of theories and the structure and function of data and evidence, a relationship which is close but hidden, according to Kertész and Rákosi (2012: 2). The pmodel reflects on, for example, the role of data and evidence in linguistic theorizing, what subtypes of data can be regarded as evidence, how different linguistic theories should treat the useable types of data/evidence, or the treatment of problems in linguistic theorizing. The most important innovations of the p-model are the following: 1) it works with a new concept of data; 2) it claims that all kinds of linguistic data are uncertain; 3) uncertainty is explicated by the p-model as plausibility; 4) according to the model, linguistic theorizing is a dynamic process of plausible argumentation which is cyclic and prismatic in its nature; 5) the p-model regards inconsistency as the natural property of linguistic theories, and offers several techniques to handle it, making problem solving in linguistic theorizing more effective; 6) it argues for the pluralism of linguistic theorizing, which means that there may be more than one possible solution to a certain problem (Kertész-Rákosi 2014: 5). Since the p-model reflects on linguistic theorizing from a metatheoretical point of view in the way described above, applying it in the course of object scientific research makes the results more reliable. In the next three sections, I introduce three of the most important innovations of the model: its concept of plausibility, its notion of the dynamic process of plausible argumentation, and the problem-solving strategies it offers. 


\subsection{The notion of plausibility: the uncertainty of linguistic data}

One of the most important innovations of the p-model is the recognition that linguistic data are most of the time uncertain. The model accounts for this uncertainty with the help of the notion of plausibility and plausible statements. It defines a datum as a statement with a positive plausibility value (strength of acceptability) originating from a direct source (e.g., corpus, linguistic intuition, experiment) (Kertész-Rákosi 2012: 169). A source is regarded as a direct source with respect to a statement, if on the basis of its reliability the given statement is assigned a plausibility value. The p-model is able to treat and use uncertain statements by placing them in the argumentation process systematically as follows. In a sense, data function as starting points for the argumentation process: plausibility values, which they receive directly from direct sources, enter the argumentation process through them. However, they supply the linguistic theory with plausibility values not only in a direct, but also in an indirect way, when functioning as the premises of plausible inferences. Plausible inferences are therefore indirect sources of linguistic theorizing, because a hypothesis obtained as the conclusion of such an inference receives a plausibility value indirectly, from the datum serving as a premise of the inference. The main body of a given argumentation process is constituted by chains of plausible inferences (KertészRákosi 2012: 169-184, 2014: 37-46).

The p-model differentiates between three types of plausible inferences. The first type consists of cases where the premises are consistent and there is a logical consequence relation between the premises and the conclusion; however, at least one of the premises is not true with certainty ${ }^{7}$ but only plausible (deductive inferences). The second group is formed by the instances in which the premises are true with certainty, and they are consistent; nonetheless, the premises and the conclusion are not connected by a logical consequence relation but only a semantic relation (e.g., analogy, necessary or sufficient condition, causality, etc.). This semantic relation has to be extendable to the so-called

\footnotetext{
${ }^{7}$ True statements and demonstrative inferences are rare in linguistic theorizing. However, Kertész and Rákosi (2012: 81) note that if a hypothetically assumed linguistic universal is tested, and the result of the testing is negative, it is often interpreted as a demonstrative inference. They bring Moravcsik's (1969) universalcandidate as an example, which is the following. (U) If the indefinite article is derived from the cardinal 'one', then non-numerable nouns cannot take indefinite article. Kertész and Rákosi (2012: 81) argue that this universal can be refuted with the help of the following inference. It is true with certainty that if $U$, then if the indefinite article was derived from the cardinal 'one' in Coptic, then non-numerable nouns cannot take an indefinite article in Coptic. It is also true with certainty that in Coptic, the indefinite article was derived from the cardinal 'one', but non-numerable nouns can take an indefinite article. From this it follows that the negation of $U$ is also true with certainty.
} 
latent background assumptions. The latent background assumptions, which have to be plausible, true, or at least not known to be false or implausible according to some source, supplement the set of premises, and from the new set of statements a deductively valid inference can be obtained (Kertész-Rákosi 2012: 99, 2014: 22). It is of great importance in the model that the plausibility of a hypothesis obtained as the conclusion of such an inference is also influenced by the plausibility of the latent background assumptions. In the case of inductive inferences, for example, the latent background assumption is that the cases not investigated also possess the characteristics of the examined ones. The third type of plausible inferences differs from the second group only in one respect: among the premises of these inferences there is at least one which is not certainly true but only plausible (Kertész-Rákosi 2012: 56-128, 2014: 20-29).

The p-model's concept of evidence grasps the relationship between hypotheses and data. Evidence in this sense is not an objective, given subcategory of data; any datum can function as evidence for a hypothesis in a given argumentation process if it is a premise of a plausible inference making the hypothesis plausible. The notion of evidence in the model is thus interpreted relative to a given hypothesis of a given theory; consequently, it plays a crucial role in the evaluation and comparison of the plausibility of rival hypotheses, i.e., in the problem solving process (Kertész-Rákosi 2012: 178-184, 2014: 41-46).

\subsection{The problem solving process}

\subsubsection{The cyclic and prismatic nature of linguistic theorizing - plausible argumentation}

In order to judge the plausibility value of the premises of an inference, and the semantic relation between the premises and the conclusion, we need all information that may be relevant. For this reason, the p-model has introduced the notion of p-context, which includes a set of sources on the basis of which the plausibility value of statements can be judged. It also includes a set of statements with their plausibility values assigned to them with respect to the sources mentioned, as well as with their logical and semantic structure. Finally, the accepted methodological norms also belong to the p-context (Kertész-Rákosi 2012: 122, 2014: 27). The p-context can be informationally overdetermined if both a statement and its negation are made plausible by some (different) source. In these cases the p-context is p-inconsistent. The p-context can also be informationally underdetermined if it contains statements neither plausible nor implausible with respect to any source within it. 
This is a case of p-incompleteness. P-inconsistency and p-incompleteness are called $p$ problems in the p-model (Kertész-Rákosi 2012: 130-134, 2014: 29-32). In order to solve a p-problem, the p-context has to be re-evaluated. The process which transforms a pproblematic p-context into another p-context which is not (or is less) p-problematic, is the systematic and heuristic process of plausible argumentation. As the re-evaluation of the pproblematic p-context may often raise new problems, it usually does not lead immediately to an unproblematic p-context. The argumentation process is therefore not linear, but cyclic: we return to problems again and again, and re-evaluate our previous decisions, for example, about the rejection or acceptance of statements. Since the cycles always change the perspective from which the p-context is evaluated, the argumentation process is not only cyclic, but also prismatic. An argumentation cycle consists of the following phases: 1) the extension of the p-context by new sources, methods, and statements; 2) the coordination of the extended p-context (e.g., checking the consistency of the set of statements, comparing the plausibility values of statements originating from the old and the new sources, comparing the old and the new pieces of information concerning the reliability of the sources, etc.); 3) the modification of the extended and coordinated pcontext, i.e., working out the p-context which will be the revised version of the starting $\mathrm{p}$ context; and 4) the comparison of the rival solutions (Kertész-Rákosi 2012: 134-153, 2014: 32-34).

\subsubsection{Problem-solving strategies}

As was noted in the previous section, the p-context can be informationally overdetermined if both a statement and its negation are plausible to a certain extent at some stage of the argumentation process. The p-model considers such inconsistencies to be the natural property of linguistic theories. It offers effective problem-solving strategies, all of which involve the retrospective re-evaluation of the p-context (i.e., the previously accepted data, data sources, evidence, plausibility values, and methodological norms) from different perspectives (Kertész-Rákosi 2012: 134-153, 2014: 32-34; see the previous section). The Contrastive Strategy compares contradictory statements and regards them as rival alternatives. By applying the Contrastive Strategy, we aim at reaching a decision between the rival alternatives on the basis of the information available. The continuation of the Contrastive Strategy may be either the Exclusive Strategy or the Combinative Strategy. While the Exclusive Strategy makes a decision between the rival alternatives, the 
Combinative Strategy keeps both: it elaborates and separates two unproblematic p-context versions which will make up the whole p-context. These different p-context versions are regarded as co-existing alternatives. The reason for this can be that the two versions illuminate a certain phenomenon from different, but equally important perspectives. The pmodel always leaves open the possibility of more alternative solutions and further argumentation cycles (on problem-solving strategies see Kertész-Rákosi 2012: 153-161, 2014: 35-37).

In order to make my object theoretical results more reliable, I attempt to build the metatheoretical issues explicated above into my object theoretical discussion. I start this with the introduction of the object theoretical background of my research, namely, conversation analysis.

\section{The object theoretical background of the thesis: conversation analysis}

\subsection{Talk-in-interaction}

Conversation analysis is an approach to language use and social interaction which assumes the orderliness of these phenomena, and aims to investigate their overall structure (StiversSidnell 2013: 2). According to this approach, as Sacks, Schegloff, and Jefferson (1974: 700) point out in their classic article, conversation is a vehicle for interaction between speakers who have any potential identities, and any potential familiarity. That is to say, language is a vehicle for social action (Stivers-Sidnell 2013: 3). Talk-in-interaction in this sense is acting: it takes place in sequences of turns (a speaker's contribution to the talk at a time $)^{8}$ in each of which we act; we design each turn to do something which is contingent on the prior turn, and by doing this we also set up contingencies for what comes next (Drew 2013: 131). Levinson (2013) regards action as a main job assigned to the turn. His definition of what counts as a main job focuses on the sequential environment of the turn: a main job is what the response has to deal with so as to count as an adequate subsequent turn (Levinson 2013: 107). A turn can therefore perform more than one action, more than one main job at a time. However, we should differentiate between actions and off-record doings (Levinson 2013), when, for example, an answer to a question at the same time hints that the questioner should have known the answer already (Stivers 2011). It is difficult to respond to these less official doings directly in such a way that we do not completely

\footnotetext{
${ }^{8}$ The term is first used in this sense by Sacks et al. (1974).
} 
redirect the conversation (Levinson 2013: 107), and hence they do not count as action. Schegloff (2007: 8) differentiates between the action-concept of speech act theory (Austin 1962, 1979; Searle 1969, 1975, 1976; Searle-Vanderveken 1985) and conversation analysis. While the former defines classes or categories of action and tries to identify their conceptual components (e.g., what makes an action a promise), the latter begins with the particular instances in their embedding contexts, i.e., it tries to identify what a certain bit of talk is designed to do. According to Schegloff, this strategy can lead the analyst to discover new actions which do not have vernacular names, and which speech act theory could not analyze (Schegloff 2007: 8). Moreover, it can also happen that in a particular situation the interactants understand something different by an action than what is usually understood by it (Schegloff 2007: 9). In this way, the number of possible actions in our conversations is unknown (see the action of problem-raising in Extract (13) below) (Schegloff 2007: xiv).

The concept turn-constructional unit (TCU) was established by Sacks et al. (1974: 702) as the turn-constructional component. TCUs are the building blocks of turns (Schegloff 2007: 3). The criterial feature of a TCU is that it has to realize a recognizable action in the context (Schegloff 2007: 4). A TCU thus has to realize at least one action, but it may embody more than one action as well (Schegloff 2007: 9), in other words, it is possible for a TCU to implement more than one main job at a time. For example, an action can serve as the vehicle for carrying out another action (Schegloff 2007: 9): questioning can be the vehicle by which making a request is implemented (e.g., Can you open the door?). Since an adequate next turn could deal with both the questioning and the request, both actions are implemented by the TCU. ${ }^{9}$ If a speaker starts a turn, s/he has the right and obligation to produce one TCU (Schegloff 2007: 9). Approaching the possible completion of the first TCU, transition to the next speaker becomes relevant, but it is also possible for the speaker to extend the same TCU or start another TCU without transition. The next occurrence of a possible TCU completion is equivalent to the next transition-relevance place (Sacks et al. 1974: 704; Schegloff 2007: 4). In Extract (13), Cili and Anna talk about Christmas. Anna is raising the question of when it is appropriate to spend Christmas together for a couple who have been going out with each other for some time.

\footnotetext{
${ }^{9}$ This point is in accordance with Searle's indirect speech act theory (Searle 1975). In Searle's framework, questioning is the secondary, requesting the primary illocutionary act (Searle 1975: 62).
} 
(13) (bea003n001)
$01 \mathrm{C}:$ bövül
a család
még jobban.
bigger becomes.INDEF
the family.NOM
even more
'the family becomes even bigger.

$(0.3)$

$02 \mathrm{~A}:$ hát igen. de ez

well yes but this.NOM

is olyan nehéz

hogy igazából

well yes. but actually it is also so difficult (to decide)

03

$\begin{array}{lllll}\text { amikormár } & \text { valaki: } & \text { hosszabb } & \text { ideje } & \text { együtt } \\ \text { when already } & \text { somebody.NOM } & \text { longer } & \text { time.ABL } & \text { together }\end{array}$

when somebody: has been going out with somebody for a longer time

04

\begin{tabular}{|c|c|c|c|}
\hline van & valakivel & hogy hogy & mikor jön \\
\hline is.INDEF & somebody.COM & that & when comes.INDEF \\
\hline
\end{tabular}

05

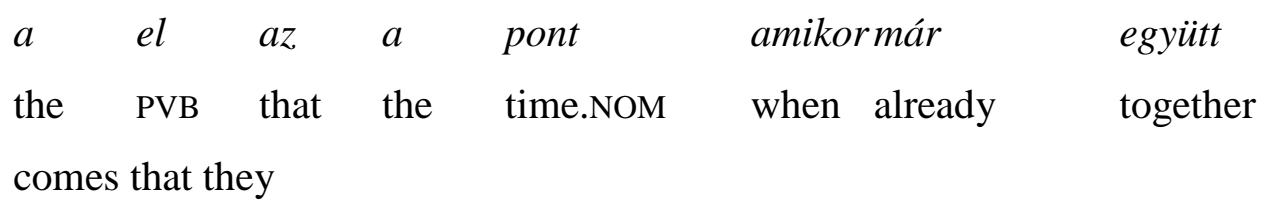

06 is karácsonyoznak mer .hh azér egy also Christmas spend.INDEF.3PL because for that matter a also spend Christmas together because .hh for that matter for a

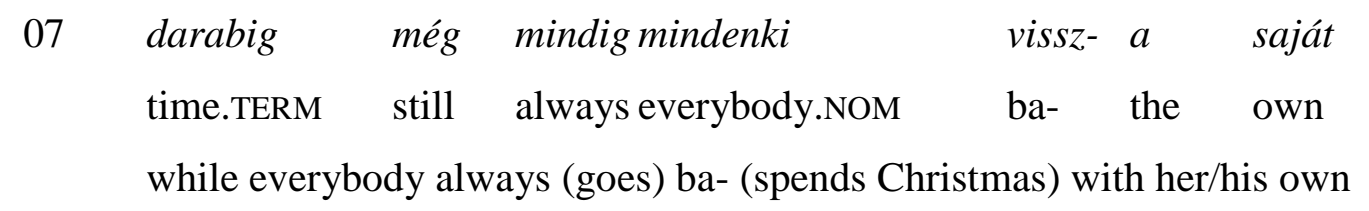

08 családjával ethon és akkor maximum másnap
family.POSs.3SG.COM at home and then at the most next day
family at home and then they meet next day at the most




$\begin{array}{lllllcl}\text { találkoznak } & \text { de } & \text { (.) } & \text { nem } & \text { tudom. } & \text { ezt } & \text { én } \\ \text { meet.INDEF.3PL } & \text { but } & & \text { not } & \text { know.DEF.1SG this.ACC } & \text { I.NOM }\end{array}$
but (.) I don't know I can't

$\begin{array}{llllll}\text { még így nem tudom } & \text { elképzelni de majd } \\ \text { yet in this way not can.DEF.1SG } & \text { imagine.INF but } & \text { sometime } \\ \text { imagine it in this way yet but sometime } & & & \end{array}$

11 biztos hogyha má ilyen saját közös kuckó certainly if alreadysuch own joint nook.NOM certainly if we already have our own joint nook

$\begin{array}{llllll}\text { lesz } & \text { akkor már } & \text { úgy } & \text { de } & \text { (.) } & \text { furi } \\ \text { will be.INDEF.3SG } & \text { then already } & \text { in that way } & \text { but } & & \text { strange }\end{array}$
then it will be in that way but (.) still it will be strange.

13 lesz

azér. nálatok hogy van, Cili?

will be.INDEF.3SG still you.ADE.PL how is.INDEF Cili what about you, Cili?

14

$\begin{array}{lllll}\text { ((laughing })) & \text { mer } & \text { te } & \text { már } & \text { férjnél } \\ & \text { because } & \text { you.NOM.SG } & \text { already } & \text { husband.ADE }\end{array}$

((laughing)) because you have already

15 vagy.

are.INDEF.2SG

got married.'

$\mathrm{C}: \quad$ the family becomes even bigger.

A: well yes. but actually it is also so difficult (to decide) when somebody: has been going out with somebody for a longer time that that when the time comes that they 
also spend Christmas together because .hh for that matter for a while everybody always (goes) ba- (spends Christmas) with her/his own family at home and then they meet next day at the most but (.) I don't know I can't imagine it in this way yet but sometime certainly if we already have our own joint nook then it will be in that way but (.) still it will be strange. what about you, Cili? ((laughing)) because you have already got married.

In line 01, a telling is getting done by Cili (cf. Schegloff 2007: 7). In line 02, Anna's response hát igen. 'well yes.' constitutes the first TCU of her turn. The second unit which a potential response as an adequate next turn could deal with, i.e., the next action in Anna's turn, is a problem-raising. In lines $02-13$, she raises the question of when a couple should decide to spend Christmas together. This action is implemented by a TCU which Anna extends twice: first she describes how couples usually spend Christmas before celebrating together (lines 06-09), then illustrates the difficulty of the question with her own personal experience (lines 09-13) (for the possibilities of turn-extension in Hungarian, see Németh 2007-2008). In lines 13-15, Anna asks Cili how she and her husband have solved the problem. This is the last TCU (and the last action) in Anna's turn, which she also extends. In the extension she gives her reason for selecting Cili as the next speaker: Cili has already got married.

Apart from action formation (Levinson 2013) and turn-constructional units (Clayman 2013), there are various fundamental structures in conversation, such as turn design (Drew 2013), sequence organization (Stivers 2013), preference (PomerantzHeritage 2013), or repair (Kitzinger 2013). In my thesis, I aim to focus on the organization of repair; nevertheless, as all the structures listed above are related to one another, I must examine repair taking into consideration the other structures as well.

\subsection{The organization of conversational repair - Defining the domain of repair, self- repair, and repair operation}

Since the classic article of Schegloff and his colleagues (1977: 361), who pointed out that an organization of repair works in conversation to deal with recurrent problems in speaking, hearing, and understanding, repair has become one of the central fields of the conversation analytic research. Its domain is "the set of practices whereby a co-interactant interrupts the ongoing course of action to attend to possible trouble in speaking, hearing or 
understanding the talk" (Kitzinger 2013: 229). This means that in the conversation analytic framework, repair involves only the problem treating practices which suspend the progressivity of the ongoing turn or sequence, and thus the ongoing activity. According to Schegloff (2007: xiv), the general motive of repair is to ensure that the interaction does not freeze where it is when a problem emerges, to maintain or restore intersubjectivity, and to make the turn, the sequence, and the activity progress to possible completion. In other words, paradoxically, repair involves the temporary interruption of the ongoing activity so as to maintain its progression to possible completion. The maintenance of the ongoing activity is possible only if there is a world which the co-interactants know and hold in common. This common world is grasped by the notion of intersubjectivity (Schegloff 1992: 1296). As Schegloff (1992: 1299) points out, the restoration and maintenance of intersubjectivity is built into the procedural infrastructure of talk-in-interaction involving the self-righting mechanism of the organization of repair. Repair is therefore a means by which intersubjectivity is maintained and defended in talk-in-interaction (Schegloff 1992: 1338). This explains what the term trouble means in the definition of repair: trouble involves everything which may endanger the maintenance of intersubjectivity, and repair is initiated when the speaker cannot handle this kind of problem without interrupting the ongoing course of action.

After differentiating between self- and other-initiated repair (see Chapter 1), Kitzinger (2013: 231) emphasizes that both types of repair interrupt the progressivity of the interaction, but while same-turn self-repair suspends the progressivity of the turn, otherrepair suspends the progressivity of the sequence. As far as the technology of the two types of repair is concerned, the initiation of other-repair can occur in a range of formats which vary along a continuum. The ordering principle of this continuum is how precisely the format grasps the trouble-source. While the open class repair initiator form (e.g., Huh? Pardon?) does not grasp the repairable precisely and thus counts as the weakest repair initiator form, offering a candidate understanding is the resaying of the trouble-source in other words, and therefore is the strongest repair initiator format (Schegloff et al. 1977: 367-368; Kitzinger 2013: 249). While Example (14) shows an open class repair initiator form, in Example (15) other-repair is initiated by offering a candidate understanding.

(14) (DB2 Angela)

1 Clt: .hhhhh But it nourished him (.) in utero well did it. 
4 Ang: Pardon?

5 Clt: It nour- The placenta nourished him

6 .hhh in utero

7 Ang: Yeah

(Kitzinger 2013: 232)

(15) (Joyce \& Stan, 5)

01 Joy: Why don'tchoo: go into Westwoo:d, (0.4) and go to

$02 \quad$ Bullocks.

03

04 Stn: Bullocks? ya mean that one right u:m (1.1) tch! (.)

05 right by thee: u:m (.) whazit the Plaza? theatre: $=$

06 Joy: = Uh huh,

(Schegloff 2013: 49)

Regarding self-repair, the interruption of the turn-in-progress may be achieved by a cut-off or devices such as $u m$, $u h$ ( $\ddot{o}$ in Hungarian), or sound stretches. It is crucial to note that instead of ipso facto initiating repair, these forms only alert the recipient to the possibility of repair. Conversely, initiating repair can also happen tacitly without any explicit indication (Kitzinger 2013: 239). While in Extract (16a) the speaker initiates repair using the combination of a cut-off and the device $\ddot{o}$ which she even stretches, in Example (16b) the repair initiation happens tacitly.

(16a) (bea003n001: 171)

$01 \mathrm{~A}:$ mi is eszünk mondjuk év közben we.NOM also eat.INDEF.1PL anyway year.GEN during 'anyway, we also eat (lentils) during the year

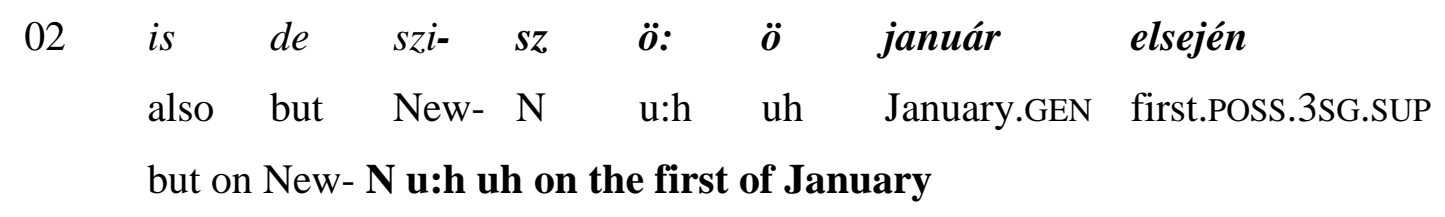




$\begin{array}{lll}\text { mindig } & \text { lencsét } & \text { eszünk. } \\ \text { always } & \text { lentil.ACC } & \text { eat.INDEF.1PL }\end{array}$

we always eat lentils.'

(16b) (BCC004 Donna)

Don: you know th' procedure complaints procedure goes

out the window the minute you take legal action.

(Wilkinson-Weatherall 2011: 68)

Schegloff et al. (1977: 363) refer to self-initiated and other-initiated repair as covering a more general domain of occurrences, while self- and other-correction are particular subtypes in this domain. The point in this distinction is that the term correction is usually understood as the replacement of an error by what is correct, whereas the phenomena Schegloff and his colleagues address are not limited to such cases. For example, a word search is in the repair domain, but does not count as correction (Example (17)).

(17) (TG, 01)

01 Ava: H'llo:?

02 Bee: hㅐi:,

03 Ava: Hi:?

04 Bee: hHowuh you:?

05 Ava: Oka:::y?hh=

06 Bee: =Good.=Yihs [ou:nd ] hh

07 Ava: [<I wan]' dih know if yih got a- uh:m

08 wutchimicawllit. A:: pah(hh)khing place ${ }^{\circ}$ th's

09 mornin'. Hh

10 Bee: A pa:rking place,

11 Ava: $\mathrm{Mm} \underline{\mathrm{hm}}$,

(Schegloff 2013: 49)

Consequently, repair can be initiated without an apparent error, and nothing is excludable from the class repairable (Schegloff et al. 1977: 363). According to Schegloff (2013: 47), repairing is often merely altering. In these cases, "it is not that something was wrong and 
had to be fixed, but it could be better realized by an alteration" (see Example (16b)). Conversely, an audible error does not always yield repair or correction (Example (18)).

(18) (Ladies:1:1:9:4)

Avon Lady: And for ninety-nine cents uh especially in,

Rapture, and the Au Coeur which is the newest fragrances, uh that is a gery good value.

Customer: Uh huh,

(Schegloff et al. 1977: 363)

Finally, it can also happen that efforts at repair (as well as correction) fail (Example (19)). For this reason, the initiation of reparative segments and their completion (i.e., the solution of the problem) should be distinguished (Schegloff et al. 1977: 364).

(19) (BS:2:1:6)

C: C'n you tell me (1.0) D'you have any records of whether you whether you who you sent- $\mathrm{Oh}(\mathrm{hh})$ shit.

(Schegloff et al. 1977: 364).

The most common type of repair is self-repair in the turn-constructional unit containing the repairable (see Examples (16a), (16b), (17)). In this type of self-repair the speaker of the trouble-source initiates repair, in other words, interrupts the progressivity of the turn to attend to the trouble-source, and produces a repair solution before the turn-constructional unit comes to a possible completion. The frequency of this repair type can be partly explained by the observation that the speaker of the trouble-source has the first opportunity to initiate repair because of the turn-taking system (Kitzinger 2013: 232; this thesis: Section 3.1).

Schegloff (2013: 41) says that in the domain of self-initiated, same-turn repair, repair operations "get implemented". Fox et al. (2009: 62) claim that self-repair can involve a variety of different operations. An anonymous reviewer of one of my previous papers claims that repair is not composed of repair operations but rather implements them. Later s/he notes that repair accomplishes repair operations. Schegloff (2013: 43) says that speakers employ repair operations to deal with some putative trouble-source in an ongoing turn-at-talk in conversation or to alter it in some interactionally consequential way 
(Schegloff 2013: 43). The Handbook of Conversation Analysis (Sidnell-Stivers 2013) does not define the term repair operation.

The above statements show that the interpretation of repair operation and the relationship between repair and repair operation is not unambiguous in the conversation analytic literature. In order to make it clearer what kinds of phenomena the researcher should identify as repair operations, I attempt to find out whether some of the above statements are more plausible than others. In doing this, I rely on the p-model explicated in Chapter 2 (Kertész-Rákosi 2012, 2014). Let us first see what the above statements say about the relationship between repair and repair operations.

Statement 1: In the domain of self-initiated, same-turn repair, repair operations "get implemented" (Schegloff 2013: 41).

Implication of Statement 1: Repair operations belong to the domain of same-turn self-repair.

Statement 2: Self-repair (understood here as same-turn self-repair) can involve a variety of different operations (Fox et al. 2009: 62).

Implication of Statement 2:

Repair operations belong to the domain of same-turn self-repair.

Statement 3: Repair implements or accomplishes repair operations (anonymous reviewer).

Statement 3 is ambiguous regarding the relationship between repair and repair operation.

Statement 4: Speakers employ repair operations "to deal with some putative troublesource in an ongoing turn-at-talk in conversation or to alter it in some interactionally consequential way" (Schegloff 2013: 43, emphasis in italics supplied).

If Schegloff (2013: 43) uses the word or in the strong sense (Grice 1989: 44), then he means that dealing with some putative trouble-source in an ongoing turn-at-talk in conversation cannot mean that the turn is merely altered in some interactionally consequential way without any problems fixed in it. If, however, Schegloff uses the word or in the weak sense (Grice 1989: 46), then he means that dealing with some putative trouble-source in an ongoing turn-at-talk in conversation can also mean that the speaker 
simply alters the turn in some interactionally consequential way without any problems fixed in it.

First, I coordinate the p-context, assuming that Schegloff (2013: 43) uses the word or in the strong sense (see Section 2.3.1). The following plausible inference presents itself (Kertész-Rákosi 2012: 56ff, 2014: 20ff; this thesis: Section 2.2):

Premise 1: According to the source Schegloff 2013: 43, it is plausible that speakers employ repair operations "to deal with some putative trouble-source in an ongoing turn-at-talk in conversation or to alter it in some interactionally consequential way". (Statement 4$)^{10}$

Premise 2: According to the sources Schegloff 2013: 43, Grice 1989: 44, as well as my intuition, it is plausible that dealing with some putative trouble-source in an ongoing turn-at-talk in conversation cannot mean that the turn is merely altered in some interactionally consequential way without any problems fixed in it.

Premise 3: According to the source Kitzinger 2013: 229, it is plausible that the domain of repair is "the set of practices whereby a co-interactant interrupts the ongoing course of action to attend to possible trouble in speaking, hearing or understanding the talk". (Statement 5)

Conclusion: According to the sources Schegloff 2013: 43, Grice 1989: 44, my intuition, and Kitzinger 2013: 229, and the inference built on the statements originating from these sources, it is plausible that the repair operations which merely alter the turn in some interactionally consequential way without any problems fixed in it do not belong to the category of repair, and therefore do not belong to the category of same-turn self-repair.

We can see that our p-context is informationally overdetermined in the sense that it contains too much information: while the direct sources Schegloff 2013: 41 and Fox et al.

\footnotetext{
${ }^{10}$ Instead of it is plausible that..., Kertész and Rákosi (2012: 69ff, 2014: 17ff) use the following notation for plausibility of statements presented here in the case of Premise 1:

$0<\mid$ Speakers employ repair operations "to deal with some putative trouble-source in an ongoing turn-at-talk in conversation or to alter it in some interactionally consequential way". $\left.\right|_{\text {schegloff } 2013: 43}<1$ $\left(|p|_{S}=1\right.$, if $p$ is true with certainty on the basis of source $S ;|p|_{S}=0$, if $p$ is of neutral plausibility on the basis of source $S$, i.e., if it is neither plausible nor implausible on the basis of source $S$ ) (Kertész-Rákosi 2014: 18). Since the sources and plausibility values do not belong to the logical structure of inferences, for the sake of convenience I will not use this notation in my thesis.
} 
2009: 62 make it plausible that repair operations belong to the domain of same-turn selfrepair, the inference as an indirect source makes it plausible that repair operations do not belong to the category of same-turn self-repair. Since the two alternatives are plausible simultaneously at this stage of the argumentation process, here we are faced with a problem of p-inconsistency, which means that both a statement and its negation are plausible according to some sources (on p-problems see Kertész-Rákosi 2012: 130-134, 2014: 29-32; this thesis: Section 2.3.1).

Furthermore, both alternatives are of neutral plausibility (they are neither plausible nor implausible) on the basis of the source of Statement 3 and The Handbook of Conversation Analysis: the anonymous reviewer mentioned above says that repair implements or accomplishes repair operations, and the term repair operation is not defined in The Handbook of Conversation Analysis (Kitzinger 2013).

In order to treat the p-problem explicated above, I extend the p-context with further data (i.e., statements made plausible by some direct sources), and retrospectively reevaluate it in the light of the new pieces of information (Kertész-Rákosi 2012: 134-153, 2014: 32-34; this thesis: Section 2.3.1). Several studies in the conversation analytic literature argue for the observation of Schegloff et al. (1977: 363) mentioned above, namely, that repair can be initiated without an apparent error, that is, nothing is excludable from the class repairable. Schegloff (2013: 47) notes that repairing is often merely altering: there are cases when instead of fixing a problem, the speaker merely changes the turn-so-far (see the differentiation between the terms repair and correction). Other studies in the conversation analytic literature argue that although every self-repair is in the interests of a better construction of the turn in order to do the interactional work it is designed to perform (Drew, Walker, and Ogden 2013: 92), there are repairs which are used specifically to do interactional work. Jefferson (1974: 181) distinguishes between the correction of production errors, i.e., a range of problems the speaker encounters when s/he attempts to produce grammatically correct speech, and interactional errors, which speakers make when they attempt to speak appropriately to a particular co-participant and/or within some situation. In Jefferson's example (Example (20)), a defendant in a courtroom replaces $k u$ - with officer. According to Jefferson (1974: 193), although $k u$ - can be either an artifact of the cop/officer alternation or an anticipation error originating from the subsequently appearing came, the judge's interruption suggests that $\mathrm{s} / \mathrm{he}$ hears it as an insult, that is, s/he hears it as the replacement of cop with officer (Jefferson 1974: 194). 
(20) [PTC Materials: I: 49]

Bassett: $\quad$ En I didn't read that ((description of violation the officer wrote on the ticket)). When thuh

ku- offi[cer came up I s-

Judge: [ [ $\quad$ ['Red traffic signal approximately thirty

feet east of the crosswalk, when signal

changed tuh red.'

(Jefferson 1974: 193)

Jefferson points out that this self-repair affords us access to the interactional business the defendant is engaged in when trying to speak appropriately in a situation which is unfamiliar to her (Jefferson 1974: 192). According to The Handbook of Conversation Analysis, repair can be used as a resource for the interactional fine-tuning of the turn in the service of the particular action the speaker designs it to perform, and not only for fixing a possible problem related to speaking, hearing, or understanding the talk: "Self-initiated repair is used not only to correct obvious errors but also to fine-tune the turn with reference to the action the speaker means to be doing and to the recipient of that action" (Kitzinger 2013: 233, emphasis in italics supplied). And: "Repair can also be used to fine-tune a turn in the service of the action(s) speakers mean to be doing" (Kitzinger 2013: 242, emphasis in italics supplied). Like Schegloff (2013: 43), Kitzinger here distinguishes between dealing with some putative trouble-source in an ongoing turn-at-talk and altering the turn in some interactionally consequential way, and claims that repair and self-repair can do both of these. Although she does not define the term repair operation, the subsection Repair operations is found in the Section Self-Initiated Repair in Same-TCU in the handbook. The structure of the chapter Repair in The Handbook of Conversation Analysis (Sidnell-Stivers 2013) thus supports the claim that repair operations belong to the domain of same-turn self-repair.

This makes it plausible that in Statement 4 (Speakers employ repair operations "to deal with some putative trouble-source in an ongoing turn-at-talk in conversation or to alter it in some interactionally consequential way" (Schegloff 2013: 43, emphasis added)), Schegloff uses the word or in the weak sense (Grice 1989: 46). That is, he says that dealing with some putative trouble-source in an ongoing turn-at-talk can mean that the speaker simply alters the turn in some interactionally consequential way without any problems fixed in it. This modifies the inference presented above in the following way: 
Premise 1: According to the source Schegloff 2013: 43, it is plausible that speakers employ repair operations "to deal with some putative trouble-source in an ongoing turn-at-talk in conversation or to alter it in some interactionally consequential way". (Statement 4)

Premise 2: $\quad$ According to the sources Schegloff 2013: 43, Grice 1989: 46, as well as my intuition, it is plausible that dealing with some putative trouble-source in an ongoing turn-at-talk in conversation can mean that the turn is merely altered in some interactionally consequential way without any problems fixed in it.

Premise 3: According to the source Kitzinger 2013: 229, it is plausible that the domain of repair is "the set of practices whereby a co-interactant interrupts the ongoing course of action to attend to possible trouble in speaking, hearing or understanding the talk". (Statement 5)

Conclusion: According to the sources Schegloff 2013: 43, Grice 1989: 46, my intuition, and Kitzinger 2013: 229, and the inference built on the statements originating from these sources, it is plausible that the repair operations which merely alter the turn in some interactionally consequential way without any problems fixed in it do belong to the category of repair, and therefore do belong to the category of same-turn self-repair.

This makes it plausible that Kitzinger's (2013: 229) definition, namely, that the domain of repair is "the set of practices whereby a co-interactant interrupts the ongoing course of action to attend to possible trouble in speaking, hearing or understanding the talk", contains the practices which merely alter the turn in some interactionally consequential way without any problems fixed in it. However, in order to avoid misunderstandings, the present thesis makes this explicit, and will work with the following repair-definition: the domain of repair is the set of practices whereby a co-interactant interrupts the ongoing course of action to attend to possible trouble in speaking, hearing, or understanding the talk or merely to alter it in some interactionally consequential way without any problems fixed in it.

Since in the modified, new p-context version there are no sources supporting the statement that repair operations do not belong to the category of same-turn self-repair, I apply the Exclusive Strategy (Kertész-Rákosi 2012: 153-161, 2014: 35-37; this thesis: Section 2.3.2), and reject this statement. After this step the new p-context version is not p- 
inconsistent any more. Moreover, it contains several sources supporting the statement that repair operations do belong to the category of same-turn self-repair. According to Kertész and Rákosi (2014: 17), if several sources make a statement plausible, then it has a higher plausibility value on the basis of these sources taken together than it does on the basis of any of the sources considered alone. Consequently, we can assign a high plausibility value to the statement Repair operations are in the domain of same-turn self-repair. The present thesis applies the definition of repair given by Kitzinger (2013: 229) to same-turn selfrepair, and defines the domain of same-turn self-repair as the set of practices whereby a cointeractant interrupts her/his ongoing turn-at-talk to attend to possible trouble in speaking, hearing, or understanding the talk or merely to alter the turn in some interactionally consequential way without any problems fixed in it.

Since I have assigned a high plausibility value to the statement Repair operations are in the domain of same-turn self-repair, I define repair operations as practices whereby a co-interactant interrupts her/his ongoing turn-at-talk to attend to possible trouble in speaking, hearing, or understanding the talk or merely to alter the turn in some interactionally consequential way without any problems fixed in it. However, the following question remains open: are there phenomena which belong to the domain of same-turn self-repair but are not repair operations? Or does same-turn self-repair manifest itself in the form of repair operations?

The focus of the present thesis is on four repair operations, namely, recycling, replacement, insertion, and aborting. Before their introduction containing several examples from the Hungarian corpus, it is necessary to describe the corpus and methodology of the research.

\section{The corpus and methodology of the study}

As was mentioned in the Introduction, conversation analysis uses audio and film recordings of naturally occurring interactions, and regards data as these recordings made and analyzed. Its analytic stance contrasts with introspection, field notes, or experiments. As Sacks (1995b: 419-20) points out, if researchers use the hypotheticalized versions of the world, they can grasp only the phenomena which an audience can accept as reasonable and not the things that actually occur. Therefore, instead of imagining or post hoc documenting social interactions, CA aims at studying the details of action as it is naturally organized by participants moment-by-moment in its very context (Schegloff 1996; Mondada 2013). This 
mentality has an impact on the conversation analytic approach to data collection. The goal of conversation analysis is to explore recognizable social actions as they actually occur, that is, empirically (and not imaginatively) provide an account of what speakers accomplish in interaction (Schegloff 1996: 167). If a certain practice, for example, occurs in several contexts, this diversity should appear in data collection (see Schegloff 1996, where the same phenomenon is analyzed in various contexts including everyday, familiar, as well as institutional settings). The way recordings are made should preserve the temporality and sequentiality of the interaction. Since turns are produced in an incremental way, and each bit of a conversation shapes the understanding of what came before and what comes next, every moment of an interaction can be potentially relevant (Mondada 2013: 42). Furthermore, conversation analysis aims at capturing the conduct of all of the participants, i.e., the entire participation framework of the conversation (Mondada 2013: 51). This is in a close relationship with the principle of preserving the sequentiality of the interaction. The sequence of a question and answer, for example, is composed of two turns produced by two different speakers of the conversation. Finally, the recording of an interaction should cover the entire interactional space of the activity (Mondada 2013: 52). This means that the recording should capture the whole place where the bodies of the participants are configurated. These principles make it possible to describe the organization of ordinary social activities, for example, taking turns-at-talk in conversation by a detailed inspection of recordings and transcriptions made from these recordings (Mondada 2013: 33, Ten Have 1990: 23). However, if we recall Labov's (1972) observers' paradox, we can ask how it is possible to record interactions by using cameras or microphones, and at the same time preserve them as they naturally occur, i.e., "endogeneously organized in ordinary life" (Mondada 2013: 34). The responses to this objection in the conversation analytic literature argue that the way in which recordings are made can be refined technologically and ethically in order to help speakers forget the presence of the microphone or the camera (Mondada 2013: 34). Moreover, according to Mondada (2013: 34 ), the camera is not omni-relevant for the speakers, and they orient to it only in certain moments which can be identified and studied.

The findings of the research presented in this thesis are based on two corpora, one compiled in the Institute of Psychology, University of Szeged (SZTEPSZI corpus), ${ }^{11}$ and the other in the Kempelen Farkas Speech Research Laboratory in the Research Institute for

\footnotetext{
${ }^{11}$ This corpus has been recorded by Ágnes Lerch and the author of the present thesis.
} 
Linguistics of the Hungarian Academy of Sciences, Budapest (Hungarian speech database (BEA) (Gósy 2012)). The examples from the corpora are indicated as SZTEPSZI1, SZTEPSZI2, etc. and bea001, bea002, etc., respectively. While the SZTEPSZI corpus consists of video recordings, the conversations from the BEA database are audio recorded. The conversations can be regarded as semi-spontaneous. The SZTEPSZI corpus has been made under laboratory conditions, however, the recorded conversations are not contrived interactions but casual, Hungarian face-to-face conversations (with 3 participants per interaction). The participants were friends or good acquaintances. Although they were given some written topics at the beginning of the conversation, the function of this was only to help them in starting the talk: they were not obliged to use these topics, but we encouraged them to talk about anything they were interested in. ${ }^{12}$ The BEA speech database has been also made under laboratory conditions. Here the participants were not given written topics, however, each conversation was initiated by one of the participants asking a question (e.g., How have you spent Christmas?, What is your opinion on getting a driving licence in Hungary?, etc.), which shaped the course of the interaction to a certain extent. After this initial question the participants equally contributed to the interactions. Neither the SZTEPSZI corpus, nor the BEA database were made in order to test preestablished hypotheses, and in neither of them were the performances of the subjects instructed and controlled.

Although the initial object theoretical framework of this thesis is conversation analysis, my research aims established in Chapter 1 make it necessary to diverge from the "conversation analytic mentality" (Schenkein 1978) in some respects. First, the metatheoretical framework of the present thesis, i.e., the p-model of plausible argumentation regards data as statements with positive plausibility values (strength of acceptability) originating from direct sources (e.g., corpus, linguistic intuition, experiment) (see Section 2.2). In my thesis, as I have mentioned in the Introduction, I will use the term data in the sense of the p-model, and in all other sections I avoid using it in the conversation analytic sense. For this reason, I will refer to the recordings I have analyzed by the term corpus.

Second, Stivers and Sidnell (2013: 2) emphasize that the conversation analytic method is primarily qualitative. It describes and explains the structures of social interaction relying on a case-by-case analysis, which leads to generalizations across cases but prevents

\footnotetext{
${ }^{12}$ Since the research can be divided into two phases which have not used the corpus in the same way, I introduce the length and other details of the corpus when describing these two phases of the study.
} 
them from congealing into an aggregate. This means that conversation analysis allows for quantitative analysis to a certain extent (seeking to notice patterns and distributional regularities), but this quantitative analysis only provides reassurance that a given phenomenon is not an isolated usage of some local setting (a particular speaker or category of speakers), but has "a prima facie robustness" (Schegloff 2009: 389). According to Schegloff (2009: 389), however, statistical methods make the research shifted from the empirical analysis of the individual cases to "puzzling" analyses on larger corpuses, which makes the cases congeal into an aggregate and therefore does not fit into the conversation analytic mentality. This suggests that the conversation analytic framework regards quantitative analysis as seeking to regularities and making generalizations, and statistical analysis as doing the same things on a larger corpus. Schegloff (1993) also argues against conducting statistical analyses when asking whether the sample of data analyzed in this way can provide reliable findings on the larger universe from which it was drawn. This reasoning, however, also questions the reliability of the inductive analyses which $\mathrm{CA}$ prefers, because the generalizations conversation analysis allows for (e.g., on the preference for self-correction as opposed to other-correction) work in a similar way.

Furthermore, according to Schegloff (2009: 389), the quantitative analysis in conversation analysis always leads back to the individual cases when, for example, the researcher specifies a phenomenon and shows its variants, or encounters a problem which makes her/him reanalyze the particular instances. Schegloff (2009: 390) says that when conducting statistical analyses, the researcher codes the recordings, which results in the distribution of the particular instances according to pre-selected variables (Schegloff 2009: 390). Instead of making the examination responsive to the observable features of the particular cases explored one-by-one, coding is a prescribed inquiry during which the variables cannot be determined or modified (Schegloff 2009: 390-391). This does not fit into the conversation analytic mentality again, since analysis in CA treats the cases in their particulars and determines what will constitute an instance of a putative phenomenon (Schegloff 2009: 391).

In contrast to this reasoning, the present thesis argues that it is impossible to analyze recordings and make observations without any preliminary theoretical considerations. In Lehmann's (2004) view, any statements made by the researcher regarding a linguistic phenomenon are based on abstraction and semiotic processes; in other words, they are not given at the outset but are, at least to some extent, produced by the researcher. Kertész and Rákosi (2012: 242) emphasize that the conceptual apparatus of 
a given theory is closely related to the methods and methodological principles of any examinations carried out in the framework of this theory, and determines the level of abstraction at which the investigated phenomena can be captured. The aspects of the linguistic phenomena which we can grasp and the ways we can describe these aspects are also determined by the conceptual apparatus used during the investigation (Kertész-Rákosi 2012: 243). That is to say, the theoretical framework within which the researcher works cannot be eliminated even when s/he analyzes speech events recorded in their original form. Otherwise we could not speak, for example, about the phenomena of repair, selfrepair, or about the ten main repair operations within a conversation analytic framework. And indeed, the conversation analytic literature allows for the existence of certain groups of occurrences which it labels repair, self-repair, recycling, replacement, insertion, aborting, etc. The Handbook of Conversation Analysis even uses the term define when it specifies the domain of repair (Kitzinger 2013: 229). Moreover, the phenomena labelled repair, self-repair, recycling, replacement, insertion, aborting, etc. are showed in the conversation analytic literature with the help of examples (see, for example, Schegloff 2013; Kitzinger 2013; Wilkinson-Weatherall 2011). Selection of those examples must have occured on the basis of pre-selected variables, i.e., the variables the values of which make a linguistic phenomenon repair, self-repair, and recycling, replacement, insertion, aborting, etc. These variables are determined by the conceptual apparatus of conversation analysis. For example, a linguistic phenomenon is labelled a repair phenomenon if it interrupts the ongoing course of action, and is not labelled a repair phenomenon if it does not interrupt the ongoing course of action. In other words, any kind of categorization requires a conceptual apparatus which determines the features a linguistic phenomenon should possess in order to belong to a certain category of linguistic phenomena. The point is that the coding process, which results in the distribution of instances according to preselected variables (Schegloff 2009: 390), even in conventional statistical analyses, does not exclude the kind of analysis CA prefers. What is more, in order to be reliable, it should be based on a careful examination of the candidate phenomena on a case-by-case basis which "treats each case in its particulars" (Schegloff 2009: 391), and is sensitive to the sequential environment of interactional items (Ten Have 1990).

From a methodological point of view, the thesis can be divided into three main parts. While Chapter 5 introduces the repair operations investigated in the study by analyzing examples (qualitative analysis), Chapter 6 and 7 present two successive phases of the research. The first phase has been carried out using eight conversations from the 
BEA database and two conversations from the SZTEPSZI corpus (17 speakers across 10 interactions, total length: $2 \mathrm{~h} 25 \mathrm{~min} 4 \mathrm{sec}$ ). Since the results of this study have provided a motivation for the continuation of the research on an extended corpus, the second phase has been carried out using eight conversations from the BEA database and nine conversations from the SZTEPSZI corpus (38 speakers across 17 interactions, total length: 4 h $58 \min 42 \mathrm{sec})$.

In Chapter 6, I examine recycling and replacement relative to each other in Hungarian, and make a comparison with the languages so far investigated in this respect. Following the cross-linguistic examinations of Fox et al. (2009) and Fox et al. (2010), I explore the length and syntactic class of words in which the speakers of the Hungarian corpus tend to initiate recycling and replacement.

In order to carry out this phase of the research I have coded the corpus for the following features: syntactic category (function or content word) and length (monosyllabic, bisyllabic, multisyllabic) of all words in the corpus, syntactic category and length of the target word ${ }^{13}$ in all recycling and replacement instances in the corpus, and site of initiation (i.e., the location in the target word where speakers initiate repair) in all recycling and replacement repairs in the corpus.

I first attempt to find out whether the speakers tend to initiate recycling and replacement in monosyllabic, bisyllabic, or multisyllabic, ${ }^{14}$ and function or content words, respectively. Labeling function and content words syntactic classes, I also follow Fox et al. (2009). While content words are open-class words with a lexical, statable meaning, the class of function words is closed and carries a grammatical meaning. The reason why they are called syntactic classes is the fact that distinguishing them plays an important role in characterizing the syntactic properties of sentences (Selkirk 2008: 464). When I decide whether a particular word in the Hungarian corpus is a function or content word, I rely on Kenesei (2000). The category of function words consists of closed word classes, which are invariable in a given language state. Their number cannot be increased, neither by borrowing words nor by internal lexical processes. For example, conjunctions, auxiliaries, and articles are function words (Kenesei 2000: 95). Conversely, the category of content words consists of open word classes (e.g., nouns, verbs, and adverbs), the elements of

\footnotetext{
${ }^{13}$ As the trouble-source may consist of more than one word, and may be different from the word in which repair initiation happens, I use the term target word when referring to the word in which speakers initiate repair.

${ }^{14}$ By multisyllabic words I mean words of three or more syllables.
} 
which can be increased without limit by, for example, borrowing words from other languages, derivation, or compounding (Kenesei 2000: 95).

I also try to reveal whether the type of the repair operation, the length of the target word, and/or the syntactic class of the target word influence the site of repair initiation. Considering repair initiation, Schegloff (1979) points out that the most common location of repair initiation is just after the start of a turn-constructional unit (post-initiation) or just before its completion (pre-completion), for example, in the case of a word after its first sound or just before its last sound (Schegloff 1979: 275). The relevant domain for the postinitiation of a unit (or as Fox et al. (2009) term it post-beginning) starts after the first sound is recognizable and continues until the first sound is complete, whereas the relevant domain for pre-completion begins just before the final sound is articulated, and continues until just before the final sound is complete (Fox et al. 2009: 65). Fox et al. (2009) introduce the term recognizable completion. Repair initiation at or after recognizable completion refers to initiations in or after the last sound of the word, while repair initiation before recognizable completion means that the speaker initiates repair before the articulation of the last sound begins (Fox et al. 2009: 71). It is of great importance to note here that the term recognizable completion does not refer to the recognition of the word in which the speaker initiates repair, but to the recognition of the word as completed. While the listener may recognize the word long before it is recognizably completed, recognizable completion allows her/him to assume that the word is finished.

After carrying out these examinations, I compare my findings to those of Fox et al. (2009) and Fox et al. (2010), and summarize the results of Chapter 6. The findings of Chapter 6 motivate the second phase of the study. In Chapter 7, I propose a model which describes repair operations relative to each other. Using the definition of repair as a starting point (see Section 3.2), I set up the model on the basis of data from previous research, the qualitative analysis of examples from the Hungarian corpus (during which I also use statements from previous research), and test it with a quantitative method. In order to find out whether this quantitative method will provide relevant and reliable results, during its elaboration I have to carry out the analysis in my mind before it takes place in reality. Therefore, the elaboration process can be regarded as a special kind of thought experiment, just like the experimental design in the case of experiments (Kertész-Rákosi 2014: 256).

The purpose of the conscious integration of the various sources and methods described above is to enhance the reliability of the hypotheses obtained as the results of the thesis (cf. Kertész-Rákosi 2014: 221). This is in accordance with Kertész and Rákosi's 
(2012: 239) metatheoretical finding, namely, that supporting the hypotheses of a given theory by as many types of data (i.e., plausible statements originating from direct sources) and as many sources as possible can increase the plausibility of these hypotheses. This means that the conscious integration of data from various data sources can reduce the uncertainty which may result from the application of a single data source.

In the next chapter, using examples both from the Hungarian corpus and the previous studies on other languages, I will introduce replacement, recycling, insertion, and aborting, i.e., the four repair operations on which I aim to build my research.

\section{Four repair operations}

\subsection{Replacement ${ }^{15}$}

Replacement involves “a speaker's substituting for a wholly or partially articulated element of a TCU-in-progress another, different ${ }^{16}$ element, while retaining the sense that 'this is the same utterance' " (Schegloff 2013: 43), i.e., without aborting the ongoing TCU. In Extract (21), Ica describes her years spent in a drama group ('one' in line 01 refers to the group). In line 03 , she interrupts the ongoing action without aborting it.

(21) (SZTEPSZI1: 661) $)^{17}$

$01 \mathrm{I}:$ aztán találtam then found.INDEF.1SG egyet, ((swallow)) az $t o ̈ k^{18} \quad j o ́$ 'then I found one, ((swallow)) that was very good=

02

$\begin{array}{lllll}\text { volt } & \text { csak } & . h & \text { így } & \text { <feltünt, } \\ \text { was.INDEF.3SG } & \text { however } & & \text { in this way } & \text { appeared.DEF.3SG }\end{array}$

$=$ however. $\mathrm{h}$ in this way <it appeared to me

03
hogy így>
(.)
hát mennyi?
hány
that in this way
well ${ }^{19}$ how many
that in this way> (.) well how many? how many years

évet

how many

year.ACC

\footnotetext{
15 Although the term replacing created by Schegloff (2013: 43) better indicates that the focus is on an operation carried out by speakers, following Fox et al. (2009; 2010), I will use the term replacement.

${ }^{16}$ In some cases this difference is found in the prosody rather than in the lexicon (Schegloff 2013: 61).

17 The relevant repair operation is always indicated by boldface.

${ }^{18}$ Tök does not only mean 'pumpkin' in Hungarian, but is also a slang adjective meaning 'very'.
} 
did I spend there? I think four? or five?

05

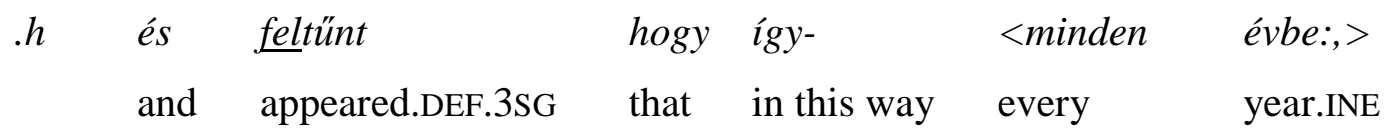

.$h$ and it appeared to me that in this way- <every yea:r, >

06

ugyanazt tanuljuk.

the same.ACC learn.DEF.1PL

we learn the same things.'

I: then I found one, ((swallow)) that was very good=however.$h$ in this way <it appeared to me that in this way> (.) well how many? how many years did I spend there? I think four? or five? .h and it appeared to me that in this way- <every yea:r, $>$ we learn the same things.

In line 03, Ica replaces the question word mennyi 'how many, how much' with the question word hány 'how many'. ${ }^{20}$ Asking questions for uncountable nouns in Hungarian is only possible with mennyi 'how many, how much'. For example, when Hungarian speakers ask for a timeframe with idö 'time' as an uncountable noun, the only possible question word they can use is mennyi 'how many, how much' (Mennyi idö? 'How much time?'). However, the countable év 'year' can be preceded both by hány 'how many' and mennyi 'how many, how much'. In the extract, we can observe that Ica prefers hány 'how many' when she reflects upon the number of years she spent in the drama group.

In Extract (22), Cili, who has recently got married, explains to the other participants how she and her husband can manage to visit all their relatives on Christmas Eve. In line 04, she interrupts the ongoing TCU within a segment which is not a recognizable word.

\footnotetext{
${ }^{19}$ Hát is a discourse marker in Hungarian (Schirm 2011). Here it indicates that the speaker is about to add some background information to the turn.

${ }^{20}$ It is debatable whether this phenomenon is a replacement repair or the speaker simply uses two synonyms one after the other. This question points to my earlier argumentation in Chapter 4, namely, that the statements made by the researcher regarding a linguistic phenomenon are not given at the outset but are, at least to some extent, produced by the researcher (Lehmann 2004).
} 
(22) (bea003n001: 152)

$\begin{array}{rllll}01 \mathrm{C}: & \text { és akkor újra: a másik családnál- (.) ugyanez } & a \\ & \text { and then again the other family.ADE } & \text { same } & \text { the }\end{array}$ 'and then with the other family- (.) the same

02 felvonás hogy vacsora .hh s akko má act.NOM that dinner.NOM and then already act again there's a dinner .hh and then in this way we already

03 így elég rosszul voltunk, he és akkor már in this way quite badly was.INDEF.1PL and then already felt quite bad, .h and then

04 utána együtt vo- vándoroltu:nk. afterwards in this way together wandered.INDEF.1PL afterwards in this way we were wandering together.'

C: $\quad$ and then with the other family- (.) the same act again there's a dinner .hh and then in this way we already felt quite bad, h and then afterwards in this way (replaced item) we were wandering together.

In line 04, Cili replaces vo- with vándoroltu:nk 'we were wandering'. This time we cannot identify any problems fixed by the replacement. On the basis of the investigated material, we can only say that when Cili constructs her turn so that it does the job it is designed to perform (cf. Drew et al. 2013: 92), she replaces an item with another one.

We have defined repair operations as practices whereby the speaker carries out same-turn self-repair, which means that the domain of repair operation is the subdomain of the domain of repair. Accordingly, we have said that the domain of repair is the set of practices whereby a co-interactant interrupts the ongoing course of action to attend to possible trouble in speaking, hearing, or understanding the talk or merely to alter it in some interactionally consequential way without any problems fixed in it; and repair operations are practices whereby a co-interactant interrupts her/his ongoing turn-at-talk to attend to 
possible trouble in speaking, hearing, or understanding the talk or merely to alter the turn in some interactionally consequential way without any problems fixed in it (see Section 3.2). In other words, apart from fixing a possible problem in speaking, hearing, or understanding the talk, repair operations can also be used "to fine-tune a turn in the service of the action(s) speakers mean to be doing" (Kitzinger 2013: 242), i.e., specifically to do interactional work, merely to alter the turn in some interactionally consequential way without any problems fixed in it. I understand the term interactional function as this "interactional task-at-hand" that repair operations can fulfil (Wilkinson and Weatherall 2011: 72).

Kitzinger (2013: 243) points out that downgrading the force of the action that the turn implements is a frequent way of interactionally fine-tuning a turn. In Kitzinger's example, the speaker, who is a helpline caller responding to a question about her pain, downgrades her admission by replacing is my f:- with the weaker formulation mi $(h) g h t$ be my fault (Example (23)) (Kitzinger 2013: 243).

(23) (PP03)

1 Clt: You're two years on and you've still go:t=

2 Mel: [yeah]

3 Clt: $=$ [still ] got pai:n.

$4 \quad$ Mel: I mean part of it I have to sa:y is my f:-

5 mi(h)ght be my fault because I've been given

6 .hh exercises to do [and I] ha:rdly ever do=

7 Clt: [yeah]

8 Mel: $=$ them...

The reverse interactional effect on the action is produced by replacements in which the speaker substitutes a weaker element with a stronger one. In Kitzinger's example, an advisor on a helpline tells the recipient that s/he is entitled to change a healthcare provider. She replaces the permissive can with the stronger have the absolute right to (Kitzinger 2013: 243) (Example (24)).

(24) (PP01)

1 Clt: If there's anybody that you fee:1 .hhh

2 isn't supporting you then: you can ch- 
Jefferson (1974) suggests that substituting one word for another, if the substituted segment is not recognizably complete ${ }^{21}$ but still recognizable, allows the speaker to produce an inappropriate $^{22}$ item without being interactionally accountable for it. She says that in these cases the speaker does not produce the word in question officially. In her example, the speaker replaces $k$ - 'colored' with Negro woman, and according to Jefferson, this can propose that "I am not a liberal but am talking by reference to the fact that you are" (Jefferson 1974: 193) (Example (25)).

(25) (TRIO: 10)

Jean: Well, she said thet there was some woman thet-the-thet they were whh- had held up in the front there, thet they were poin'ing the gun at, 'n everything, (0.4) a $k$ - Negro woman.

Drew (2013) establishes three principles guiding turn design. Speakers design their talk to make it appropriate for its sequential environment, for the action they intend it to do, and for the recipient to whom it is addressed. In Section 3.2, we have already seen how replacement can be employed when the initially selected word does not fit its sequential environment appropriately (a defendant in a courtroom starts to say cop, then replaces it with officer (Jefferson 1974: 192)). In Extract (26), replacement is used to downgrade a formulation to make it appropriate for its sequential environment. Gábor, Pali, and Viola are discussing what they would do in an imaginary situation where they have to decide whether to help a friend or not. The situation is the following: you have a friend who has failed an exam eight times. If s/he fails once more, s/he will be dismissed from the university. Before the last exam, s/he asks you to go into one of the toilets of the university building with the exam topics worked out (in Hungary, at oral exams there are usually 1020 topics from which the teacher selects one or two for the student to work out). During the exam, after your friend has been given the topic titles, s/he plans to go to the toilet and

\footnotetext{
${ }^{21}$ Recognizable completion allows the listener to assume that the word is finished (Fox et al. 2009, see Chapter 4).

${ }^{22}$ Here and everywhere else in the thesis, by the expression inappropriate word, segment, or item I will mean that the speaker labels the word, segment, or item as inappropriate.
} 
smuggle the papers s/he needs into the room. If the cheating comes to light, both of you will be dismissed from the university.

(26) (SZTEPSZI2: 953)

$\begin{array}{llllll}\text { 01 G: } & \text { mit } & \text { mondtál } & \text { hogyért } & \text { mennél } & \text { be. } \\ \text { what.ACC said.INDEF.2SG that why } & \text { go.INDEF.COND.2SG } & \text { PVB } \\ \text { 'why have you said you would go in. } & & & \end{array}$

$02 \mathrm{G}$ : már- már- [mármos hogy-]

no- no- now that-

I I [I mean that-]

$03 \mathrm{~V}: \quad$ [én $c s-]$ hát $\quad$ o: $\quad$ több: dolgot is

I.NOM jus- well u:h several thing.ACC also

[I jus-] well, u:h I have said several things,

04 mondtam, anyrészt añägrényében

said.INDEF.1SG on the one hand that.GEN depend.NDER.POSS.3SG.INE

on the one hand it depends on

05 hogy ö hogy gyöz meg engem (0.2) a másik

that s/he how persuade.INDEF.3SG PVB me the other.NOM

how s/he persuades me $(0.2)$ on the other hand

06 az meg hogy már csak a (.) poén

that.NOM and that even just the fun.GEN

(I would go in) even just for

07 kedvéér. én: nem szoktam ilyeneket csinálni

for the sake I.NOM not usually do.INDEF.1SG such things.ACC do.INF

fun. I: usually don't do such things 
08

$\begin{array}{lll}\text { és } & ((\text { laughing })) & \text { [most ez } \\ \text { and } & & \text { now this.NOM } \\ \text { and } & ((\text { laughing })) & \text { [now this }\end{array}$

$09 \mathrm{G}$ :

$$
\begin{aligned}
& \text { [de hogy te nem félted } \\
& \text { but that you.NOM.SG not fear.DEF.1SG the } \\
& \text { [but don't you fear for your: }
\end{aligned}
$$

10

$\begin{array}{llllll}\text { merhogy } & \text { ne- } & \text { nem félted } & a & \text { saját helyzetedet? } \\ \text { because } & \text { no- } & \text { not fear.DEF.1SG the own place.POSS.2SG.ACC }\end{array}$
because don- don't you fear for your own place (at the university)?

$11 \mathrm{G}$ : merhogy ez egy poén. igen.

because this.NOM a joke.NOM yes

because this is a joke. yes.

$12 \mathrm{~V}$ : nem.

no

no.

$13 \mathrm{G}$ : de hogy egy egy poén kedvéért fölál- ö but that a a joke.GEN for the sake sacri- uh but for a joke do you sacri- uh

14 kockára teszed egyébként a:? risk.DEF.2SG by the way the risk, by the way, your (place at the university)?'

G: why have you said you would go in.

(0.3)

G: I I [I mean that-] 
V:

[I jus-] well, u:h I have said several things, on the one hand it depends on how s/he persuades me (0.2) on the other hand (I would go in) even just for fun. I: usually don't do such things and ((laughing)) [now this

G:

[but don't you fear for your: because don- don't you fear for your own place (at the university)?

G: because this is a joke. yes.

$\mathrm{V}: \quad$ no.

G: but for a joke do you sacri- uh risk, by the way, your (place at the university)?

In line 01, Gábor asks Viola to sum up her arguments for helping the friend. When Viola says that she would do it even just for fun (lines 05-07), Gábor expresses his disagreement in the form of a negative question (lines 09-10). In line 11, he extends this turnconstructional unit accepting that the situation would be funny, and by doing this he expresses partial agreement with Viola. In line 12 Viola answers 'no', which makes it obvious that the two speakers' orientations towards the situation are different. The negotiation process continues with Gábor's question started in line 13, when he asks whether Viola would sacrifice her university place for a joke. In the middle of the word föláldozod 'you sacrifice' he breaks off (fölál- 'you sacri-'), and replaces it with the much weaker kockára teszed 'you risk'. The reason for the substitution becomes understandable if we take into consideration the sequential environment of the repair. The rejected selection föláldozod 'you sacrifice' means that Viola will in any case be dismissed if she helps her friend. However, in the imaginary situation they will be dismissed only if they are caught; therefore, the turn is better constructed with kockára teszed 'you risk'.

The downgrading function of replacement can also be seen in Extract (27), when Linda gives her opinion on the frequency of theft in Hungary. She says that the situation is quite bad: it is enough to leave a bag unattended in a bicycle basket; thieves will not leave it there.

(27) (SZTEPSZI8: 1089)

$\begin{array}{llll}01 \mathrm{~L}: & \text { alapból hogy valami } & \text { érték } \\ \text { enough that.NOM that something.NOM } & \text { value.NOM } \\ \text { 'it is enough that something valuable } & \end{array}$


02
ami:
ott van
szabadon
$a z$
[így]
which.NOM there is.INDEF
unattended that.NOM
in this way

which is left there unattended that [in this way]

03 B:

[azt]

that.ACC

[it]

$04 \quad$ igy

(.) biz[tos hogy nem hagyod ott.]

in this way

it is sure

that not leave.DEF.2SG there

is $\mathrm{su}$ [re that people won't leave it there.]

$05 \mathrm{~L}$ :

[Tök mindegy ká]bé hogy
very no matter roughly that
[we can say that it doesn't matter at] all

06

$\begin{array}{llllll}\text { mi } & \text { te[hát](.) } & \text { most } & \text { általá-vagy én legalábbis } & \text { mindig= } \\ \text { what.NOM } & \text { that is } & \text { now usua- or } & \text { I.NOM at least } & \text { always }\end{array}$

what it is, that [is] (.) usua- or at least that's always=

$07 \mathrm{~B}$ :

[ja.]

yeah

[yeah.]

$08 \mathrm{~L}:=e z t$

tapasztalom hogy ha most a biciklikosárba

this.ACC find.DEF.1SG that if now the bicycle basket.INE

$=$ my experience if there is a bag in a bicycle basket

09

$\begin{array}{lcccccc}\text { van } & \text { egy } & \text { zacskó } & \text { nem } & \text { tudja } & \text { mi } & \text { van } \\ \text { is.INDEF } & \text { a } & \text { bag.NOM } & \text { not } & \text { know.DEF.3SG what.NOM } & \text { is.INDEF } \\ \text { s/he doesn't know what is } & & & \end{array}$

10 benne akkor is elviszi.

it.INE still also take.DEF.3SG 
in it but s/he will still take it.'

$\mathrm{L}$ : it is enough that something valuable which is left there unattended that [in this way]

B:

is $\mathrm{su}[\mathrm{re}$ that people won't leave it there. ]

L: [we can say that it doesn't matter at] all what it is, that [is ] (.) usua- or at least=

B:

[yeah.]

$\mathrm{L}:=$ that's always my experience if there is a bag in a bicycle basket $\mathrm{s} / \mathrm{he}$ doesn't know what is in it but $\mathrm{s} /$ he will still take it.

In line 06, when Linda refers to the frequency of theft in Hungary, at first she seems to say that this is the usual way things happen in Hungary. Nonetheless, before the last syllable of általában 'usually', she initiates repair with a cut-off, and replaces the word with the weaker vagy én legalábbis mindig ezt tapasztalom 'or at least that's always my experience', which restricts her opinion to her own experience. This repair therefore does not fix a possible problem in speaking, hearing, or understanding the talk, but merely alters the turn in an interactionally consequential way without any problems fixed in it: by employing a replacement repair, Linda reduces her responsibility for the radical criticism of Hungarian people. The importance of the interactional work these kinds of repair perform is indicated by Linda's attempt to decrease the power of her critical remark despite the fact that one of the other speakers, Boglárka, strongly agrees with her (lines 03-04, and 07).

As was noted earlier, the speaker has to design the turn taking into consideration not only its position in the sequence (see Extract (26)) and the action it is intended to achieve (see Extract (27)), but also the particular recipient it is addressed to (Drew 2013). In Extract (28), we can see how the speaker employs replacement repair so as to make the turn appropriate for the relationship between the speaker and the recipient. In Hungarian, formal address is possible in two forms, i.e., there are two polite equivalents of you: Maga (plural: Maguk) and $\ddot{O} n$ (plural: Önök). $\ddot{O} n$ is used exclusively in formal situations when the speaker addresses somebody who s/he is not on familiar terms with (e.g., at a police station). Maga is less formal than $\ddot{O} n$. It can be used both in formal and informal situations if there is not a close relationship between the speaker and the recipient (e.g., between 
teacher and student, or passengers happening to travel together). Both forms occur with a third person verb. In Extract (28), two students, Enikő and Márta are talking to an old (at least 70-year-old) man, Tibor. Enikő asks Tibor how he has spent Christmas and how it is usually celebrated at his place.

(28) (bea004f003: 200)

$01 \mathrm{E}:$ arra gondoltunk Mártá(.)val hogy ö: that.SUB thought.DEF.1PL Márta.COM that u:h 'me and Márta have been thinking about u:h

02

szeretnénk

$\ddot{O} n t$ megkérdezni hogy a

karácsonyt

like.INDEF.COND.1PL You.ACC.SG ask.INF that the

Christmas.ACC asking You how (.)

03

$\begin{array}{lllll}\text { azt (.) hogyan töltötte } & \text { Ön? } & \text { meg hogyan } \\ \text { that.ACC } & \text { how } & \text { spent.DEF.3SG You.NOM.SG } & \text { and how }\end{array}$

did You spend Christmas time? and how

04 szokott

Ma- Önöknél zajlani?

(.) az egész

usually do.INDEF.3SG Yo- You.ADE.PL happen.INF

the whole is it celebrated at Yo- Your place? (.) the whole

05
(.) ünnep?
holiday.NOM

(.) Christmas holiday?

(1.0)

$06 \mathrm{~T}:$ na jó.

now alright

now it's alright.

$07 \mathrm{~T}$ : akkor kezdjék

Maguk!

then begin.DEF.IMP.3PL You.NOM.PL

but You should begin!' 
E: me and Márta have been thinking about u:h asking You how (.) did You spend Christmas time? and how is it celebrated at Yo- Your place? (.) the whole (.) Christmas holiday?

T: now it's alright.

T: but You should begin!

Enikö addresses Tibor three times in the extract (in lines 02, 03, and 04). While on the first two occasions she uses $\ddot{O} n$, in line 04 at first she selects Maguknál, but after the first syllable (Ma-) she replaces it with Önöknél 'at Your place', which increases the distance between Enikö and Tibor. This indicates not only that Enikö is not on familiar terms with Tibor, but also that the use of Maga and $\ddot{O} n$ should not alternate in the same conversation when addressing the same co-participant. In line 07, the old man also addresses the students. In contrast to Enikö, he uses the less formal Maguk, which makes it probable that there is a formal and hierarchical relationship between the students and the old man.

\subsection{Recycling}

According to Schegloff (2013: 59), the term recycling refers to a speaker's repeating some stretch of talk that they have previously uttered, most typically a stretch which has been said just before. This definition refers to all uses of recycling, including those cases when it is not a repair operation, for example, when the repeated element(s) only frame the repair (e.g., when the speaker repeats a word before replacement) (Example (29)), or when the second utterance emphasizes or stresses the first (Rieger 2003: 51) (Extract (30)).

(29) (TG, 7)

Bee: was I sid no I sid but we're supposetuh know what it is fuh Weh- .hh yihknow fuh tihday's class. 'n, (Schegloff 2013: 44) 
(30) (bea002f002: 83)

$01 \mathrm{~B}: a z$

nem volt

könnyü

megtanulni. $=$

that.NOM

not was.INDEF.3SG

easy

PVB.learn.INF

'it wasn't easy to learn that. $=$

02 =föleg az ilyen (.) beparkolásos manöver

especially the such parking manoeuvre.NOM

$=$ especially this kind of (.) parking manoeuvre

03 ilyen (.) mittöminek hívják ezt

such whatever.DAT call.DEF.3PL this.ACC

this kind of (.) whatever they call it .h

$04 \mathrm{~A}:[\mathrm{mhm}]$

uhm

[uhm]

$05 \mathrm{C}:[d e]$ ez

a szervofék

$e z-$

$e z$

but this.NOM the servo brake.NOM this.NOM this.NOM

[but] this servo brake isn' - isn't it

06 nem veszélyes? hogy igy

csak >nyomod

nyomod<

not dangerous that in this way just push.DEF.2SG push.DEF.2SG

dangerous? that in this way you just >push it push it<

07 és akkor mikor állsz

meg? = vagy

and then when stop.INDEF.2SG

PVB

or

and then when do you stop?=or'

B: $\quad$ it wasn't easy to learn that. = especially this kind of (.) parking manoeuvre this kind of (.) whatever they call it .h

A: $\quad[\mathrm{uhm}]$ 
C: [but ] this servo brake isn'- isn't it dangerous? that in this way you just >push it push it $<$ and then when do you stop?=or

In line 06, nyomod nyomod 'push it push it' is delivered more rapidly than usual for the speaker. This way of delivery expresses the continuity and intensity of using a servo brake, therefore it cannot be regarded as a recycling repair operation.

Furthermore, if the second utterance of the same item diverges from the first only in a prosodic respect, the consecutive usage of the same element(s) may be a repair operation, but rather a replacement than a recycling (Schegloff 2013: 60). In Example (31), grow is produced at higher a pitch when the speaker articulates it for the second time.

(31) $(\mathrm{KC}-4,07)$

Kay: I don think they grow a I don think they $\uparrow$ grow a culture to do a biopsy. (Schegloff 2013: 59)

This thesis regards recycling as a repair operation when the speaker repeats some stretch of talk that they have just previously produced, and the second utterance does not diverge from the first in a prosodic respect, and furthermore, the second does not emphasize or stress the first.

Recycling as a repair operation can be used at the emergence of overlapping talk in order to deal with possible problems in hearing or understanding caused by simultaneous talk (Schegloff 2013: 59-60; cf. Schegloff 1987), or at the emergence of inattentiveness in order to attract the nongazing recipients' gaze (Goodwin 1980). While in the former case the speaker repeats some stretch of talk in order to say it in the clear (Schegloff 2013: 60), in the latter the function of the repair operation is to elicit gaze from recipients. To these functions of recycling as a repair operation Fox et al. (2009: 75) add another: it can also serve as a device for delaying the next item due, e.g., when the speaker needs time to select the appropriate next word or choose between alternatives (Jefferson 1974). Although the former functions also delay the talk that follows literally, in those cases the repair operation deals with a problem concerning the repeated talk: the potentially compromised hearing of the stretch of talk uttered in interactionally problematic moments (overlap or inattentiveness) (Schegloff 2009: 386). That is, at the emergence of overlapping talk and inattentiveness, delaying the next item due is only a by-product of the recycling repair operation. The Hungarian corpus contains recyclings which combine the functions 
described by Schegloff (2013) and Fox et al. (2009). In Extract (32), Ábel, Boglárka, and Linda are talking about Hungarian music bands which have become famous outside Hungary.

(32) (SZTEPSZI8: 1062)

01 Á: sok olyan zenekar van amúgy aki: sokat many such band.NOM is.INDEF anyway who.NOM a lot 'there are a lot of bands by the way who:

02 játszik külföldön [tehát tehát tehát olyan]ok is= play.INDEF.3SG abroad that is that is that is kind.NOM.PL also play a lot abroad [that is that is that is even band] $\mathrm{s}=$

$03 \mathrm{~L}$ :

$$
\begin{aligned}
& \text { [hát ige:n. tényleg sokan.] } \\
& \text { well yes really many.NOM } \\
& \text { [well ye:s. there are really a lot.] }
\end{aligned}
$$

04 Á: =ak- akik a

wh- who.NOM.PL who.NOM.PL who.NOM.PL who.NOM.PL

=wh- who wh $[$ o who who $]=$

$05 \mathrm{~B}$ :

$$
\begin{aligned}
& \text { [de lehe-] } \\
& \text { but maybe- } \\
& \text { [but maybe-] }
\end{aligned}
$$

06 Á: =Magyar[orszá]gon annyira nem is durván ismertek. Hungary.SUP so much not also well known.PL =are not so well-known in Hun[gar]y.'

07 B: $\quad \begin{aligned} & \text { [ja::] } \\ & \text { yeah } \\ & \\ & \text { [ye:ah.] }\end{aligned}$


Á: $\quad$ there are a lot of bands by the way who: play a lot abroad

[that is that is that is even band]s wh- who=

L: [well ye:s. there are really a lot.]

Á: $\quad=$ wh[o who who] are not so well-known in Hun[ gar ]y.

B: [but maybe-] [ye:ah.]

In lines 02 and 04, Ábel recycles his talk which overlaps Linda and Boglárka's talk, but not in the way Schegloff (2013: 60) describes this kind of recycling. That is to say, it is not the repeated talk that Ábel produces in the clear. The stretch of talk which is produced in the clear is the talk that follows the recycling. Therefore, in these cases the repair operation serves as a device for delaying the talk that follows in order to say it in the clear. In this way the recycling deals with a problem concerned not with the repeated but with the upcoming talk: by recycling, the speaker can avoid ${ }^{23}$ a possibly compromised hearing of the upcoming talk. This analysis is supported by Ábel's gaze direction, which he changes during his overlapping talk. Realizing that Boglárka has started to talk simultaneously, he recycles akik 'who' twice, and at the same time directs his gaze towards her. Boglárka responses to this by a cut-off (de lehe- 'but maybe-') and lets him continue his talk.

Schegloff (2009: 385-386) argues against the proposal made by Fox et al. (2009). He rejects the idea that recycling, if its sole function is to delay the next item due, can be interpreted as repair operation. He says that there are other practices which also delay the next item due, such as $u h(m), y^{\prime} k n o w$, and silence ${ }^{24}$, which can occur separately or together "in the environment of repair" (Schegloff 2009: 385). He asks: "What then is done by recycling distinctively?" (Schegloff 2009: 386, emphasis original). That is to say, Schegloff argues here that the practices such as $u h(m), y^{\prime} k n o w$, and silence can have the same function as recycling, but they can occur in the environment of repair, they themselves therefore are not repair operations. And indeed, they are listed in The Handbook of Conversation Analysis as practices of repair initiation (Kitzinger 2013: 239, see above). In other words, Schegloff's problem is that although the practices listed above do the same thing as recycling, they are not repair operations, consequently, recycling with the sole function of delaying the next item due cannot be interpreted as repair operation either.

\footnotetext{
${ }^{23}$ Here and everywhere else in the thesis I use the term avoid to refer to the speakers' institutionalized attitudes towards dispreferred actions (see, e.g., the error avoidance format described by Jefferson 1974: 194).

${ }^{24}$ In Hungarian, a practice of this kind is $\ddot{o}:$.
} 
Now, we are once again confronted with p-inconsistency in the conversation analytic literature (Kertész-Rákosi 2012: 130-134, 2014: 29-32; this thesis: Section 2.3.1). According to Schegloff (2009), recycling with the same delaying function as the practices such as $u h(m), y^{\prime} k n o w$, and silence should not be interpreted as repair operation, because the practices listed above are not repair operations either. However, according to Fox et al. (2009), recycling with the sole function of delaying the next item due should be interpreted as repair operation. Unlike in the case of the p-inconsistency concerning the relationship between repair and repair operation (see Section 3.2), this time I apply the Combinative Strategy as a problem-solving strategy (Kertész-Rákosi 2012: 153-161, 2014: 35-37; this thesis: Section 2.3.2). I keep both Schegloff's (2009: 385-386) and Fox and her colleagues' (2009: 75) statements as co-existing alternatives; however, I separate two domains of occurrences of the practices such as $u h(m), y^{\prime} k n o w$, and silence listed by Schegloff (2009: 385-386) and Kitzinger (2013: 239). I propose that if their function is to indicate a "possible disjunction with the immediately preceding talk" (Schegloff 2000: 207), then they should be interpreted as repair initiation practices (see Extract (26), line 13). However, as Schegloff (2009: 385) suggests, there are cases when their function is the same as the function of recycling when it delays the next item due. My proposal here is that instead of not regarding these occurrences of recycling as repair operations, the practices such as $u h(m), y^{\prime} k n o w$, and silence should be regarded as repair operations when they are used as devices for delaying the talk that follows. The basis of this argumentation is the definition of repair operation accepted in Section 3.2: I have defined repair operations as practices whereby a co-interactant interrupts her/his ongoing turn-at-talk to attend to possible trouble in speaking, hearing, or understanding the talk or merely to alter the turn in some interactionally consequential way without any problems fixed in it. That is, if recycling or the practices such as $u h(m), y^{\prime} k n o w$, and silence are employed solely to delay the next item due so that the speaker can attend to possible trouble in speaking, hearing, or understanding the talk or merely alter the turn in some interactionally consequential way, then we should interpret them as repair and repair operation.

Lerner (2013: 105) suggests that the turn-constructional delaying strategies used when searching for a word can display "some unease or hesitancy about what one is saying or is about to say". Hesitation may appear before a predictably delicate term or before a term that is part of a turn-constructional unit formulating a delicate matter or implementing a delicate action, when the speaker, for example, negatively evaluates someone's character or actions (Lerner 2013: 104). This way of delivery can show that although the speaker is 
loath to say something, s/he still voices it (cf. Whitehead 2009). In Extract (33), the delicate action the speaker engages in is the delivery of self-praise. Szili (2004: 283) points out that Hungarian speakers follow the principle of modesty when replying to compliments on their personal performances (see also, Szili 2010). Therefore, the delivery of self-praise relating to the speaker's personal performance may make her/him feel unease in Hungarian conversations. In the extract, three teacher trainees, Bogi, Feri, and Eszter are talking about their teaching practices. Feri tells the others that after his teaching exam, which is always the last lesson of the teaching practice, one of his students went up to him and gave a positive opinion on his work. Feri has not been asked earlier in the conversation whether his teaching practice was successful or not; in other words, he himself decides to share his student's opinion with the others. This means that his telling is a delivery of self-praise in the context of Hungarian culture.

(33) (bea007f005: 430)

01 F: és aztán: (.) tehát ö már a már a: and then that is uh already the already the 'and then: (.) that is uh after after my

$\begin{array}{llll}\text { a vizsgatanitásom } & \text { után tehát amikor már } \\ \text { the teaching exam.POSS.1SG after that is when } & \text { already } \\ \text { my teaching exam that is when he } & & & \end{array}$

03 tényleg semmi tétje nem volt annak really nothing.NOM risk.POSS.3SG not was.INDEF.3SG that.GEN really didn't take any risk

04 hogy milyen véleményt mond a thh arról (.) that what kind of opinion.ACC tell.INDEF.3SG the that.DEL telling his opinion on the .hh on (.)

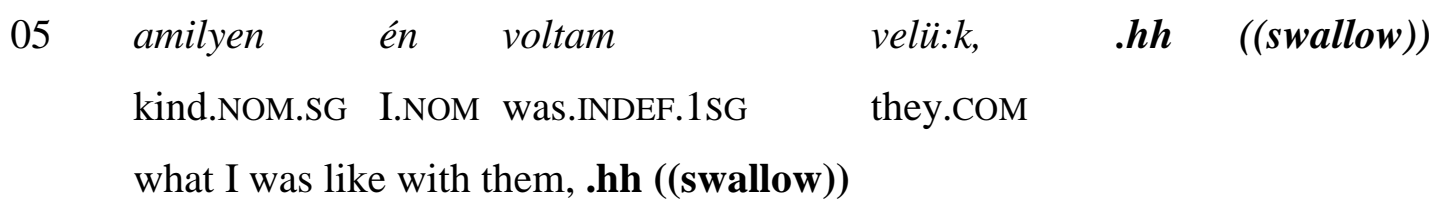




$\begin{array}{llllll}\text { akkor azt } & \text { mondta } & \text { hogy } & \text { hogy } & \text { hogy (.) } & \text { hogy } \\ \text { then that.ACC } & \text { told.DEF.3SG } & \text { that that that } & \text { that }\end{array}$

then he told that that that (.) that

07
tetszettek
(.)
nekik $=j$
hát $a: z$
egész osztály
like.PASS.3PL
they.DAT
OK well the
whole class.GEN

they liked (.) them (the lessons)=well it's OK he spoke

08
nevében
beszélt
dehát ige:n legyünk
name.POSS.3SG.INE spoke.INDEF.3SG
but yes be.INDEF.IMP.1PL
on behalf of the whole class but we should be

09
realisták
tehát $\ddot{o}$
$\underline{N E k i}$
nagyon
tetszett
realists.NOM that is uh
DAT.3SG
very much
like.PASS.3SG

realists that is uh $\underline{\mathrm{HE}}$ very much liked

$10 \quad$ a- ahogy tanítottam

as taught.INDEF.1SG

th- the way I taught'

F: and then: (.) that is uh after after my my teaching exam that is when he really didn't take any risk telling his opinion on the .hh on (.) what I was like with them, .hh ((swallow)) then he told that that that (.) that they liked (.) them (the lessons)=well it's OK he spoke on behalf of the whole class but we should be realists that is uh $\underline{\mathrm{HE}}$ very much liked th- the way I taught

In line 05, before Feri refers to his success, there is an audible inhalation and a swallow. Then in line 06, just prior to the self-praising expression (tetszettek nekik 'they liked them') in line 07 , he recycles hogy 'that' three times with a pause before the last recycling. The self-praising expression also contains a pause. The assumption that these phenomena result from Feri's unease about delivering self-praise is strengthened by the extension of the turn: after he talks about the praise, he hastens to add that although the student has spoken on 
behalf of the whole class, Feri thinks that it was merely the student's own opinion. This modest comment may serve as a compensation for the earlier immodesty. Feri's last selfreflection in line 10 also contains a recycling (a- ahogy tanitottam 'the- the way I taught'). This analysis makes it probable that the turn-constructional delaying practices in this extract alter the turn in some interactionally consequential way, and their interactional function is to display Feri's unease about what he is about to say during the delivery of self-praise.

Hesitating before a critical judgement may also express the speaker's unease about what s/he is about to say (Lerner 2013: 104), and therefore decrease the power of the critical assessment. In Extracts (34) and (35), Móni, Attila, and Lilla are talking about Hungarian youngsters who use alcohol and drugs. In Extract (34), Móni tells the others why she has not tried any kind of drugs: she saw their effects on her friends. In line 09, she closes her opinion with a strong critical judgement and uses the expression undoritó 'disgusting'.

(34) (SZTEPSZI3: 856)

$01 \mathrm{M}$ : és például a drogokat. egyszerüen nem próbáltam and for example the drugs.ACC simply not tried.DEF.1sG 'and I have simply never tried for example drugs.

02

$\begin{array}{lllll}k i & \text { soha azért } & \text { mert } & \text { láttam } & a \\ \text { PVB never that.CAUS } & \text { because } & \text { saw.DEF.1SG the } \\ \text { because I saw }\end{array}$

03 barátaimat hogy hogy ö: egy normális ember friends.POSS.1SG.ACC that that $\mathrm{u}: \mathrm{h}$ a normal human being my friends that that $\mathrm{u}$ :h a normal human being

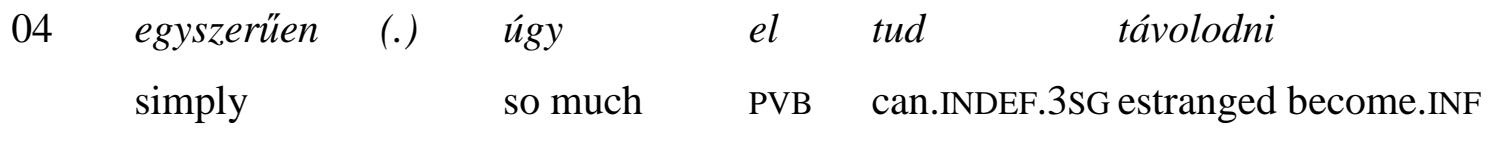
can simply become so estranged 


$\begin{array}{llllll}\text { és } & \text { annyira: } & \text { embertelen } & \text { lesz } & \text { attól } & \text { amikor } \\ \text { and } & \text { so much } & \text { inhuman } & \text { becomes.INDEF } & \text { that.ABL } & \text { when }\end{array}$

and so: inhuman because of

06
drogozik,
hogy ez
engem totál visszataszított
drugs uses.INDEF
that this.NOM
I.ACC totally repelled.INDEF.3SG
using drugs, that totally repelled me

07

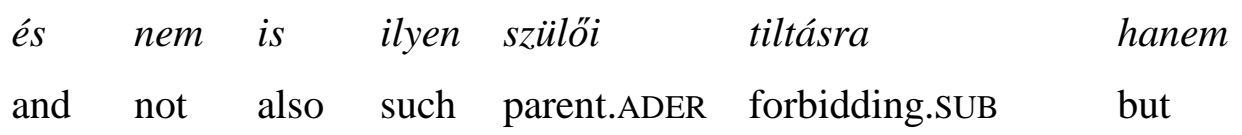

and not because my parents forbade me to do that but

$08 \quad \boldsymbol{e z}$

this.NOM
(.) $\quad e z$

this.NOM $\boldsymbol{e z}$

this.NOM számomra

I.DAT úgymond

so to say

because this (.) this this was so to say

09 undorító volt

disgusting was.INDEF.3SG

disgusting for me'

M: and I have simply never tried for example drugs. because I saw my friends that that $\mathrm{u}: \mathrm{h}$ a normal human being can simply become so estranged and so: inhuman because of using drugs, that totally repelled me and not because my parents forbade me to do that but because this (.) this this was so to say disgusting for me

Before using the delicate expression undoritó 'disgusting' in line 09, Móni employs the double recycling of the subject ( $e z e z e z$ 'this this this') with a pause. Since using the word undorító 'disgusting' is a very strong negative evaluation of someone's behavior, Móni may be loath to voice it, which supports that the double recycling and the pause preceding it are delaying strategies. It is necessary to note here that beyond these turn-constructional delaying practices, Móni uses other mitigating devices as well (számomra 'for me', 
úgymond 'so to say') in the delivery of her critical judgement. These practices, however, do not interrupt the ongoing turn-at-talk, and thus cannot be analyzed as repair.

Extracts (35) and (36) show that recycling in itself can also fulfil the interactional function Lerner (2013) describes, and thus alter the turn in some interactionally consequential way. In Extract (35), Móni explains what kind of behavior she can and cannot tolerate when somebody is drunk in her company.

(35) (SZTEPSZI3: 816)

$01 \mathrm{M}$ : egyébként (.) én azt még úgy úgy (.) by the way I.NOM that.ACC still in a way in a way 'by the way (.) I can still (tolerate) it in a way in a way

02 tudom (.) hogyha:, mittudomén, tényleg elmegy can.DEF.1SG if whatever in fact goes.INDEF.3SG

if, in fact, s/he goes to a party or whatever

03 buliba és akko (.) berúgott. kész. de amikor party.ILL and then drunk got.INDEF.3SG done but when and then s/he got drunk. it's done. but when

04 amikorez a totál nem tud magáról. when this.NOM the totally not knows.INDEF herself/himself.DEL when s/he doesn't know anything about himself/herself.

05 semmi képe nincs az egész világról nothing.NOM idea.POSS.3SG.NOM is.NEG.INDEF the whole world.DEL s/he doesn't have any idea of reality (.)

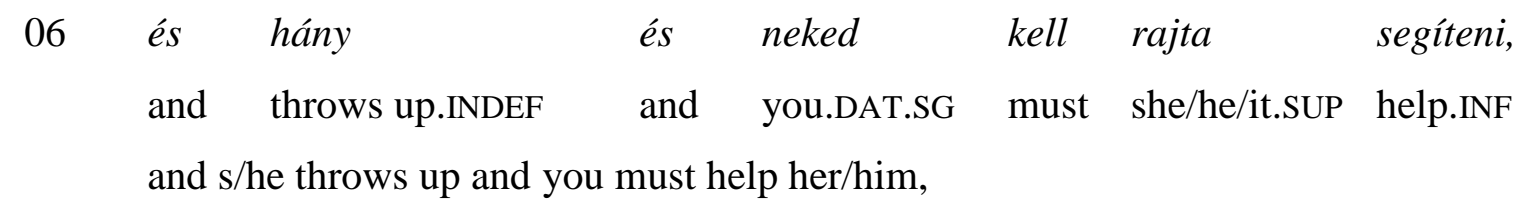




$\begin{array}{llllll}n a & \boldsymbol{a} z & \boldsymbol{a} z & \boldsymbol{a z} & \text { má } & \text { szerintem } \\ \text { well } & \text { that.NOM } & \text { that.NOM } & \text { that.NOM } & \text { already } & \text { think.DEF.1SG }\end{array}$

well that that that I think already

08
megint
a gáz
gáz kategória.
again
the
$\operatorname{gas}^{25}$ category.NOM
is the gas category.'

M: by the way (.) I can still (tolerate) it in a way in a way if, in fact, s/he goes to a party or whatever and then s/he got drunk. it's done. but when when s/he doesn't know anything about himself/herself. s/he doesn't have any idea of reality (.) and s/he throws up and you must help her/him, well that that that I think already is the gas category.

In lines 08-09, Móni closes her opinion with a strong critical judgement on the behavior she cannot stand. The delivery of this judgement takes place with the double recycling of the subject ( $a z a z a z$ 'that that that'). The delaying function of this recycling is supported by Móni's gaze direction. She does not look at any of the other participants till the last saying of the recycled item, when she directs her gaze towards another participant (who is selected as the next speaker), and finishes her turn with a final intonational contour (indicated by a dot in the transcription).

The Hungarian corpus shows that displaying hesitancy or unease about what the speaker is about to say (Lerner 2013) may not only occur during the delivery of self-praise and criticism, but also in avoiding offensive language. In Extract (36), Ági, Zsuzsi, and Marcsi are talking about a freestyle rapper who has walking difficulties.

\footnotetext{
${ }^{25}$ Gáz 'gas' does not only mean 'aerial material' in Hungarian, but is also a slang adjective. It can be used for describing practically anything negative: it may mean 'bad', 'awkward', 'intolerable', 'unbearable', etc. (e.g., gáz helyzet 'bad situation').
} 
(36) (SZTEPSZI2: 725)

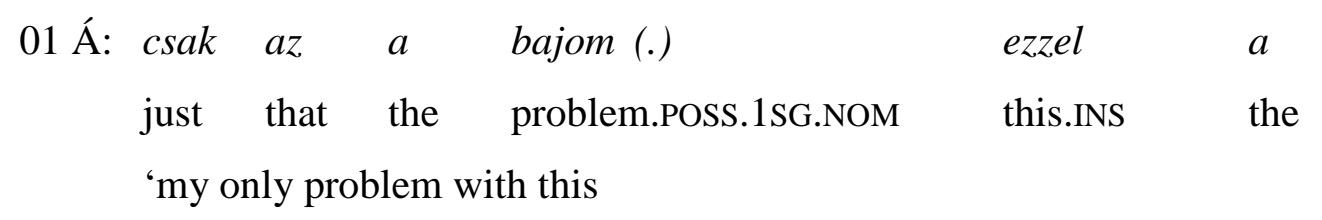

02 gyerekkel, hogy ilyen: totál elszállt. tehát legalábbis így guy.INS that such totally smart.alec so at least like guy is that he is a smart alec. so at least

$03 \begin{array}{lllll}\text { ránézésre, és emiatt } & \text { unszimpatikus, } & \text { emiatt } \\ \text { looking.SUB and } & \text { this.CAUS } & \text { antipathetic } & \text { this.CAUS }\end{array}$ he seems to be, and for this reason he doesn't appeal to me, for this reason

04 már a tehetségét $\quad$ sem $\quad$ tudom already the talent.POss.3SG.ACC neither can.DEF.1SG I cannot appreciate his talent any more,

05 értékelni, mondjuk nem mintha a freestyleosokat appreciate.INF by the way not as if the freestyle rappers.ACC by the way we cannot say that I appreciate freestyle rappers

06 értékelném mert szerintem nem tehetségek, appreciate.DEF.COND.1SG because think.DEF.1SG not talents.NOM because I don't think they are talented,

$07 \mathrm{M}$ : én ennek tök örülök mert I.NOM this.DAT very much happy am.INDEF because I am so happy about that (the rapper's success) because

$\begin{array}{lllll}08 & \text { szerintem ilyen óriási (.) } & \text { hátrányokkal } & \text { indul. } & \text { tehát } \\ \text { think.DEF.1SG such huge } & \text { disadvantages.INS } & \text { starts.INDEF } & \text { that is } \\ \text { I think he starts with huge disadvantages. that is } & & \end{array}$


with an enormous handicap that that that he is like that'

Á: my only problem with this guy is that he is a smart alec. so at least he seems to be, and for this reason he doesn't appeal to me, for this reason I cannot appreciate his talent any more, by the way we cannot say that I appreciate freestyle rappers because I don't think they are talented,

M: I am so happy about that (the rapper's success) because I think he starts with huge disadvantages. that is with an enormous handicap that that that he is like that

In line 09, before Marcsi refers to the rapper's health problem, she recycles hogy 'that' twice. This may indicate her unease about referring to the disorder in an inoffensive way (cf. the replacement of cop with officer in Jefferson 1974: 192), and also her selectional difficulties in finding the interactionally appropriate expression (Jefferson 1974). Finally, she refers to the health problem without naming it.

Extracts (33), (34), (35), and (36) show that when recycling and the practices such as $u h(m), y$ 'know and silence are used for delaying the talk that follows, they can be a part of a searching, which is regarded as a repair operation in its own right by Schegloff (2013). However, even in these cases these practices do not occur "in the environment of repair" (Schegloff 2009: 385), but they are the repair itself. This makes the proposal of Fox et al. (2009: 75) plausible: if the speaker employs recycling as a device for delaying the next item due, and s/he does this in order to attend to possible trouble in speaking, hearing, or understanding the talk or merely alter the turn in some interactionally consequential way without any problems fixed in it, then we should interpret recycling as a repair operation. ${ }^{26}$

\footnotetext{
${ }^{26}$ However, when we analyze the particular occurrences of recycling in conversations, sometimes it can be difficult to identify this function. In these cases, the analysis of other features of the phenomenon (e.g., site of initiation) can help us to decide whether we are dealing with a repair operation or not (see Chapter 6).
} 


\subsection{Insertion $^{27}$}

Insertion is a "practice in which speakers halt their talk-in-progress to go back and add something else into the turn before resuming" (Wilkinson-Weatherall 2011: 65). In this repair operation the speaker "inserts one or more new elements into the turn-so-far, recognizable as other than what was on tap to be said next" (Schegloff 2013: 45). Schegloff (2013: 47) notes that insertion is a repair operation which often merely alters the turn instead of fixing an apparent problem in it. When this is the case, the turn is not on the way to be defective, i.e., the added word is not missing, but the "speaker may find that saying the thing they are in the course of saying could be better realized by this-or-that change" (Schegloff 2013: 47). In Extract (37), Gábor shares the adventures he experienced when looking for the location of his driving test. In line 05 and 06, we can see the insertion of a location adverb into the TCU.

(37) (bea001f001: 16)

$\begin{array}{rllll}01 \mathrm{G}: & \text { visszamentem. } & \text { mondták hogy az elején } \\ & \text { PVB.went.INDEF.1SG } & \text { told.DEF.3PL that the beginning.POSS.3SG.SUP }\end{array}$
'I went back. they told me that at the beginning of it

02

\begin{tabular}{|c|c|c|c|}
\hline van & valami: & autós- >me & mondtam \\
\hline is.INDEF & something.NOM & drivingbecause & told.DEF.1SG \\
\hline
\end{tabular}

$\begin{array}{lllll}\text { nekem vizsgázni } & \text { kéner } & \text { van } & \text { ott valami: } \\ \text { I.DAT an exam take.INF } & \text { should } & \text { is.INDEF } & \text { there } & \text { something.NOM }\end{array}$

I should take an exam $<$ at that place there is some kind of

\begin{tabular}{|c|c|c|c|}
\hline $\begin{array}{l}\text { autós } \\
\text { driving }\end{array}$ & $\begin{array}{l}\text { intézet. }= \\
\text { institute.NOM }\end{array}$ & $\begin{array}{l}\text { valami } \\
\text { something.NOM }\end{array}$ & $\begin{array}{l}\text { autóbiztonsági } \\
\text { car security.ADER }\end{array}$ \\
\hline
\end{tabular}

\footnotetext{
${ }^{27}$ Although the term inserting created by Schegloff (2013: 45) better indicates that the focus is on an operation carried out by speakers, following Wilkinson and Weatherall (2011), I will use the term insertion.
} 


\section{mondt-}

to-$$
\text { ott mondták hogy }
$$$$
\text { there told.DEF.3PL that } \mathrm{oh}^{28} \text { not not }
$$

there

they to- there they told me that $\underline{\mathrm{o}: \mathrm{h}}$ no no. $=\mathrm{s} / \mathrm{he}$ says'

G: I went back. they told me that at the beginning of it there is some kind of .h driving$>$ because I told them that I should take an exam< at that place there is some kind of driving institute. = some kind of car security I don't know what kind of institute was there. .hh they to- there they told me that $\underline{\mathrm{o}: \mathrm{h}}$ no no. $=\mathrm{s} / \mathrm{he}$ says

When Gábor has articulated mondt- 'they to-' in line 06, he initiates repair by a cut-off, and incorporates an additional word (the location adverb ott 'there'). Since the turn would not be appropriately articulated without repeating the element which has already been articulated before the insertion, the inserted word is always framed by repeating some of the talk around it (cf. Kitzinger 2013: 239). As this repetition constitutes a part of the repair operation, i.e., the operation would not work without it, we can say that insertion inherently includes the repetition of one or more element(s).

As was noted above, insertion is often employed merely to alter the turn in some interactionally consequential way rather than to fix a problem in the turn-so-far (Schegloff 2013: 47). Perhaps that is the reason why insertion is one of the most elaborately explored repair operations regarding its interactional functions in the conversation analytic literature. Wilkinson and Weatherall (2011), analyzing more than 500 insertion repairs in British, New Zealand, and U.S. English, differentiate between the repairing action insertion can accomplish (specifying, intensifying, and other modifications) and the interactional action which is served by the modifications. Several interactional actions can be accomplished through insertion: highlighting newsworthiness, strengthening an account, accounting for an assessment, providing evidence for an assertion, etc. Nevertheless,

\footnotetext{
${ }^{28} A$ : or $a ́$ intensifies negation in Hungarian.
} 
although there are typical repairing actions (e.g., specifying or intensifying) insertion may accomplish, Wilkinson and Weatherall suggest that interactional actions tend to be casespecific, and should be analyzed on a case-by-case basis (Wilkinson and Weatherall 2011: $88)$.

Intensifying by insertion can have the same upgrading effect on the action as replacements have when they are used for intensifying (Kitzinger 2013: 243). In Wilkinson and Weatherall's example (Example (38)), the presenter of a radio arts program inserts spanking before new when naming a museum (spanking new (.) Wedgwood museum). This intensifies the newness of the museum, and thereby highlights the newsworthiness of the report (Wilkinson-Weatherall 2011: 81). The authors point out that intensifying through the insertion of words like completely, really, or extremely can result in an extreme case formulation (Pomerantz 1986).

(38) (BBC Radio 4, Front Row, 23.3.09)

Pre: I'm now at thee ne:w (0.2) spanking new (.) Wedgwood

museum in Stoke on Tre:nt. hh A:: (.) very swish

ne:w modern buil:ding

(Wilkinson-Weatherall 2011: 81)

When there are two or more possible referents available, inserting a specifying term can fix a possible problem in understanding (e.g., inserting Cary before cemetery (WilkinsonWeatherall 2011: 73) (Example (39)).

(39) (Holt: X (C) 1:1:3)

Phi: $\quad$ at uhm (0.2) Yeh the service's at uhm twelve o'clock 'n then: the .hwhhhh the: uh:m (0.5) it'll be in the cehthe Cary cemet'ry afterwards

(Wilkinson-Weatherall 2011: 73)

Specifying through insertion may also serve an interactional task-at-hand, when, instead of differentiating between two or more possible referents, it alerts the recipient to the relevance of the referent being of a specific type. For instance, inserting micro before habitats in the description of a zoo can provide evidence for the assertion that the zoo 
offers vast amounts of space for the animals (Wilkinson-Weatherall 2011: 79) (Example (40)).

(40) (BBC Radio 4, 'What's the Point of...The British Zoo', 2.6.09)

Dav: The importance of this enclo:sure is that .hh uh:m we gave him opportunity .hh to really display his who:le (.) behavioural repertoire. hh The complexi:ty of the enclo:sure .hhh the whole different habitats microhabitats in the enclo:sure.

(Wilkinson-Weatherall 2011: 79)

Furthermore, the modification of a reference formulation can also have a specifying function. In Example (41), the speaker proposes that the thieves working in the street steal branded goods instead of basic things (Wilkinson and Weatherall 2011: 78).

(41) (WCSNZE: DPC235)

DR: They steal your bloody sh: Doc Mar:tens shoe:s

an : ::: wh:: whatever you've got o:n it's-

(Wilkinson and Weatherall 2011: 78)

Luke and Wei Zhang (2010: 175) provide examples of insertion in Mandarin Chinese. Inserting ying 'by force, against one's will' before la shangqu le 'dragged me up', the speaker accounts for his feeling as a victim of privately-run bus services in Shenzhen, where the hired conductor grabbed him and forcibly kidnapped him onto the bus (Example (42)).

(42) (XFZB-3 A-3)

L: $\quad$ en la shangqu le ying la shangqu

'en dragged me onto the bus, forcibly dragged me up'

(Luke-Wei Zhang 2010: 175)

In Example (43), the hosts of Consumer Hotline insert the deontic verb yinggai 'should' before shi meiyou wenti 'there's no problem', which turns the statement 'It's not a problem' into 'It shouldn't be a problem'. Since this is in a response to a telephone call 
during which the caller complains about a shop being reluctant to take back a ring, the authors argue that the hosts are in this way defending the consumer rights of the caller, and expressing that they are on her/his side (Luke-Wei Zhang 2010: 168-169).

(43) (DJY-1 A-2)

S: $\quad$ wo kan zhege shi meiyou shenm- yinggai shi meiyou wenti 'I think this is not- this shouldn't be a problem'

(Luke-Wei Zhang 2010: 168)

Insertion can also be used to do identity work in Mandarin Chinese: inserting words like zanmen 'us' or tamen 'them' may have the effect of reducing or increasing distance, respectively (Examples (44) and (45)).

(44) (=1) AS-P9

S: $\quad$ natian wo zai Gang-zai zanmen GangDa de zhe-ge shudian qu mai shu 'the other day I was at the Hong- at our Hong Kong U bookshop buying some books.'

(Luke-Wei Zhang 2010: 171)

(45) (AS-0118)

S: $\quad$ nabian hai you xie-tamen you xie shiqing xiang gen wo taolun taolun 'over there there are still some- they have some things that (they) want to discuss with me'

(Luke-Wei Zhang 2010: 172)

In Hungarian, insertion can also be employed solely to do interactional work, when it simply alters the turn instead of fixing an apparent problem in it. The Hungarian corpus represents that the interactional function Lerner (2013: 105) suggests for turnconstructional delaying practices, i.e., expressing the speaker's unease about what $s /$ he is about to say, can be applied not only for turn-constructional delaying practices, but also for insertion in Hungarian. According to my observations, this interactional function can appear during the delivery of criticism in the Hungarian corpus. This means that the speakers of the corpus not only use replacement (Extract (27)) and recycling (Extracts (34), (35)) in the delivery of criticism, but insertion as well. In Extracts (46) and (47), the 
speakers decrease the power of their critical assessments by modifying talk through insertion. In Extract (46), Anna, Bálint, and Gabi are discussing the situation of women who go to a job interview, and want to have a baby in the near future. Bálint criticizes the companies which do not employ such women because of the future disadvantages that the women's maternity leave would bring about for their businesses. That is to say, in Hungary, women can spend two years at home with their babies, and during this time they receive maternity benefit.

(46) (bea008f006: 507)

$\begin{array}{rlllll}01 \mathrm{~B}: & \text { mélyen } & \text { felháborít hogy } & \ddot{o}: & \text { hogy ezt } & \text { bármilyen } \\ \text { deeply } & \text { shocks.INDEF that } \mathrm{u}: \mathrm{h} & \text { that this.ACC } & \text { any kind of }\end{array}$ 'I am deeply shocked at the situation that $\mathrm{u}$ :h that any kind of

02 m:unkaadó (.) mh bármilyen mértékben ö: employer.NOM um any kind of degree.INE u:h employer (.) um to any degree $\mathrm{u}: \mathrm{h}$

$03 f$ - megpróbálja figyelembe venni hogy $\ddot{o}$ :

t- PVB.tries.DEF consideration.ILL take.INF that $u: h$

t- makes an attempt to take into consideration $\mathrm{u}: \mathrm{h}$

04 hogy ki(.)nek mik a családalapítási

that who.GEN what.NOM.PL the family starting.ADER

who takes on what in connection with

05 vállalásai

endeavours.POSS.3SG.NOM

starting a family'

B: I am deeply shocked at the situation that $\mathrm{u}$ :h that any kind of employer (.) um to any degree $u: h$ t- makes an attempt to take into consideration $u$ :h who takes on what in connection with starting a family 
In line 03, Bálint starts to say in a critical tone that companies take into consideration women's future plans for starting a family, i.e., having a baby. After the first sound he breaks off ( $f$ - 't-'), and inserts megpróbálja 'tries to', 'makes an attempt to' before figyelembe venni 'take into consideration'. This modification decreases the power of his critical remark and reduces his responsibility for it: instead of stating that companies take into consideration the candidates' plans when deciding whether to employ them or not, he just says that the companies make an attempt to do that. This may also express Bálint's unease about producing criticism, which is supported by the fact that he employs the hesitation marker $\ddot{o}$ : ' $\mathrm{u}: \mathrm{h}$ ' before the insertion. This stretched hesitation marker cannot be regarded as the repair initiation of the insertion, because the insertion is initiated later, by a cut-off, after the speaker has pronounced the voice $f$. For this reason, I argue that it is a repair operation with a delaying function (see Section 5.2).

In Extract (47), Ági, Zsuzsi, and Marcsi are talking about Hungarian television talent shows.

(47) (SZTEPSZI2: 790)

$\begin{array}{llllllll}01 \text { Á: } & a & \text { média } & \text { nem föltétlenül } & \text { (.) } a & \text { (.) } & \text { csak } & \boldsymbol{a} \\ & \text { the media.NOM } & \text { not } & \text { necessarily } & & \text { the } & & \text { only the }\end{array}$
'the media is not necessarily (.) guided by (.) only by

02 jóindulat v:ezérli. hogy majd tehetséget faragunk goodwill.NOM guides.DEF that then talent.ACC create.INDEF.1PL goodwill. the intention of making a talented person

\begin{tabular}{|c|c|c|c|}
\hline belő[le & hanem NEKI & HASZNOS & $H O G Y]=$ \\
\hline $\begin{array}{l}\text { belolle } \\
\text { she/he/it.ELA }\end{array}$ & but she/he/it.DAT this.NOM & the useful & that \\
\hline
\end{tabular}

04 Zs: $\begin{array}{ll}\text { [hát } & \text { nem.] } \\ \mathrm{DM}^{29} & \text { not }\end{array}$

[it's not.]

\footnotetext{
${ }^{29}$ The discourse marker hát expresses emphasis here.
} 
$05 \mathrm{M}$ : [persze hogy nem. sőt, biztos hogy nem.]

of course that not what is more sure that not

[of course, it's not. what is more, it's certainly not.]

06 Á: =hogy esetleg ( I

that possibly

$=$ that possibly $($ [

$07 \mathrm{M}$ :
[szerintem semmi más csak] a pénz.
think.DEF.1SG nothing.NOM other.NOM only the money.NOM
[in my opinion, nothing else but] money.

08 Á: igen.

yes

yes.

09 Zs: csak a pénz. ja. (.) azt

only the money.NOM yeah that.ACC broadcast.DEF.3PL

only money. yeah. (.) they broadcast only the programs

10 le amit az emberek néznek.

PVB what.ACC the people.NOM watch.INDEF.3PL

that people will watch.'

Á: the media is not necessarily (.) guided by (.) only by goodwill. the intention of making a talented person of somebo[dy but IT'S USEFUL FOR IT (the media) THAT]= Zs: [it's not.]

$\mathrm{M}$

[of course, it's not. what is more, it's certainly not.]

Á: =that possibly (

])

M: [in my opinion, nothing else but] money.

Á: yeah.

Zs: only money. yes. (.) they broadcast only the programs that people will watch. 
When in line 01 Ági begins to give her opinion about what the aims of these programs can be, her turn-design projects that she is about to tell Marcsi and Zsuzsi what is not the leading ethical principle of the Hungarian media (a média nem föltétlenül (.) a the media is not necessarily (.) guided by'). After a short pause, however, she goes back to change the turn: the insertion of csak 'only' creates a concessive form; goodwill can be one of the leading principles (but not the only one) of the media (a média nem föltétlenül (.) a (.) csak a jóindulat v:ezérli 'the media is not necessarily (.) guided by (.) only by goodwill'). The repair operation in this way decreases the power of Ági's critical opinion and reduces her responsibility for it. The possibility that the self-repair also results from her unease about giving a critical opinion is supported by the two pauses in line 01, and by another interesting phenomenon. After the other co-participants agree with Ági, they form a much more radical opinion (the media is guided only by money), and in line 08 Ági joins them with a categorical 'yeah'. This suggests that her earlier, milder opinion (designed by the use of the insertion) may have been due to her unease about what she was about to say: she was somewhat loath to deliver her criticism before knowing the others' opinions on the topic. This means that similarly to the interactional function Lerner (2013) suggests for turn-constructional delaying practices, employing insertion during the delivery of criticism may also show that the speaker "is somewhat loath to say" something, in other words, this way of delivery "can be understood as a somewhat milder substitute for another, more accusatory formulation" (Lerner 2013: 104).

\subsection{Aborting}

In aborting, the speaker interrupts the ongoing turn-constructional unit and starts anew with another TCU (cf. Laakso-Sorjonen 2010: 1153). That is to say, the speaker starts the same action in a different form, with a different TCU. Schegloff (2013: 52) says that there are two possible orientations towards a TCU which is left uncompleted: the speaker may abandon what s/he has said altogether, or s/he may only abandon the way the project of the turn has been done so far, in favor of another way of doing the same undertaking. Laakso and Sorjonen (2010: 1157) note that while insertion and replacement preserve the syntactic shape of the utterance (e.g., the type of the clause), abandoning leaves the syntactic construction altogether uncompleted. The present thesis will regard only the second orientation described by Schegloff as the aborting repair operation, when the abandoning of the TCU is followed by a new effort to implement the same action. In Extract (48), Péter 
tries to explain how engines worked in old cars. In line 02 , he abandons his TCU-so-far (this is indicated by a cut-off on the article) to restructure his description in a simpler way.

(48) (bea002f002: 77)

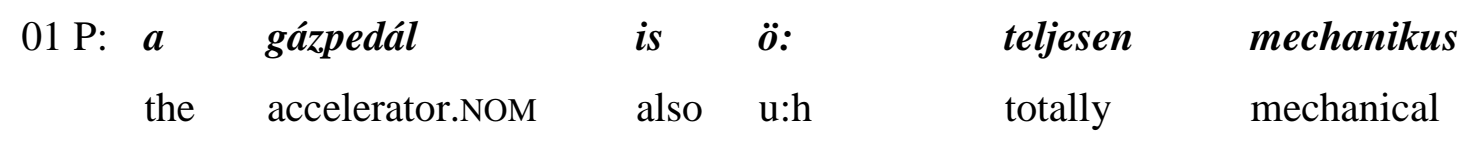

'the accelerator also $u: h$ in a totally mechanical

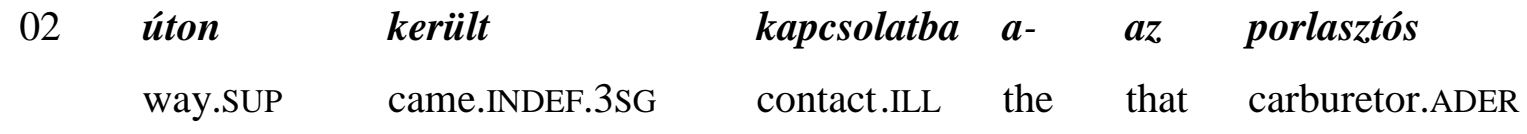

way came into contact with the- there was a carburetor

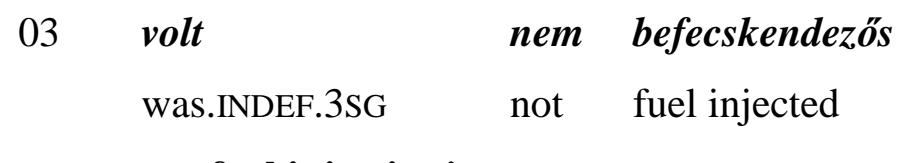

not fuel injection'

\section{P: the accelerator also $u: h$ in a totally mechanical way came into contact with the- there was a carburetor not fuel injection}

In Extract (48), the speaker aborts the ongoing TCU in order to restructure his utterance in a simpler way. Aborting can also be used as a device for downgrading the force of the action. In Extract (49), Ábel, Boglárka, and Linda are talking about the effects of marijuana. Since earlier in the conversation all of them say that they have not tried any kind of drugs, Ábel quotes his acquaintances' opinions; they have said that the effects of marijuana are similar to those of drinking alcohol. After a brief discussion, Linda also quotes her acquaintances' opinions (the extract starts here).

(49) (SZTEPSZI8: 1067)
$01 \mathrm{~L}$ : hát nekem akik
$\ddot{o} \quad$ ismeröseim
mondták
well I.DAT who.NOM.PL uh acquaintances.POSS.1SG.NOM told.DEF.3PL
'well my acquaintances who have told me 
02
ők
nem nem ezt
mondták
hanem
inkább
they.NOM not not this.ACC
told.DEF.3PL but
rather

they didn't didn't tell me that but rather

03
$a z t$
hogy- vagy
több (.)
olyat
hallottam
that.ACC
that or several
kind.ACC.SG heard.INDEF.1SG
that- or I have heard several (.) opinions like

04

$\begin{array}{llllll}\text { hogy } & \text { mondjuk } & \text { szar } & \text { volt } & \text { vagy } & \text { vagy } \\ \text { that } & \text { so to say } & \text { shit.NOM } & \text { was.INDEF.3SG } & \text { or } & \text { or }\end{array}$

so to say it felt like shit or or

05

rossz, volt

bad was.INDEF.3SG

it felt bad [after it]

06 Á:

07

$a z t$

that.ACC

mondják

say.DEF.3PL

shit.' [utána]

after.POSS.3SG

[hát az el]sőket mindig

well the first ones.ACC always

[well they say that the fir]st ones are always

hogy szar.

that shit.NOM

L: well my acquaintances who have told me they didn't didn't tell me that but rather that- or I have heard several (.) opinions like so to say it felt like shit or or it felt bad [after it]

Á: [well they say that the fir]st ones are always shit.

At first, Linda refers to all of her acquaintances who have told her of their experiences with using marijuana ( $o k$ 'they' in line 02 ), but in line 03 she initiates an aborting repair with a cut-off, and restricts the category of referents to 'several opinions': vagy több (.) olyat 
hallottam 'or I have heard several (.) opinions like'. In this way she downgrades the force of the opinion she invokes, namely, that after smoking a joint it feels worse than after drinking alcohol. This kind of repair makes it possible for the speaker to take responsibility only for the restricted category of referents: only for more than one opinion. In line 06, Ábel adds that the first ones (i.e., the first joints) are always said to be bad. It is interesting to observe that the words drug, marijuana, or joint are nowhere pronounced in the extract. This may be due to the fact that in Hungary all types of drugs are banned, which means that the speakers are talking about people who are their acquaintances and are involved in an illegal activity.

In Schegloff's (2013) example we can see the double abandoning of the TCU-inprogress, and two new efforts to carry out the same action. This English example thus contains two aborting repairs following one another (a1 and a2) (Example (50)).

(50) $(\mathrm{SN}-4,08)$

01 Shr: Who w's the girl that was outside

02 his door? the store?

$03 \quad(0.8)$

04 Mrk: Debbie.

$05 \quad(0.8)$

06 Shr: Who's Debbie.

07 Mrk: ${ }^{\circ}$ Katz.

$08 \quad(0.7)$

09 Mrk: ->a1 She's jus' that girl thet: uh:, (0.2)

$10 \quad->a 2$.hh I met her through uh:m::, (1.0)

11 I met 'er in Westwood.=I caught that - (.)

12 'Member I wenttuh see the premie:r of (0.3)

13 Lost Horizon? [( )

14 Shr: [I DID'N KNOW YOU did,=

(Schegloff 2013: 53)

When Sherrie cannot identify who Debbie is in line 06, instead of the recognitional reference form which is designed for someone who already knows about the person who is referred to (line 04) (Sacks-Schegloff 1979), Mark tries to refer to the woman in issue in a different form, with a different TCU (a1 in line 09). However, he changes his mind again, 
and launches another try in line 10 (a2). This time instead of a recognitional reference to the target person he describes how he has met her. Mark therefore produces three turnconstructional units implementing the same action (identifying a person): 1. Debbie (line 04), 2. She's jus' that girl thet: uh:, (0.2) (line 09), 3. .hh I met her through uh:m::, (1.0) I met 'er in Westwood (lines 10,11), and he employs two aborting repairs (a1 and a2).

To summarize: in this chapter, I have introduced the four repair operations which are in the focus of my research. This introduction of recycling, replacement, insertion, and aborting shows that relatively few of the previous conversation analytic studies have focused on repair operations in their own right, that is, explored some aspects of their interactional import or the techniques employed in accomplishing them. Even fewer have examined repair operations relative to each other. The studies by Fox et al. (2009) and Fox et al. (2010) are exceptional in this respect: they are the first investigations to compare two repair operations, namely, recycling and replacement with each other in various respects, and they are the only cross-linguistic studies to compare two repair operations with each other. Although both comparative studies show a preference for recycling over replacement in all the languages examined, neither of them offer an explanation for this observation. Fox et al. (2010: 2488) refer to it in the following way: "Although there are interesting differences in the frequency of each repair type across the languages, due to limitations of space a discussion of those differences will not be offered here." The findings of Fox et al. (2009) and Fox et al. (2010) prompt the following questions: Is there such a difference between the frequency of recycling and replacement in Hungarian? If yes, how could we explain this cross-linguistic phenomenon? In order to answer these questions, Chapter 6 presents the systematic analysis of the appearance of recycling and replacement in the Hungarian corpus, considering the factors Fox et al. (2009) and Fox et al. (2010) have examined, and then compares the results with their findings.

\section{Comparing recycling with replacement}

\subsection{Recycling and replacement in the languages examined so far}

Fox and her colleagues (2009) examine the site of repair initiation in the case of recycling and replacement repairs in seven languages: English, Bikol, Sochiapam Chinantec, Finnish, Indonesian, Japanese, and Mandarin. They involve the following factors in their investigation: site of initiation, word length, and syntactic class. After their cross-linguistic investigation, Fox et al. (2009: 80) argue that there is an underlying universal tendency in 
their seven languages to initiate recycling after and replacement before recognizable completion (the only exception is Japanese), but this pattern is sometimes masked by language-specific features. Taking into account word length and syntactic class, they find that in both recycling and replacement repairs monosyllabic words tend to be repaired after recognizable completion, and multisyllabic words tend to be repaired prior to recognizable completion (Fox et al. 2009: 99). In the case of bisyllabic words, speakers do not tend to show any preference for site of initiation (Fox et al. 2009: 100). In five of the seven languages investigated (English, Sochiapam Chinantec, Finnish, Indonesian, Mandarin), speakers range from moderately to much more likely to initiate repair in a function word than in a content word (Fox et al. 2009: 97). The study by Fox et al. (2010) focuses on whether there is a relationship between the typological characteristics of English, German, and Hebrew and the appearance of recycling and replacement repairs in these languages. They find an over-representation of content words in replacement repairs and function words in recycling repairs in each of the three languages. As far as the Hungarian language is concerned, considering the lexical categories which serve as destinations of recycling in Hungarian, both Lerch's (2007) conversation analytic and Gyarmathy's (2009) psycholinguistic studies observe that the speakers of their Hungarian corpora tend to recycle back to function words rather than content words.

Although neither Fox et al. (2009) nor Fox et al. (2010) explore the frequencies of recycling and replacement in their corpora, their collections of self-repair instances contain many more recycling than replacement repairs in all the examined languages in both studies (cf. Fox et al. 2009: 63; Fox et al. 2010: 2490) (Table 1).

\section{Table 1}

The number of recycling and replacement instances in the collections of Fox et al. (2009) and Fox et al. $(2010)^{30}$

\begin{tabular}{|c|c|c|}
\hline & Recycling repair & Replacement repair \\
\hline English & 111 & 36 \\
\hline Hebrew & 128 & 27 \\
\hline German & 98 & 44 \\
\hline Indonesian & 117 & 29 \\
\hline
\end{tabular}

\footnotetext{
${ }^{30}$ While the source of the English, Hebrew, and German results is Fox et al. 2010, the numbers of the repair operation instances in Indonesian, Sochiapam Chinantec, Japanese, Mandarin, Bikol, and Finnish come from the study by Fox et al. (2009).
} 


\begin{tabular}{|c|c|c|}
\hline Sochiapam Chinantec & 185 & 16 \\
\hline Japanese & 147 & 53 \\
\hline Mandarin & 115 & 35 \\
\hline Bikol & 162 & 23 \\
\hline Finnish & 116 & 46 \\
\hline
\end{tabular}

On the basis of the research of Fox et al. (2009) and Fox et al. (2010) involving a total of nine languages in their examinations, it can be suggested that recycling is a more frequent repair operation than replacement in all the examined languages. In the next section I attempt to find out whether there is such a difference between the frequency of recycling and replacement in Hungarian. Following the methodology of Fox et al. (2009) and Fox et al. (2010), I examine recycling and replacement in Hungarian conversations relative to each other, and compare my results with the previous findings concerning the other languages so far examined in this respect.

\subsection{Recycling and replacement in Hungarian}

\subsubsection{Recycling repair - syntactic category and word length in Hungarian}

The total number of self-repair instances examined in the first phase of the present research on Hungarian is 557, consisting of 415 recycling and 142 replacement repairs (Németh 2012: 2024). As far as the ratio of the number of recycling repairs to the number of replacement repairs is concerned, Hungarian shows the same pattern as the languages examined so far (see Table 1). Unlike the previous examinations, however, the present research takes into account all recycling and replacement self-repairs in the given corpus (see Chapter 4); therefore it can be regarded as a frequency analysis. In order to explain the difference between the frequencies of the two repair operations, in this section I explore recycling and replacement relative to each other, and compare my results with the previous findings concerning the other languages so far examined in this respect (see Section 6.1). Following the cross-linguistic examinations of Fox et al. (2009) and Fox et al. (2010), I explore the length and syntactic class of words in which the speakers of the Hungarian corpus tend to initiate recycling and replacement; i.e., I find out whether they tend to initiate recycling and replacement in monosyllabic, bisyllabic, or multisyllabic, and function or content words, respectively. Then I try to reveal whether the type of the repair operation, the length of the target word, and/or the syntactic class of the target word 
influence the site of repair initiation in recycling and replacement repairs in Hungarian conversations. In order to see the relationship between the variables listed above, I will use $2 \times 2$ and $2 \times 3$ Pearson's chi-square statistics, and calculate the Cramér's V measure of nominal association. Using these analyzing methods, I intend to test how likely it is that the observed distributions are due to chance (Pearson's chi-square), and how strong the relationship is between the variables (Cramér's contingency coefficient). The asterisk will indicate a significant chi-square value in each case. Where the result of the test is significant, I will check whether the different variables equally contribute to this result or the significance comes entirely from certain rows or columns. I will do this analysis by using chi-square goodness-of-fit tests. I will also check whether the frequencies of the word length and syntactic class categories observed in recycling and replacement repairs follow from their overall frequencies in the corpus. For this reason, I have coded the corpus not only for the syntactic category, length, and site of initiation of the words involved in recycling and replacement, but also for the syntactic category and length of all words in the corpus.

I first explore how word length and syntactic class influence the execution of recycling repair in the Hungarian corpus. Tables $2 \mathrm{a}$ and $2 \mathrm{~b}$ display the distribution of repair types (recycling and replacement) by syntactic class and word length in the corpus. We can see that the result of the chi-square test is significant in both cases, which means that there is a relationship both between the type of the repair operation and the syntactic class of the target word, and between the type of the repair operation and the length of the target word.

\section{Table 2a}

Observed frequencies of recycling and replacement repairs by syntactic class

\begin{tabular}{|l|l|l|l|}
\hline & Destination of recycling & Replaced item & Total \\
\hline Function words & $315(76 \%)$ & $48(34 \%)$ & 363 \\
\hline Content words & $100(24 \%)$ & $94(66 \%)$ & 194 \\
\hline Total & 415 & 142 & 557 \\
\hline
\end{tabular}

$\chi^{2}(1)=82.61 *, \mathrm{p}<.01 ;$ Cramér's $\mathrm{V}=.385^{*}$ (very strong association between the two variables), $\mathrm{p}<.01$ 


\section{Bar Chart}

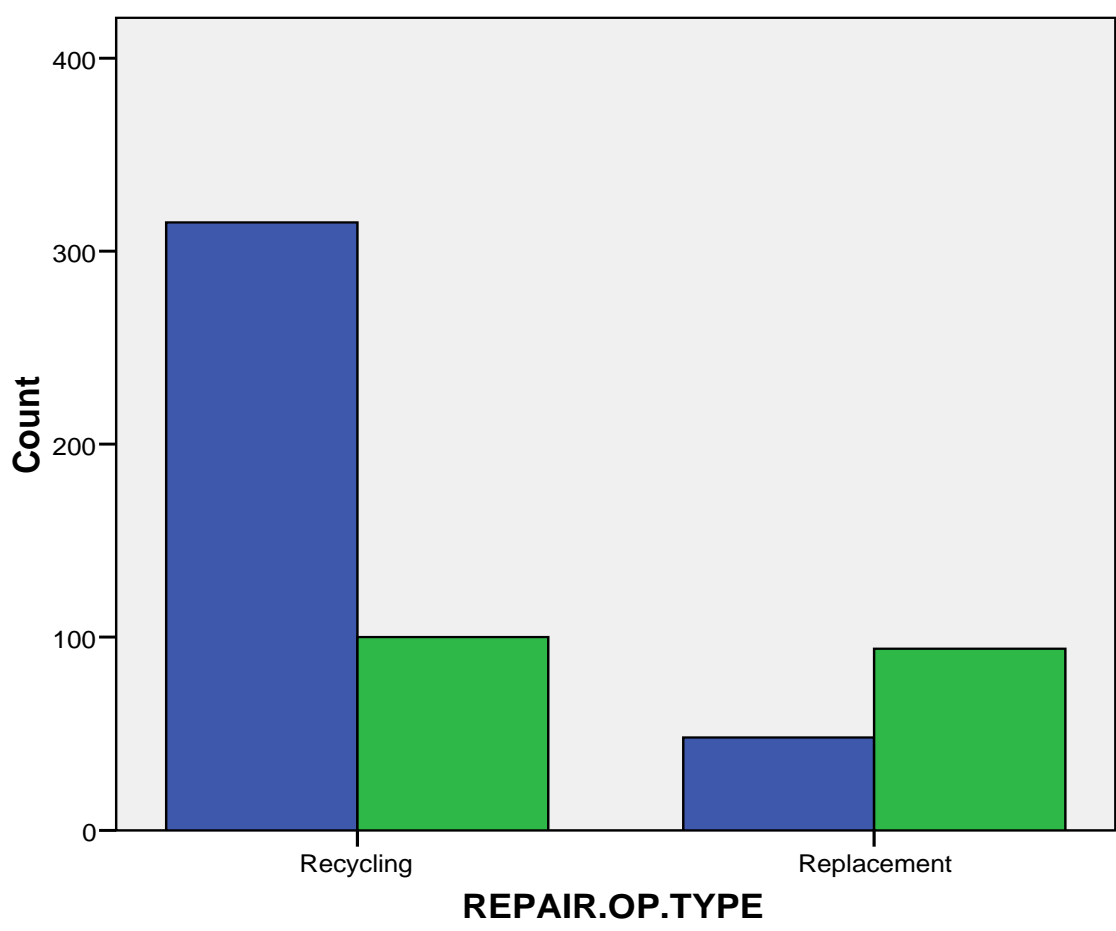

Table 2b

Observed frequencies of recycling and replacement repairs by word length

\begin{tabular}{|l|l|l|l|}
\hline & Destination of recycling & Replaced item & Total \\
\hline Monosyllabic words & $304(73 \%)$ & $50(35 \%)$ & 354 \\
\hline Bisyllabic words & $75(18 \%)$ & $32(23 \%)$ & 107 \\
\hline Multisyllabic words & $36(9 \%)$ & $60(42 \%)$ & 96 \\
\hline Total & 415 & 142 & 557 \\
\hline
\end{tabular}

Monosyllabic/Bisyllabic/Multisyllabic: $\chi^{2}(2)=94.40^{*}, \mathrm{p}<.01$ 


\section{Bar Chart}

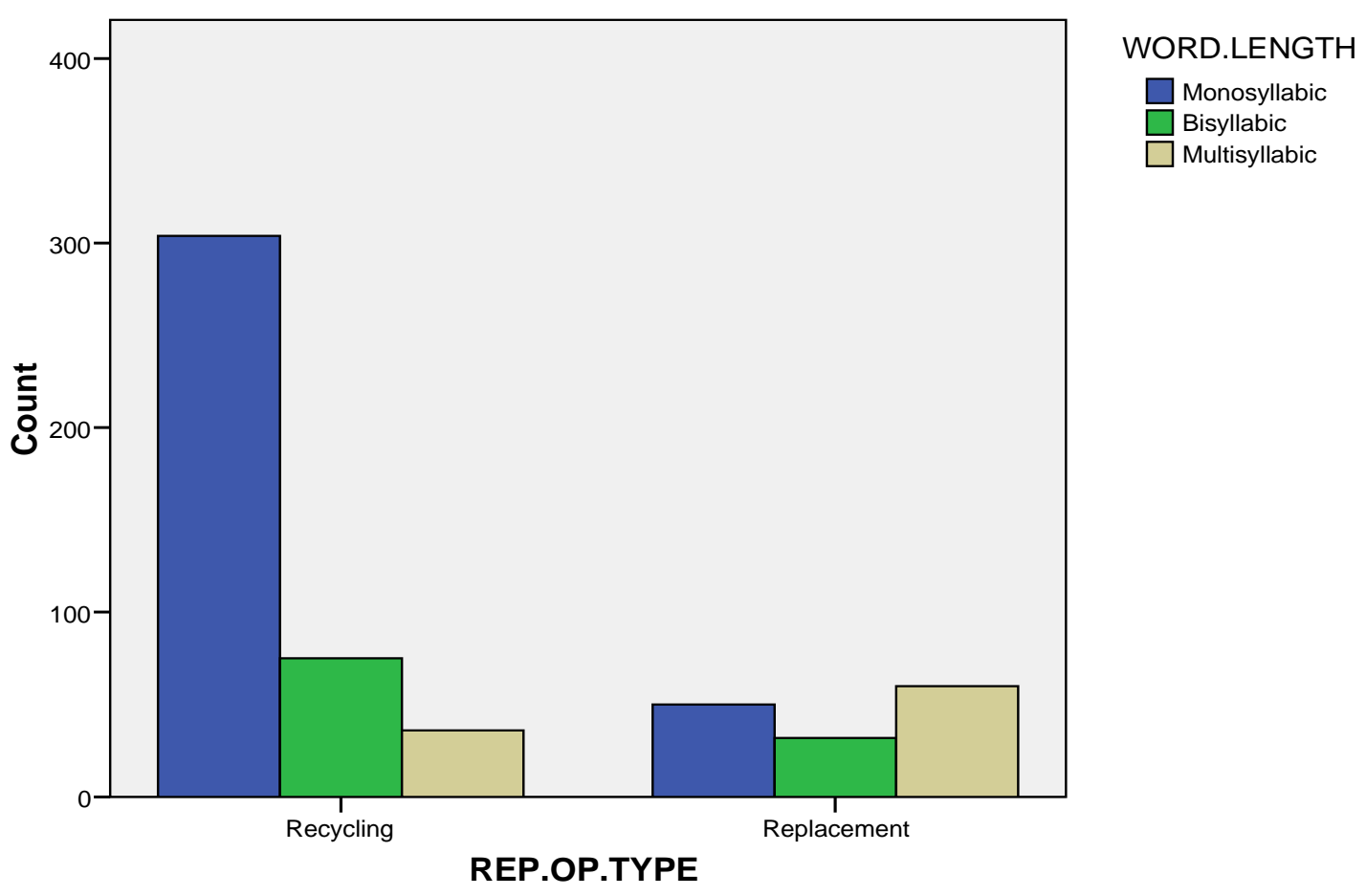

Let us see recycling and replacement separately. Tables $2 \mathrm{a}$ and $2 \mathrm{~b}$ show that the speakers of the Hungarian corpus recycle back most frequently to function words (cf. Lerch 2007; Gyarmathy 2009) and monosyllabic words (see Extracts (33)-(36) in Section 5.2). First, let us consider syntactic categories. The result of the chi-square goodness-of-fit test for the distribution of recycling instances with respect to syntactic class is significant: $\chi^{2}(1)=111.38^{*}, \mathrm{p}<.01$. This means that the distribution of this repair type across syntactic class is not random. Although function words make up $76 \%$ of all destinations of recycling compared with $24 \%$ for content words, in order to be sure that this difference does not derive from the relative frequencies of the two syntactic categories in the corpus, we have to consider our result in relation to the whole corpus. Table 3 provides the figures for the syntactic class and word length of all words in the corpus. 
Table 3

Observed frequencies of words by word length and syntactic class in the corpus

\begin{tabular}{|l|l|l|l|}
\hline & Function words & Content words & Total \\
\hline Monosyllabic words & 7,377 & 2,884 & $10,261(46 \%)$ \\
\hline Bisyllabic words & 1,995 & 4,815 & $6,810(31 \%)$ \\
\hline Multisyllabic words & 209 & 4,899 & $5,108(23 \%)$ \\
\hline Total & $9,581(43 \%)$ & $12,598(57 \%)$ & 22,179 \\
\hline
\end{tabular}

The corpus contains 9,581 function words (43\%) and 12,598 content words (57\%). In Table $2 \mathrm{a}$ we have seen that in recycling repairs the function-content word ratio is $76 \%-$ $24 \%$. Since in the whole corpus there are more content words than function words, the frequency of function words in recycling repairs cannot follow from their frequency in the corpus. If we turn to word length, Table $2 b$ shows that the most common destinations of recycling repairs in the Hungarian corpus are monosyllabic words. Monosyllabic words make up $73 \%$ of all destinations of recycling compared with $18 \%$ to bisyllabic and $9 \%$ to multisyllabic words. The result of the chi-square goodness-of-fit test for the distribution of recycling instances with respect to word length is significant, i.e., the distribution is not random: monosyllabic/bisyllabic/multisyllabic: $\chi^{2}(2)=303.09^{*}, \mathrm{p}<.01$. Again, to be sure that this difference does not come from the relative frequencies of the three word length categories in the corpus, we have to consider this result in relation to the whole corpus (Table 3). While $46 \%$ of the words are monosyllabic, $31 \%$ are bisyllabic, and $23 \%$ are multisyllabic in the corpus. This ratio does not justify such a high frequency of monosyllabic words in recycling repairs $(73 \%$ of all destinations of recycling are monosyllabic). Therefore, the frequency of monosyllabic words in recycling repairs does not follow from their frequency in the corpus either. In other words, the speakers of the corpus recycle back most frequently to monosyllabic function words. Here we can ask whether the speakers make this frequent use of monosyllabic function words because most of the function words are monosyllabic or because most of the monosyllabic words are function words in the corpus? To see this clearly, we have to compare the occurrence of monosyllabic and function words in the whole corpus. According to Table 3, 77\% of the function words are monosyllabic (9,581 function words; 7,377 monosyllabic function words) and $72 \%$ of the monosyllabic words are function words in the corpus $(10,261$ monosyllabic words; 7,377 monosyllabic function words). This suggests that the reason of the high frequency of monosyllabic function words in recycling repairs is that most of the function words are monosyllabic, rather than our other observation, namely, that most of 
the monosyllabic words are function words in the corpus. Thus, as Jurafsky et al. (1998) observed in the case of English, high-frequency function words are often phonologically reduced in Hungarian as well, and this can explain the high frequency of monosyllabic function words as the destinations of recycling in the corpus. In other words, when the speakers of the Hungarian corpus recycle back to monosyllabic function words, syntactic class plays a more important role than word length.

Let us examine word length categories separately. Tables $4 \mathrm{a}-\mathrm{c}$ below display the three word length categories with the corresponding figures from the whole corpus.

\section{Table 4a}

Observed frequencies of monosyllabic words in recycling repairs and the corpus

\begin{tabular}{|l|l|l|}
\hline & Destination of recycling & Whole corpus \\
\hline Function words & $265(87 \%)$ & $7,377(72 \%)$ \\
\hline Content words & $39(13 \%)$ & $2,884(28 \%)$ \\
\hline
\end{tabular}

Table 4b

Observed frequencies of bisyllabic words in recycling repairs and the corpus

\begin{tabular}{|l|l|l|}
\hline & Destination of recycling & Whole corpus \\
\hline Function words & $47(63 \%)$ & $1,995(29 \%)$ \\
\hline Content words & $28(37 \%)$ & $4,815(71 \%)$ \\
\hline
\end{tabular}

Table 4c

Observed frequencies of multisyllabic words in recycling repairs and the corpus

\begin{tabular}{|l|c|c|}
\hline & Destination of recycling & Whole corpus \\
\hline Function words & $3(8 \%)$ & $209(4 \%)$ \\
\hline Content words & $33(92 \%)$ & $4,899(96 \%)$ \\
\hline
\end{tabular}

Table $4 \mathrm{a}$ shows that taking into consideration the whole corpus, the frequency of monosyllabic function words is much higher than the frequency of monosyllabic content words (72\%-28\%). However, in recycling repairs we find an even bigger difference between the two syntactic class categories (87\%-13\%), which means the privileged status of function words among monosyllabic words serving as destinations for recycling repairs. The group of bisyllabic words is the only word length category where the figures for 
recycling repairs are in inverse proportion to the same figures for the whole corpus (Table 4b). Although there are more bisyllabic content words than bisyllabic function words in the corpus (71\%-29\%), in recycling repairs we can find more bisyllabic function words than bisyllabic content words (63\%-37\%). As far as multisyllabic words are concerned, in the whole corpus there are many more multisyllabic content words than multisyllabic function words (96\%-4\%). Although in recycling repairs there are still many more multisyllabic content words than multisyllabic function words (92\%-8\%), this difference is not so sharp than in the whole corpus, which together with the other word length category results supports the privileged status of function words in recycling repair in the Hungarian corpus.

These results are in accordance with Lerch's (2007) and Gyarmathy's (2009) previous findings concerning Hungarian, and the results of Fox et al. (2010) concerning Hebrew, English, and German. Fox and her colleagues point out that all three languages they examine have function words which precede the content words they serve as adjuncts to (e.g., prepositions or determiners), and in all three languages there is a tendency to recycle back to function words rather than content words. On the basis of these observations, they predict that languages with function words preceding their respective content words (which they think are mainly verb-initial and verb-medial languages) will show a preference for recycling back to function words rather than content words (Fox et al. 2010: 2504). This is also supported by earlier studies (Fox et al. 1996; Rieger 2003; Lerch 2007; Gyarmathy 2009; Fox et al. 2009), among which Fox et al. (1996: 205) note that in the languages where speakers have no function words preceding nouns (e.g., the postpositional Japanese), speakers do not use this strategy. Fox and her colleagues (2010) also suggest that function words may be recycled to delay the next content word due, and therefore are likely to be used as the destinations of recycling (Fox et al. 2010: 2503). Fox et al. (2009: 97) also claim that the recycling of function words is an extremely useful device for the speaker to delay the next content word due. Lerch (2007) considers the lexical categories serving as destinations for recycling in Hungarian. She observes that the speakers of her Hungarian corpus tend to recycle back to function words, and they employ recycling to delay the next lexical element due (Lerch 2007: 127). Since the phrasebeginning elements tend to be function words in Hungarian, there are several function words preceding content words in the language. While definite and indefinite articles or demonstrative determiners project an upcoming noun phrase, conjunctions and relative 
pronouns occur at the beginning of clauses (Lerch 2007: 127) (see the recycling in Extract (33) repeated here as Extract (51)).

(51) (bea007f005: 430)

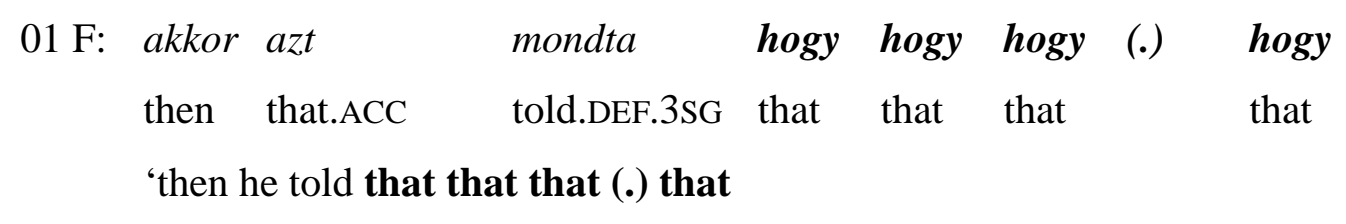

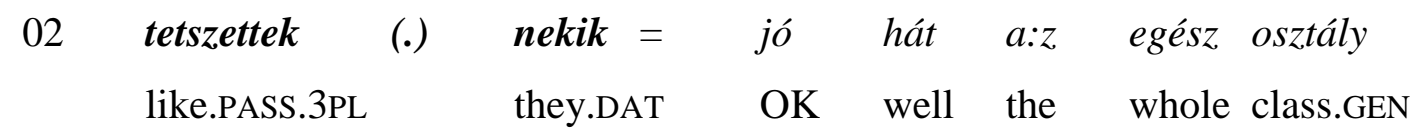

they liked (.) them (the lessons)=well it's OK he spoke'

The present examination thus also supports the prediction of Fox et al. (2010: 2504): my results show that the speakers of my Hungarian corpus tend to recycle back to function words. All these findings illuminate how the methods of repair are shaped by the linguistic resources of the language in question, and therefore draw our attention to the close relationship between grammar and repair.

All the explanations listed above for the over-representation of function words in recycling repair imply that in conversations, speakers may find it necessary to delay content words rather than function words. What can be the motive for this? Fox et al. (2009: 103) remark that content words are open class, hence there are a larger number of potential candidates among them in any given context than there are for function words. They also note that the particular content words are usually of lower frequency than are the particular function words, and the interactants face a greater challenge in selecting the appropriate word (Fox et al. 2009: 103). This claim can serve as a potential answer to our question: speakers may find it necessary to delay content words because they face a greater challenge in selecting the appropriate content word as opposed to the selection of appropriate function words. Selecting content words can thus demand more time than selecting function words. Furthermore, in the cases when recycling is used at the emergence of overlapping talk, and it serves as a device for delaying the talk that follows in order to get it said in the clear, it can be assumed that speakers tend to avoid the possible compromised hearing of content words rather than of function words (see Extract (32) in Section 5.2). Finally, the interactional function Lerner (2013: 105) suggests for turnconstructional delaying strategies, namely, the function of delaying a projectably delicate 
term, also supports the idea that speakers tend to delay content words rather than function words: it can be assumed that a projectably delicate term is a content word rather than a function word (see Section 5.2).

In this section I have found that the speakers of the Hungarian corpus tend to recycle back to monosyllabic function words, and in the recycling repairs of the corpus syntactic class plays a more important role than word length. In the next section, I examine replacement repair in the Hungarian corpus regarding the same features.

\subsubsection{Replacement repair - syntactic category and word length in Hungarian}

If we look at Table 2a again (repeated below as Table 5 for the sake of convenience), we can realize that the speakers of the Hungarian corpus employ content words in replacement repairs nearly twice as frequently as function words $(66 \%-34 \%)$. The result of the chisquare goodness-of-fit test for the distribution of replacement instances with respect to syntactic class is significant: $\chi^{2}(1)=14.90^{*}, \mathrm{p}<.01$ (the distribution is not random). Let us consider this ratio in relation to the whole corpus again (see Table 3, repeated below as Table 6). We can see that the corpus contains 12,598 content words (57\%) and 9,581 function words $(43 \%)$. Table 5 shows that in replacement repairs the content-function word ratio is $66 \%-34 \%$. This difference is bigger than the content-function word ratio in the whole corpus, which suggests that content words have a privileged status in replacement repairs (see the replacement in Extract (26) repeated here as Extract (52)).

Table 5

Observed frequencies of repair types by syntactic class

\begin{tabular}{|l|l|l|l|}
\hline & Destination of recycling & Replaced item & Total \\
\hline Function words & $315(76 \%)$ & $48(34 \%)$ & 363 \\
\hline Content words & $100(24 \%)$ & $94(66 \%)$ & 194 \\
\hline Total & 415 & 142 & 557 \\
\hline
\end{tabular}

$\chi^{2}(1)=82.61^{*}, \mathrm{p}<.01$; Cramér's $\mathrm{V}=.385^{*}$ (very strong association between the two variables), $\mathrm{p}<.01$ 
Table 6

Observed frequencies of words by word length and syntactic class in the corpus

\begin{tabular}{|l|l|l|l|}
\hline & Function words & Content words & Total \\
\hline Monosyllabic words & 7,377 & 2,884 & $10,261(46 \%)$ \\
\hline Bisyllabic words & 1,995 & 4,815 & $6,810(31 \%)$ \\
\hline Multisyllabic words & 209 & 4,899 & $5,108(23 \%)$ \\
\hline Total & $9,581(43 \%)$ & $12,598(57 \%)$ & 22,179 \\
\hline
\end{tabular}

(52) (SZTEPSZI2: 953)

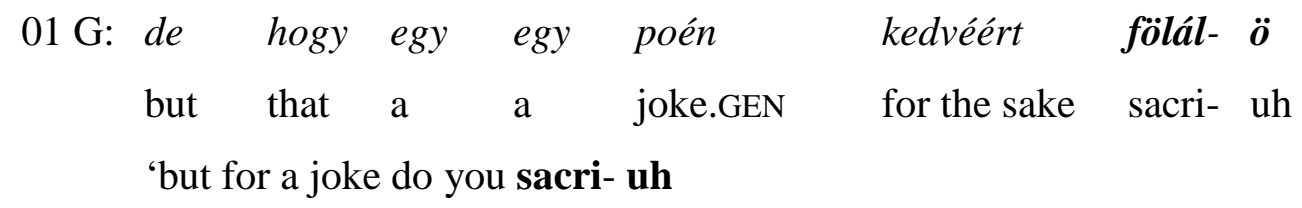

$\begin{array}{lll}02 & \text { kockára } & \text { egyébként } a: ? \\ & \text { risk.DEF.2SG by the way the }\end{array}$

risk, by the way, your (place at the university)?'

These results support the findings of the previous research on replacement in the conversation analytic literature. As was noted earlier, Fox et al. (2010: 2487) emphasize that the speakers of all their three languages replace content words at a disproportionately high rate. As a possible explanation, they note that content words may need to be replaced because they are inapposite (Fox et al. 2010: 2503). Focusing on English, Fox et al. (2009: 76) also suggest that English speakers may employ replacement "in cases where an inappropriate word or pronunciation has been produced". Why are content words more likely to be inapposite or inappropriate than function words? Here we can use exactly the same arguments as we have used when explaining the necessity of delaying content words in the previous section: on the one hand, content words are open class, hence the number of potential candidates among them is higher in any given context than the number of candidates among function words (Fox et al. 2009: 103). On the other hand, the content words in question are usually of lower frequency than the function words, which means that the speaker faces a greater challenge when trying to select the appropriate term (Fox et al. 2009: 103). If the selection of the appropriate content word represents a greater challenge for the speaker than the selection of the appropriate function word, we can assume that during the production of content words, the speakers are also more likely to 
face a problem leading to a need for replacement than during the production of function words.

Taking into account the length of the words in which the speakers of the Hungarian corpus initiate replacement, as Table $2 \mathrm{~b}$ (repeated here as Table 7) shows, the most common destinations of replacement repairs in the Hungarian corpus are multisyllabic words (42\%). However, the observed frequencies are not as unbalanced as they were in the case of recycling repairs.

\section{Table 7}

Observed frequencies of repair types by word length

\begin{tabular}{|l|l|l|l|}
\hline & Destination of recycling & Replaced item $^{31}$ & Total \\
\hline Monosyllabic words & $304(73 \%)$ & $50(35 \%)$ & 354 \\
\hline Bisyllabic words & $75(18 \%)$ & $32(23 \%)$ & 107 \\
\hline Multisyllabic words & $36(9 \%)$ & $60(42 \%)$ & 96 \\
\hline Total & 415 & 142 & 557 \\
\hline
\end{tabular}

Monosyllabic/Bisyllabic/Multisyllabic: $\chi^{2}(2)=94.40^{*}, \mathrm{p}<.01$

The chi-square goodness-of-fit test for the distribution of replacement instances with respect to word length is significant (monosyllabic/bisyllabic/multisyllabic: $\chi^{2}(2)=8.50^{*}$, $\mathrm{p}<.05)$. As the second column of Table 7 shows, although the most common replaced items are multisyllabic words, monosyllabic words are also replaced at a relatively high rate by the speakers of the corpus. To find a possible explanation for this, let us include syntactic class in our examination.

\footnotetext{
${ }^{31}$ According to Table 6 and Table 7, the frequencies of the three word length categories in replacement repair are different from their frequencies in the whole corpus, which suggests that their frequencies in replacement repair do not follow from their frequencies in the corpus.
} 


\section{Table 8a}

Observed frequencies of monosyllabic words in replacement repairs and the corpus

\begin{tabular}{|l|l|l|}
\hline & Replacement repairs & Whole corpus \\
\hline Function words & $37(74 \%)$ & $7,377(72 \%)$ \\
\hline Content words & $13(26 \%)$ & $2,884(28 \%)$ \\
\hline
\end{tabular}

Table 8b

Observed frequencies of bisyllabic words in replacement repairs and the corpus

\begin{tabular}{|l|l|l|}
\hline & Replacement repairs & Whole corpus \\
\hline Function words & $9(28 \%)$ & $1,995(29 \%)$ \\
\hline Content words & $23(72 \%)$ & $4,815(71 \%)$ \\
\hline
\end{tabular}

Table 8c

Observed frequencies of multisyllabic words in replacement repairs and the corpus

\begin{tabular}{|l|l|l|}
\hline & Replacement repairs & Whole corpus \\
\hline Function words & $2(3 \%)$ & $209(4 \%)$ \\
\hline Content words & $58(97 \%)$ & $4,899(96 \%)$ \\
\hline
\end{tabular}

Although the speakers of the Hungarian corpus replace content words at a higher rate than function words, this difference does not appear in the case of monosyllabic words (Table 8a). This result may follow from the over-representation of function words among monosyllabic words (the function-content word ratio is $72 \%-28 \%$ in monosyllabic words), and the usage of the Hungarian definite article also contributes to it. That is to say, the Hungarian definite article has two alternants. $A$ is used before words beginning with consonants and $a z$ before vowels. The article is used in order to delay its respective noun phrase in 51 cases in the corpus. In 36 cases the article is recycled. However, since the speaker may employ the delay strategy because s/he does not know yet which noun to select (i.e., whether it will start with a consonant or a vowel), it can happen that s/he has to substitute $a$ with $a z$. The replacement of $a$ with $a z$ occurs 15 times in the corpus (this means $40 \%$ of the monosyllabic function word replacements) (see Extract (53)). 
(53) (SZTEPSZI3: 853)

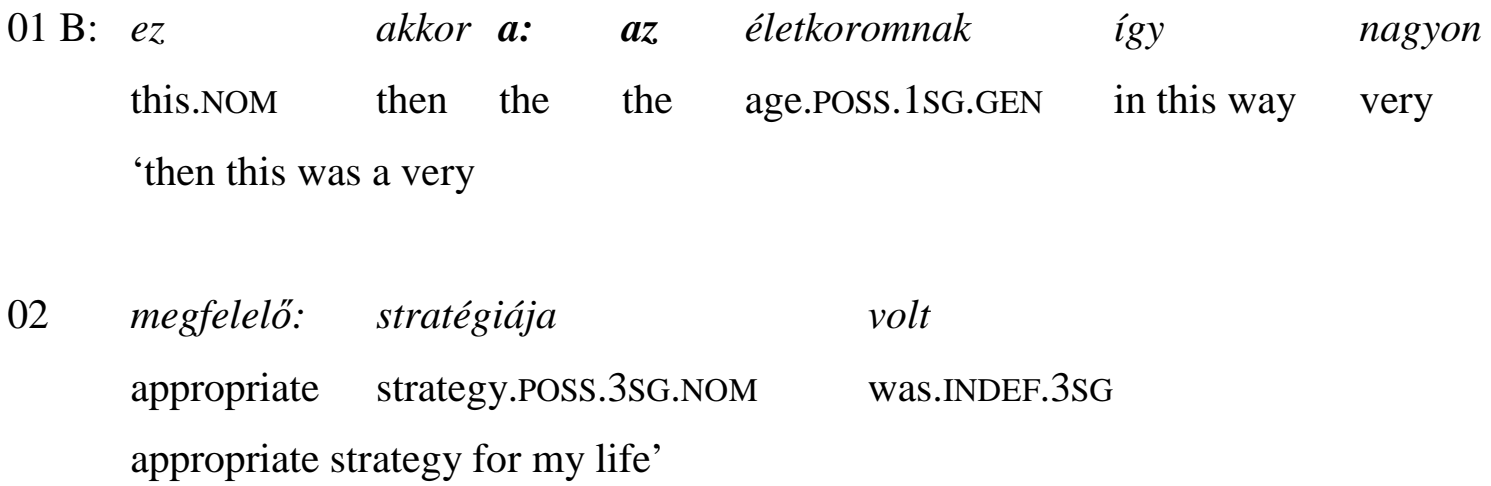

Table 8c shows that multisyllabic content words are the most frequently replaced words in the corpus. Here comes the question again: when the speakers of the Hungarian corpus replace multisyllabic content words, word length or syntactic class plays the key role? If we compare the occurrence of multisyllabic and content words in the whole corpus, we can see that $39 \%$ of the content words are multisyllabic (12,598 content words; 4,899 multisyllabic content words) and $96 \%$ of the multisyllabic words are content words in the corpus (5,108 multisyllabic words; 4,899 multisyllabic content words) (Table 6). This suggests that the reason of the high frequency of multisyllabic content words in replacement repairs is that most of the multisyllabic words are content words in the Hungarian corpus. Thus, when the speakers of the Hungarian corpus replace multisyllabic content words, word length plays a more important role than syntactic class (see Extract (52)).

Taking into account the difference between bi- and multisyllabic words, we find that the two word length categories differ from monosyllabic words in that there are more content words than function words replaced in both categories (Tables 8b, 8c). While the bisyllabic function-content word ratio is $28 \%-72 \%$ in replacement repairs, the same ratio is $3 \%-97 \%$ in multisyllabic words. This means that the speakers of the Hungarian corpus replace multisyllabic content words at a higher rate than bisyllabic content words. This difference between bisyllabic and multisyllabic content words in replacement repairs could only be explained with the frequency of content words in the repair type if there were more content words among multisyllabic words than among bisyllabic words in the corpus. However, according to Tables $8 \mathrm{~b}$ and $8 \mathrm{c}$, there are 4,815 bisyllabic content words and 4,899 multisyllabic content words in the corpus. The numbers are nearly the same, which means that the different representations of bisyllabic and multisyllabic words in 
replacement repair cannot be explained by anything else but the fact that multisyllabic words are longer than bisyllabic ones.

All these observations suggest that longer words are more likely to be used in replacement repair than shorter ones in the Hungarian corpus. What can be the reason for this? If we concentrate on the second half of the observation by Fox et al. (2009: 76), namely, that English speakers may employ replacement in cases where they have produced "an inappropriate word or pronunciation", it can be assumed that in the case of longer words inappropriate pronunciation is more likely to occur than in the case of shorter words. Our finding that in the replacement of multisyllabic content words word length plays a more important role than syntactic class may be due to the rich system of inflectional and derivational morphology in the language (see Section 6.2.1; cf. Lerch 2007: 127).

In this section I have found that the speakers of the Hungarian corpus tend to employ replacement repair in multisyllabic content words, and in the replacement repairs of the corpus word length plays a more important role than syntactic class. Following the cross-linguistic examination of Fox et al. (2009) on recycling and replacement, in the next section I try to reveal whether the type of the repair operation, the length of the target word, and/or the syntactic class of the target word influence the site of repair initiation, i.e. the location in the target word where speakers initiate repair in the Hungarian corpus.

\subsubsection{Repair type, word length, syntactic class, and the site of repair initiation in Hungarian}

\subsubsection{Repair type and site of initiation}

As for repair types and site of initiation in the Hungarian corpus, in Table 9 we can see that while $61 \%$ of all replacement repairs are initiated before the word is recognizably complete, with recycling repairs this only occurs in $17 \%$ of cases. Conversely, $83 \%$ of all simple recycling repairs are initiated after recognizable completion, but with replacements the figure is only $39 \%$. The result of the chi-square test is significant, which means that there is a relationship between the variables. The value of Cramér's V also shows a strong association between site of initiation and repair type in the Hungarian corpus. The results of the chi-square goodness-of-fit tests for the distribution of repair types with respect to repair initiation are also significant, in other words, neither the distribution of recycling nor the distribution of replacement repairs are random across repair initiation type (recycling: $\chi^{2}(1)=184.88^{*}, \mathrm{p}<.01$; replacement: $\left.\chi^{2}(1)=6.33^{*}, \mathrm{p}<.05\right)$. 


\section{Table 9}

Recognizable completion and repair operation types in the Hungarian corpus

\begin{tabular}{|l|c|l|l|}
\hline & Not recognizably complete & Recognizably complete & Total \\
\hline Recycling & $69(17 \%)$ & $346(83 \%)$ & 415 \\
\hline Replacement & $86(61 \%)$ & $56(39 \%)$ & 142 \\
\hline Total & $155(28 \%)$ & $402(72 \%)$ & 557 \\
\hline
\end{tabular}

$\chi^{2}(1)=101.69^{*}, \mathrm{p}<.01 ;$ Cramér's $\mathrm{V}=.427^{*}$ (very strong association between the two variables), $\mathrm{p}<.01$

\section{Bar Chart}

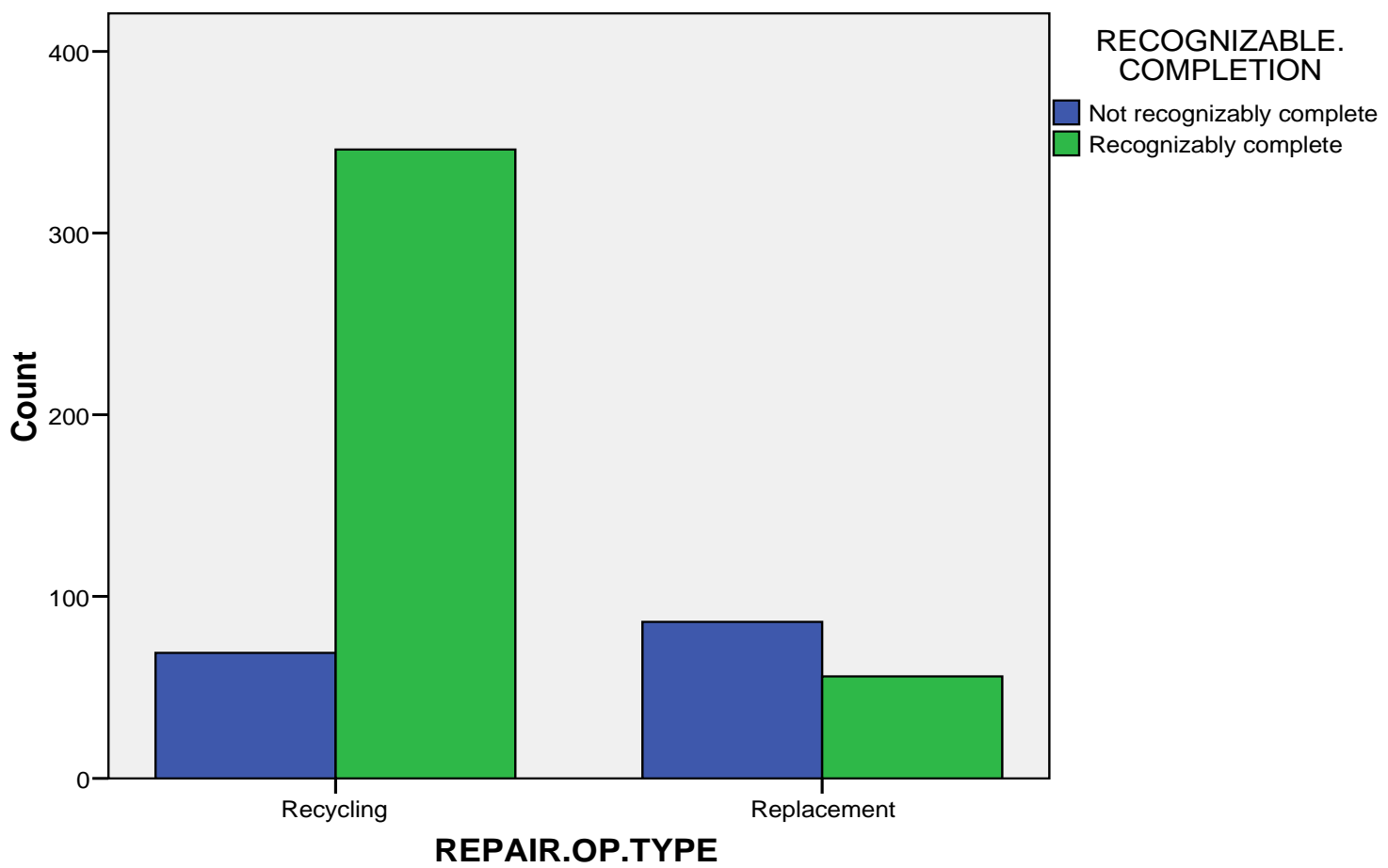

These results also support the cross-linguistic findings presented by Fox et al. (2009). Based on Jasperson's (1998) notions, Fox and her colleagues (2009: 74) suggest that repair initiation before recognizable completion is associated with repairs that change the preceding talk, i.e., have a retrospective orientation. The cross-linguistic results are in accordance with this prediction: replacement changes the preceding talk, i.e., has a retrospective orientation, and there is an underlying universal tendency in the languages examined to initiate replacement prior to recognizable completion. Fox et al. (2009: 80) propose that by using this strategy speakers may reduce accountability for inappropriate words. However, if we take into consideration the interactional aims described in the 
literature in connection with replacement repair, we can appreciate that although the repair type always has a retrospective orientation, not all of its interactional functions support initiation before recognizable completion. While repair initiation in replacement can usually be associated with the speaker's accountability for the repairable, this accountability does not imply that the speaker is unwilling to take responsibility. It can happen that the speaker wants to take responsibility for the replaced item (Fox et al. 2009: 102). This case supports initiation after recognizable completion. It can also happen that although the speaker wants to make the replaced segment recognizable, s/he still does not want to take responsibility for its production. This is Jefferson's interactional situation described in Section 5.1. Jefferson (1974: 193) suggests that replacing a word with another, if the replaced segment is not recognizably complete but still recognizable, allows the speaker to produce an inappropriate word without being interactionally accountable for it. This case also supports initiation before recognizable completion in replacement repairs. The Hungarian results fit the pattern Fox et al. (2009) propose: replacement tends to be initiated before recognizable completion.

Continuing their train of thought, Fox et al. (2009: 74) argue that repair initiation after recognizable completion is associated with repairs that operate on the talk that follows, e.g., by delaying the next item due. Here, let us recall our argumentation for the repair operation status of recycling when it is employed solely to delay the talk that follows (see Section 5.2). If the speaker employs recycling as a device for delaying the next item due, and s/he does this in order to attend to possible trouble in speaking, hearing, or understanding the talk or merely to alter the turn in some interactionally consequential way, then we should interpret recycling as a repair operation. Nevertheless, as was noted in the argumentation at issue, when we analyze the particular occurrences of recycling in conversations, sometimes it can be difficult to identify their delaying function. In these cases, the analysis of other features of the phenomenon may help us to decide whether we face a delaying function or not. For example, if we take into consideration the site of repair initiation in these occurrences of recycling, repair initiation carried out after the word is recognizably complete supports a potential delaying function. According to the proposal of Fox et al. (2009: 80), the reason for the tendency to late repair initiation in the case of recycling is that it is frequently used to delay the next content word due. The Hungarian examination supports this statement: the observation that recycling tends to be initiated after recognizable completion may indicate that it is frequently employed to delay the next content word due in Hungarian conversations. 
All in all, we can see that Hungarian fits the patterns suggested as universal: while recycling tends to be initiated after recognizable completion, replacement is generally initiated before the word is recognizably complete. However, the cross-linguistic investigation by Fox et al. (2009) shows that the patterns regarded as universal are often masked by language-specific features. Thus, it is plausible that there is a tendency to initiate recycling after, and replacement before recognizable completion, but this pattern can be manifested in various ways in different languages. In Japanese, speakers tend towards initiation before the word is recognizably complete in both repair operation types. In Mandarin and Sochiapam Chinantec, speakers favor initiation after recognizable completion for both types of repairs. In Bikol, speakers do not prefer either type of initiation. In English and Indonesian, the universal pattern assumed by Fox et al. (2009) appears to be uncovered: recycling tends to be initiated after the word is recognizably complete, and replacement is mainly initiated before recognizable completion. Finally, Finnish speakers favor initiation before recognizable completion for replacement repairs, and do not show any preference as to the site of repair initiation in recycling repairs (Fox et al. 2009: 79-80). One possible explanation for this diversity is the role of other factors beyond the functions of repair operation types, such as word length and syntactic class.

\subsubsection{Word length, syntactic class, and the site of repair initiation}

Taking into account word length and syntactic class, Fox et al. (2009: 99) find that both recycling and replacement tend to be initiated after recognizable completion in monosyllabic and prior to recognizable completion in multisyllabic words. In the case of bisyllabic words speakers do not show any preference for a single site of initiation. The consequence of this is the following: in languages in which speakers tend to initiate repair in monosyllabic words (e.g., Sochiapam Chinantec, Mandarin, and English), they usually initiate repair after recognizable completion, while in languages in which speakers initiate repair mainly in multisyllabic words (e.g., Japanese), they prefer initiation prior to recognizable completion. However, in languages where speakers do not show any preference as to the length of the words they initiate repair in, they will not show any preference for a single site of initiation either (Fox et al. 2009: 100).

Let us see whether the syntactic class and/or the length of the target word influence the site of repair initiation in Hungarian conversations. So far we have seen that the speakers of the Hungarian corpus tend to use mainly monosyllabic function words as the 
destinations of recycling (see Extracts (33)-(36) in Section 5.2), while they prefer multisyllabic content words in replacement repairs (see Extract (52)). If we consider the suggestion of Fox et al. (2009) explicated above, namely, that the functions of repair operations have a pronounced effect on the site of initiation, we have to assume that in content and multisyllabic words speakers will tend to initiate repair before the word is recognizably complete, and they will tend to initiate repair after recognizable completion in function and monosyllabic words. The results of the statistical analyses carried out on the figures of Table 10 and Table 11 meet our expectations. The results of the chi-square tests show an association both between site of initiation and syntactic class (Table 10), and between site of initiation and word length in the Hungarian corpus (Table 11). The results of the chi-square goodness-of-fit tests for the distribution of the certain syntactic class and word length categories with respect to repair initiation are the following: function words: $\chi^{2}(1)=252.91^{*}, \mathrm{p}<.01$; content words: $\chi^{2}(1)=16.16^{*}, \mathrm{p}<.01$; monosyllabic words: $\chi^{2}(1)=$ $264.50^{*}, \mathrm{p}<.01$; bisyllabic words: $\chi^{2}(1)=.75, \mathrm{p}>.05$; multisyllabic words: $\chi^{2}(1)=48.16^{*}$, $\mathrm{p}<.01$. The only word length category where the result of the test is not significant is the category of bisyllabic words. Here the speakers of the Hungarian corpus show no preference for site of initiation.

\section{Table 10}

Recognizable completion and syntactic class

\begin{tabular}{|l|l|l|l|}
\hline & Not recognizably complete & Recognizably complete & Total \\
\hline Function words & $30(8 \%)$ & $333(92 \%)$ & 363 \\
\hline Content words & $125(64 \%)$ & $69(36 \%)$ & 194 \\
\hline Total & $155(28 \%)$ & $402(72 \%)$ & 557 \\
\hline
\end{tabular}

$\chi^{2}(1)=198.60 *, p<.01 ;$ Cramér's $V=.597 *$ (very strong association between the two variables), $\mathrm{p}<.01$ 


\section{Bar Chart}

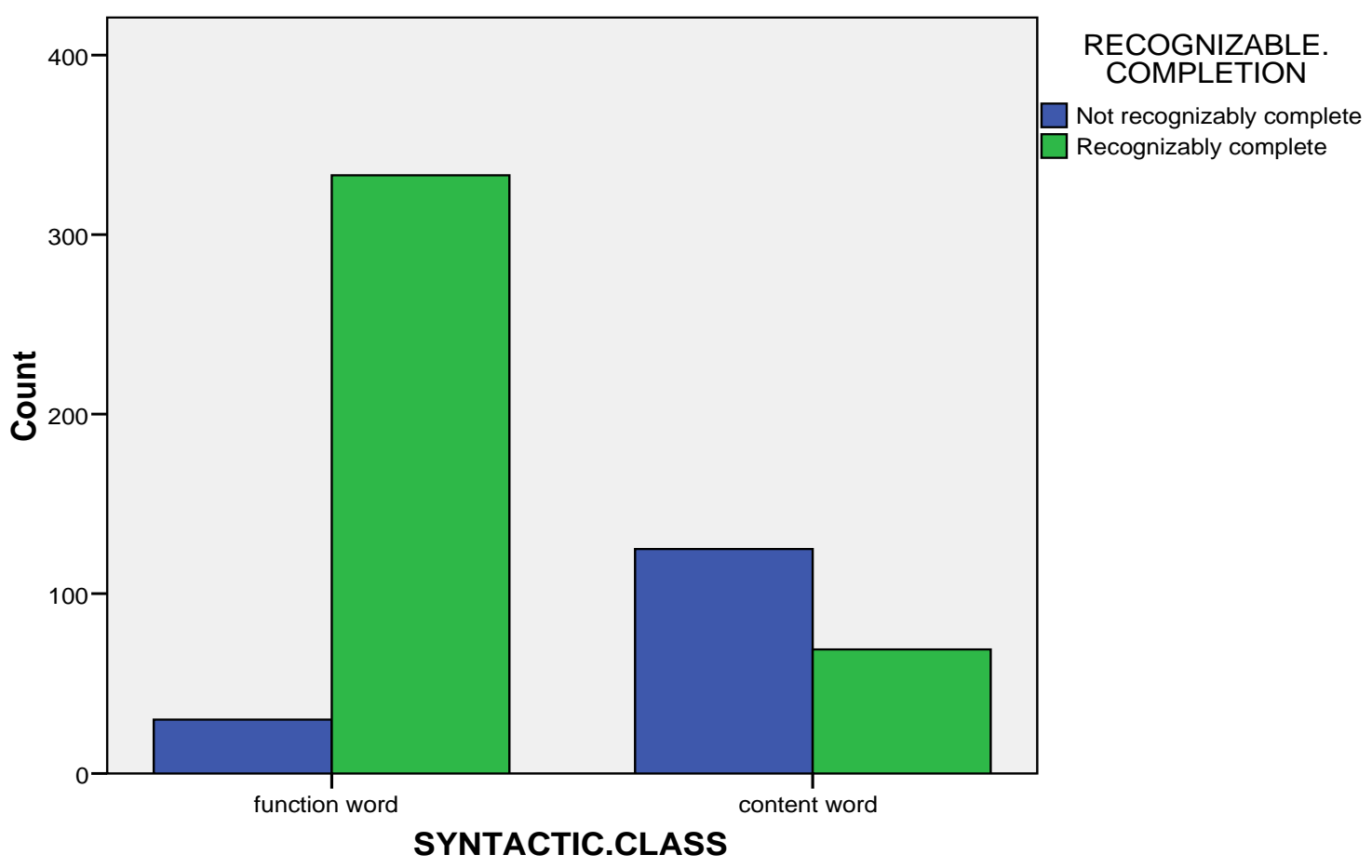

Table 11

Recognizable completion and word length

\begin{tabular}{|l|c|l|l|}
\hline & Not recognizably complete & Recognizably complete & Total \\
\hline Monosyllabic words & $24(7 \%)$ & $330(93 \%)$ & 354 \\
\hline Bisyllabic words & $49(46 \%)$ & $58(54 \%)$ & 107 \\
\hline Multisyllabic words & $82(85 \%)$ & $14(15 \%)$ & 96 \\
\hline Total & $155(28 \%)$ & $402(72 \%)$ & 557 \\
\hline
\end{tabular}

Monosyllabic/Bisyllabic/Multisyllabic: $\chi^{2}(2)=253.81^{*}, \mathrm{p}<.01$ 


\section{Bar Chart}

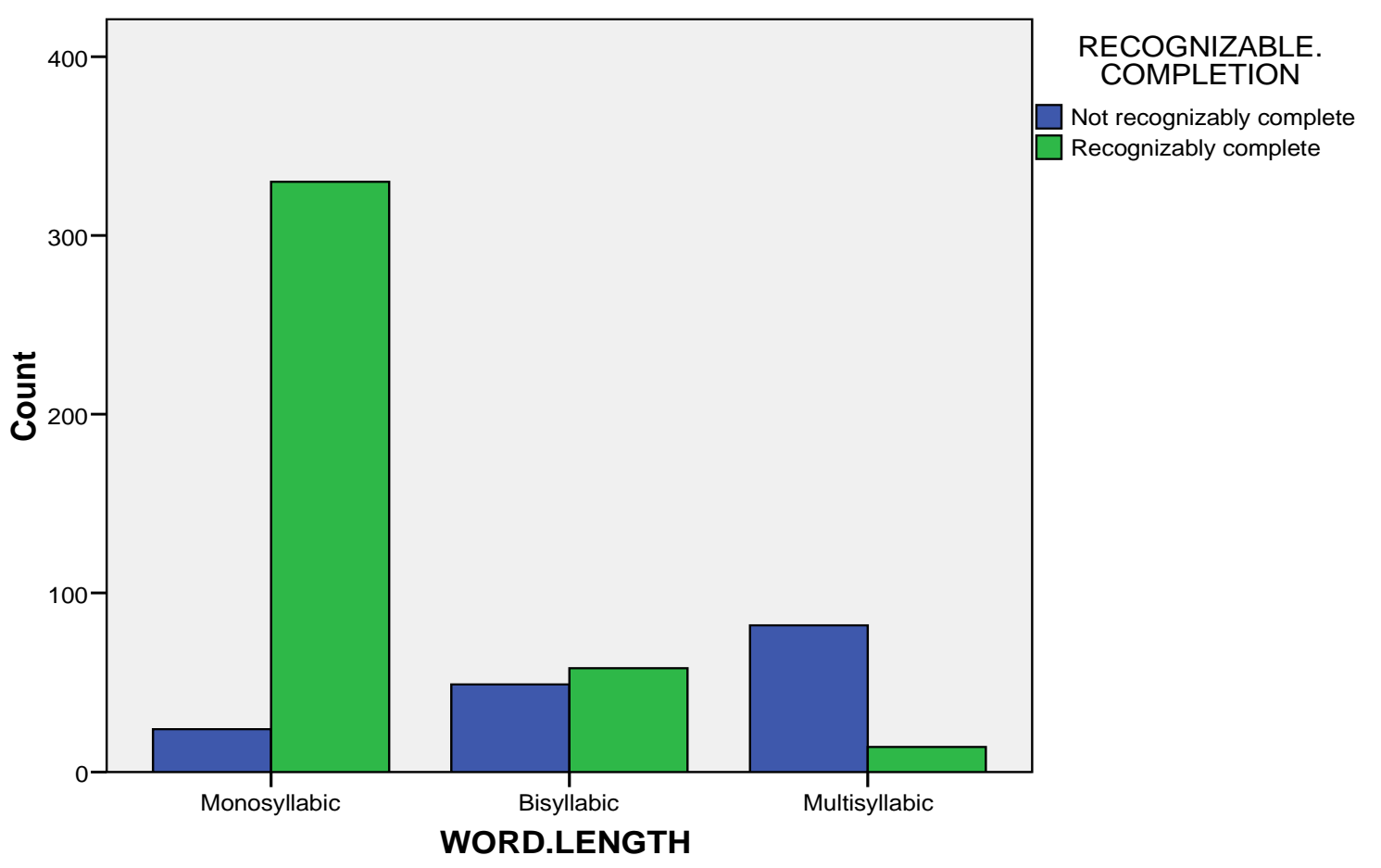

These results also fit the prediction of Fox et al. (2009: 100) relating to word length: in languages in which speakers tend to initiate repair in monosyllabic words, they usually initiate repair after recognizable completion. As the speakers of the Hungarian corpus initiate repair mainly in monosyllabic words, they tend towards initiation after recognizable completion. Taking into consideration bisyllabic words, in the case of Hungarian we meet the cross-linguistic pattern again: the speakers of the corpus show no preference for site of initiation in this word length category.

Fox et al. (2009) offer several explanations for these findings. In monosyllabic words, speakers tend to initiate repair when the word is recognizably complete "because of late decisions to initiate repair" (Fox et al. 2009: 100); in other words, by the time the speaker decides to initiate repair in a monosyllabic word, it is already recognizably complete (Fox et al. 2009: 100). Furthermore, in languages with function words preceding content words, one of the most important functions of recycling is that it provides a temporal delay (Fox et al. 2009: 101); hence the speaker may want to achieve only one or two beats of delay ${ }^{32}$ by recycling function words. High-frequency function words are often

\footnotetext{
${ }^{32}$ One syllable gives roughly one conversational beat of delay (Fox et al. 2009: 96).
} 
phonologically reduced (cf. Jurafsky et al. 1998), ${ }^{33}$ which may also contribute to late repair initiation in monosyllabic words (Fox et al. 2009: 100). For early repair initiation in replacement repairs they also offer a possible explanation which takes into consideration factors other than the function of the repair. They suggest that in several languages, there is a preference for early initiation in replacement repairs just because speakers generally replace content words (Fox et al. 2009: 101), and content words tend to be longer in most languages in their study. This argumentation is not plausible for the Hungarian findings, because we have seen that in the replacement repairs of the corpus word length plays a more important role than syntactic class (Section 6.2.2). In other words, the speakers of the Hungarian corpus generally replace multisyllabic content words because most multisyllabic words are content words, and not because content words tend to be longer in the Hungarian corpus.

As far as recognizable completion and word length in Hungarian are concerned, we have seen that the only word length category where the speakers of the Hungarian corpus show no preference for site of initiation is the category of bisyllabic words. Let us take a closer look at this word length category.

\subsubsection{Bisyllabic words and restarting repair in Hungarian}

As we can see in Table 11, there are nearly the same numbers of bisyllabic words in early and late initiation in the Hungarian corpus. To explain this balance in an indirect way by the functions of the two repair operations would only be possible if there were approximately as many bisyllabic words employed in recycling repairs as in replacement repairs. That is, in that case we could assume that most of the recycling repairs are initiated after, and most of the replacement repairs are initiated before recognizable completion. However, this is not the case, even though the observed frequency of bisyllabic function and bisyllabic content words is also balanced (56 bisyllabic function words and 51 bisyllabic content words) (Table 12), ${ }^{34}$ and even though most of the bisyllabic content words are repaired before recognizable completion, and most of the bisyllabic function words are repaired after recognizable completion (Table 13).

\footnotetext{
${ }^{33}$ We have seen that in the Hungarian corpus most of the function words are monosyllabic (see Table 3 in Section 6.2.1).

${ }^{34}$ As the speakers of the Hungarian corpus tend to recycle back to function words and replace content words, this could mean that there are as many bisyllabic words employed in recycling repairs as in replacement repairs.
} 


\section{Table 12}

Repair in bisyllabic words

\begin{tabular}{|l|l|l|l|}
\hline & Replacement repairs & Recycling repairs & Total \\
\hline Bisyllabic content words & $23(45 \%)$ & $28(55 \%)$ & 51 \\
\hline Bisyllabic function words & $9(16 \%)$ & $47(84 \%)$ & 56 \\
\hline Total & $32(30 \%)$ & $75(70 \%)$ & 107 \\
\hline
\end{tabular}

$\chi^{2}(1)=10.72 *, \mathrm{p}<.01 ;$ Cramér's $\mathrm{V}=.317 *$ (strong association between the two variables), $\mathrm{p}<.01$

\section{Bar Chart}

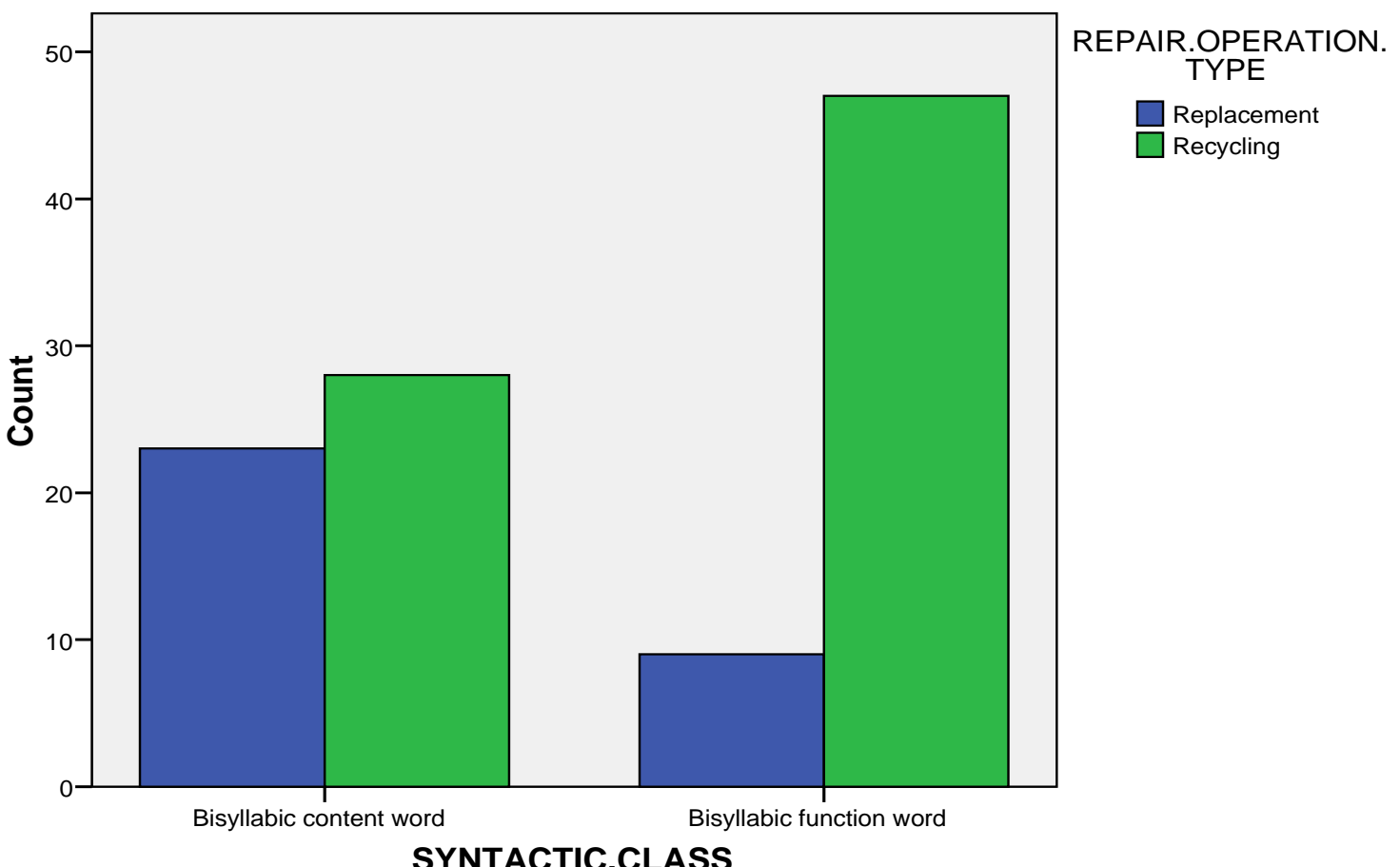

Table 13

Site of initiation in bisyllabic words

\begin{tabular}{|l|l|l|c|}
\hline & Not recognizably complete & Recognizably complete & Total \\
\hline Bisyllabic content words & $34(67 \%)$ & $17(33 \%)$ & 51 \\
\hline Bisyllabic function words & $15(27 \%)$ & $41(73 \%)$ & 56 \\
\hline Total & $49(46 \%)$ & $58(54 \%)$ & 107 \\
\hline
\end{tabular}

$\chi^{2}(1)=17.10^{*}, \mathrm{p}<.01 ;$ Cramér's $\mathrm{V}=.400^{*}$ (very strong association between the two variables), $\mathrm{p}<.01$ 


\section{Bar Chart}

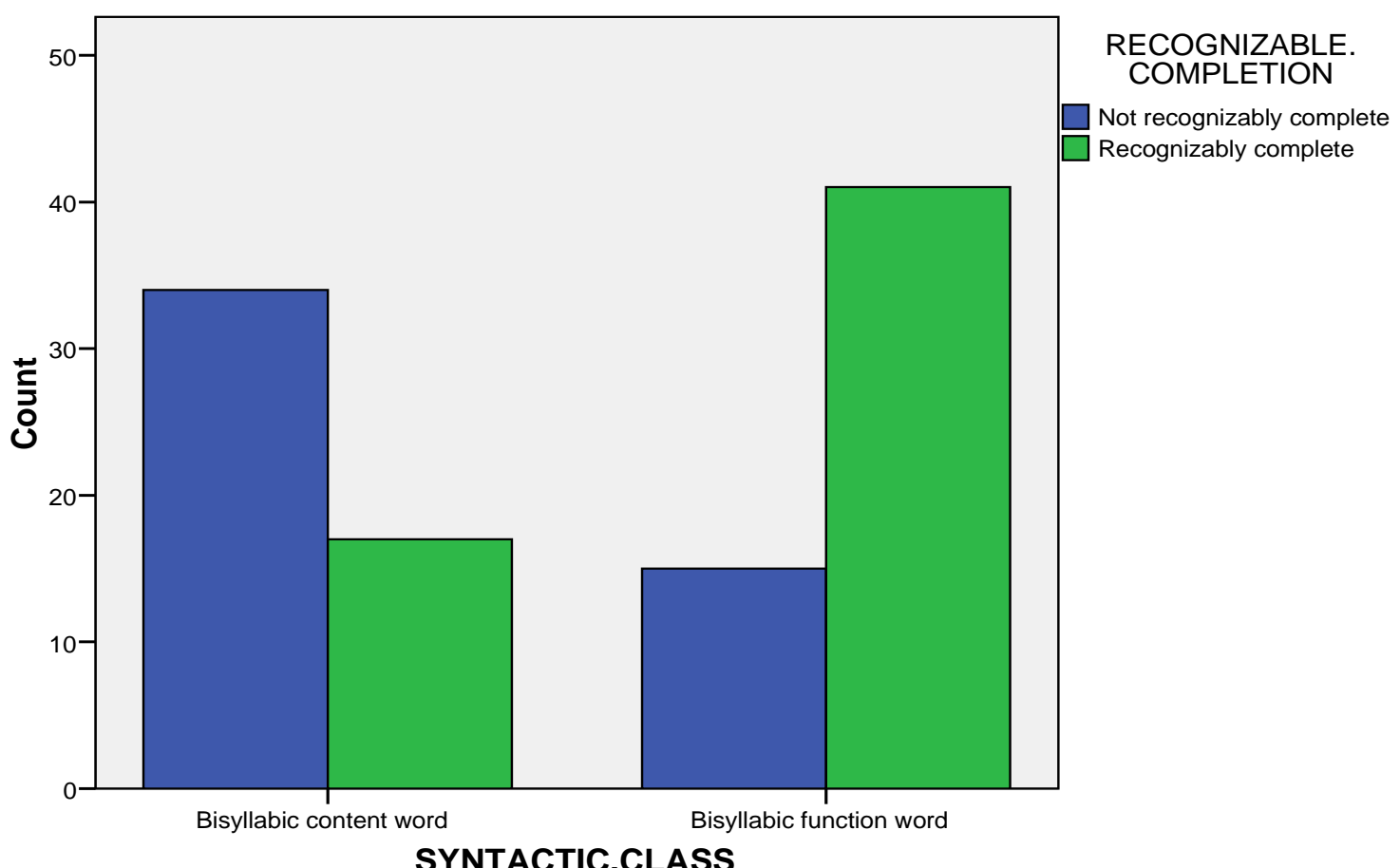

Although the result of the chi-square goodness-of-fit test for the distribution of bisyllabic content words with respect to repair type is not significant $\left(\chi^{2}(1)=.49, \mathrm{p}>.05\right)$, contrary to our expectations, there are more bisyllabic content words involved in recycling repairs than employed in replacement repairs (Table 12). Early repair initiation is still more frequent in the case of bisyllabic content words than in the case of bisyllabic function words (the result of the chi-square goodness-of-fit test for the distribution of bisyllabic content words with respect to repair initiation is significant $\left(\chi^{2}(1)=5.66^{*}, \mathrm{p}<.05\right)$, (Table 13). These results draw attention to bisyllabic content words which are recycled before recognizable completion, i.e., restarted (Extract (54)).

(54) (bea004f003: 211)

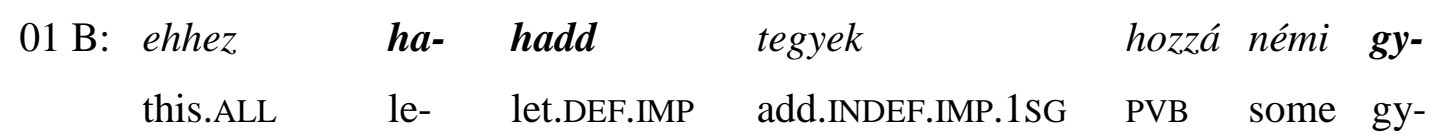


'Le- let me add some memories from Gy- Győr to this.'

I will regard restarting repair as a recycling repair which is initiated before the word is recognizably complete. ${ }^{35}$ Restarting in this sense is a type of recycling repair. Although the Hungarian results show the same pattern as the one Fox et al. (2010: 2503) predict, namely, that recycling often affects function words preceding content words and its function in these cases is likely to delay the next content word due, in the Hungarian corpus $74 \%$ of the restarted words are content words. In Section 6.3 , I attempt to find a possible explanation for this difference between recycling repairs initiated before and after recognizable completion.

\subsection{Recycling initiated after recognizable completion, restarting, and replacement}

The universal pattern Fox et al. (2009) propose, namely, that speakers tend towards repair initiation after recognizable completion in recycling repairs, makes them suppose that recycling often has a delaying function in the languages (Fox et al. 2009: 80). We have also seen that in languages having function words which precede the content words they serve as adjuncts to, speakers tend to recycle back to function words rather than content words (Fox et al 2010: 2504). Fox et al. (2010: 2503) also suggest that in these languages the speakers use function word recycling to delay the next content word due. In all their three languages (English, Hebrew, and German), the speakers tend to recycle back to function words, but replace content words at a disproportionately high rate (Fox et al. 2010: 2487). The authors do not offer any explanations for the first claim, but they do for the second. They note that content words may need to be replaced because they are inapposite (Fox et al. 2010: 2503; see Section 6.2.2). Fox et al. (2009: 85) also say that content words are likely to be interactionally delicate or inappropriate. In Section 6.2.1, I have used the same argument when explaining the frequent use of function word recycling as a practice to delay the next content word due. On the basis of this argumentation, I assume that in the languages where speakers tend to use function word recycling to delay

\footnotetext{
${ }^{35}$ The term restart can also be found in Gósy's (2004) taxonomy which was elaborated to deal with speech disfluencies. However, Gósy does not regard restart as a subcategory of recycling. She uses the term for all cases when a word which is not completely pronounced is followed by the same word completely pronounced (see also, Gyarmathy 2009, 2012a).
} 
the next content word due and replacement repair to replace content words, the function of recycling repair and the function of replacement repair may not be independent of each other. While recycling provides the speaker with extra time so that $\mathrm{s} / \mathrm{he}$ can select the appropriate item, replacement appears when the articulation of an inappropriate item has already begun, i.e., the selection was not satisfactory. Continuing this train of thought, I suppose that while replacement comes into action when an inappropriate segment has already been produced, recycling may be employed to prevent the speaker from producing inappropriate segments. This hypothesized preventive function, however, is not in conflict with the repair status of recycling. The problem which makes the speaker interrupt the ongoing turn in these cases is the danger of producing inappropriate item(s). Going even further, if it is plausible that recycling may be employed to prevent the speaker from producing inappropriate segments, it is also plausible that the speaker may employ recycling repair to avoid replacement.

We have seen that the speakers of the Hungarian corpus tend to recycle back to monosyllabic function words (see Section 6.2.1), and to replace multisyllabic content words (see Section 6.2.2). However, while in recycling repair syntactic class plays a more important role than word length, in replacement repairs word length plays a more important role than syntactic class. If we found that most of the function word recyclings in the Hungarian corpus occur before multisyllabic words, the hypothesis that the speaker may employ recycling repair to avoid replacement repair would also be supported empirically. Table 14 displays the result of this examination. ${ }^{36}$

\section{Table 14}

Word length after function word recycling in the Hungarian corpus

\begin{tabular}{|l|l|l|}
\hline Monosyllabic words & Bisyllabic words & Multisyllabic words \\
\hline $65(35 \%)$ & $55(29 \%)$ & $67(36 \%)$ \\
\hline
\end{tabular}

In Table 14 we can see that the analysis of all the function word recyclings does not conform to our previous expectations. Function word recyclings are distributed evenly with respect to the length of the word following them $\left(\chi^{2}(2)=1.326, p>.05\right)$. The number of monosyllabic words delayed by function word recycling is nearly the same as the number of multisyllabic words delayed in the same way. To find an explanation for this, we have to

\footnotetext{
${ }^{36}$ Table 14 does not contain function word recyclings followed by other function word recyclings.
} 
differentiate between the recycling of different function words. While the recycling of articles may indicate a word search process and usually occurs before content words, the recycling of conjunctions or relative pronouns may indicate a clause search process in Hungarian and, in this way, can be followed by function words as well. The variability of syntactic class can be eliminated if we test function word recyclings projecting an upcoming noun phrase, for example, article recyclings (Extract (55)).

(55) (SZTEPSZI 3: 818)

$01 \mathrm{~B}: \begin{aligned} & \text { és akkor ugye } a \quad a \quad \text { részeg } \\ & \text { and then now the the drunk.NOM that.NOM }\end{aligned}$
'and then now the the drunk so to say
02 elkezd
PVötekedni vagy verekedni
starts provoking or fighting'

Although the sample is quite small, in Table 15 the frequency of article recycling is directly proportional to the length of the word delayed by this strategy (the result of the chi-square goodness-of-fit test for the distribution of article recyclings with respect to the length of the word following them is significant, i.e., their distribution is not random $\left(\chi^{2}(2)\right.$ $\left.=23.17^{*}, \mathrm{p}<.01\right)$. Since the speakers of the Hungarian corpus tend to replace multisyllabic words (see Section 6.2.2), this finding supports the presumption that they may employ recycling to avoid replacement.

\section{Table 15}

Word length after article recycling in the Hungarian corpus

\begin{tabular}{|l|l|l|}
\hline Monosyllabic words $^{37}$ & Bisyllabic words & Multisyllabic words \\
\hline $2(6 \%)$ & $9(25 \%)$ & $25(69 \%)$ \\
\hline
\end{tabular}

Although Fox et al. (2010) do not examine the syntactic class of words following function word recycling in their three languages, their finding that the speakers tend to use function word recycling to delay the next content word due and replacement repair to

\footnotetext{
${ }^{37}$ It is interesting to remark that one of the two monosyllabic words delayed by article recycling in the corpus is a German word (in a conversation about second language acquisition).
} 
replace content words supports the hypothesis. This assumption about the potential preventive function of recycling repair may serve as an explanation for the difference between the number of recycling and replacement self-repairs in Hungarian, in the corpora of Fox et al. (2010), and in all the languages which have function words preceding content words and in which replacements are initiated mainly in content words. According to the hypothesis, the speakers in these languages may avoid the necessity of employing replacement in content words by recycling the function words immediately preceding them. Let us consider the table displaying the number of self-repair instances in the languages examined by Fox et al. (2009) and Fox et al. (2010), supplemented by the Hungarian results (Table 16).

Table 16

Recycling and replacement repair in the languages examined so $\operatorname{far}^{38}$

\begin{tabular}{|c|c|c|c|}
\hline & Recycling repair & Replacement repair & Total \\
\hline English & $111(76 \%)$ & $36(24 \%)$ & 147 \\
\hline Hebrew & $128(83 \%)$ & $27(17 \%)$ & 155 \\
\hline German & $98(69 \%)$ & $44(31 \%)$ & 142 \\
\hline Indonesian & $117(80 \%)$ & $29(20 \%)$ & 146 \\
\hline Sochiapam Chinantec & $185(92 \%)$ & $16(8 \%)$ & 201 \\
\hline Japanese & $147(73 \%)$ & $53(27 \%)$ & 200 \\
\hline Mandarin & $115(77 \%)$ & $35(23 \%)$ & 150 \\
\hline Bikol & $162(88 \%)$ & $23(12 \%)$ & 185 \\
\hline Finnish & $116(72 \%)$ & $46(28 \%)$ & 557 \\
\hline Hungarian & $415(75 \%)$ & $142(25 \%)$ & \\
\hline
\end{tabular}

Fox et al. (2009: 101) claim that in the corpora of their seven languages replacements are generally initiated in content words. On the basis of the examination of English, Hebrew, and German, Fox et al. (2010: 2504) predict that verb-initial and verb-medial languages tend to have function words preceding content words. When we consider the structures of the languages examined by Fox et al. (2009), we notice that their sample is typologically, genetically, and areally diverse: Indonesian is verb-medial and prepositional, Sochiapam

\footnotetext{
38 The sources are the following. English, Hebrew, German: Fox et al. 2010; Indonesian, Sochiapam Chinantec, Japanese, Mandarin, Bikol, Finnish: Fox et al. 2009, Hungarian: Németh 2012.
} 
Chinantec, which is spoken in Oaxaca, Mexico, is verb-initial and prepositional, Japanese is verb-final and postpositional, Mandarin is verb-medial and prepositional, Bikol is verbinitial and prepositional, and finally, Finnish is verb-medial, with both prepositions and postpositions (Fox et al. 2009: 61-62). It is striking that all the languages examined - and not only those with function words before content words - show a preference for recycling repairs over replacement repairs. Is it possible that recycling is a universally more preferred repair operation than replacement? If so, what can be the reason for this?

Fox et al. (2009: 80) make a remark the explication of which has an interesting implication: "Recycling tends to be initiated after recognizable completion, as it is frequently employed to delay the next content word due. The only exception to this is Japanese, where recycling repairs are generally initiated prior to recognizable completion and where function words generally follow content words" (emphasis in italics supplied). This implies the following: in Japanese, function word recycling cannot be used to delay the next content word due, therefore recycling repairs do not tend to be initiated after recognizable completion: restartings are over-represented in the language (see the Japanese example of Fox et al. 1996: 207 as Example (56)).

(56) (Fox et al. 1996: 207)

\begin{tabular}{lllll} 
M: tteyuuka & koko denwa & \multicolumn{2}{c}{ kaket- kaketekite sa, } \\
& I.mean $\quad$ here telephone ca call come FP (final particle) \\
& 'I mean, (they) ca- called us here,'
\end{tabular}

Considering the length ${ }^{39}$ and syntactic class of words in which Japanese speakers initiate recycling, Fox et al. (2009: 85) point out that Japanese is unique among their languages because it has the lowest rate of short words in which speakers initiate recycling repairs (only 5\% of the recycled words are monosyllabic in the Japanese corpus). They explain this observation by the low frequency of one-mora words in the language. They note that these one-mora words are mainly postpositions (see Example (56)), and as postpositions generally follow their nouns instead of preceding them, they are usually not used to delay the next content word due (Fox et al. 2009: 86). Furthermore, 68\% of the bisyllabic words and $93 \%$ of the multisyllabic words recycled are content words in the Japanese corpus (Fox

\footnotetext{
39 Instead of syllables, Japanese words are divided into units called mora determining syllable weight. Syllable weight determines stress and timing (Fox et al. 2009: 61). As in the case of the other languages, the study by Fox et al. (2009) refers to the Japanese words as mono-, bi-, and multisyllabic.
} 
et al. 2009: 91-92). Since recycling repairs are generally initiated prior to recognizable completion in Japanese, we can say that the restarted words tend to be content words in the language. This result is similar to the Hungarian findings: $74 \%$ of the restarted words are content words in the Hungarian corpus.

Although Fox et al. (2009) do not explore the syntactic class of the restarted words in their languages, we can acquire some information concerning the length of words in which the speakers of their seven languages employ restarting repair. In order to acquire this information, we have to examine their tables showing the relationship between site of initiation and word length in recycling repair. Their corpora (except for the Japanese corpus) contain so few instances of restarting repair, that it seems reasonable to consider bi- and multisyllabic words together. Since the speakers of the Hungarian corpus also prefer late repair initiation in recycling repairs, I follow the same strategy when presenting the Hungarian results relating to word length in restarting repair.

Comparing Table 3.9 in Fox et al. 2009: 81, Table 3.11 in Fox et al. 2009: 84, and Table 3.15 in Fox et al. 2009: 89, we realize that all the restarted words are bi- and multisyllabic, and $75 \%$ of the restarted words are multisyllabic in the Japanese corpus. As far as the other languages are concerned, $85 \%$ of the restarted words are bi- and multisyllabic in Finnish and Sochiapam Chinantec, 97\% of the restarting repairs affect biand multisyllabic words in Indonesian, and $92 \%$ of the restarted words are initiated in biand multisyllabic words in Bikol. Mandarin and English do not show such a high frequency of bi- and multisyllabic words in restarting repairs: while 58\% of the restarted words are bi- and multisyllabic in Mandarin, only 33\% of the English restartings are initiated in longer words. Regarding the Hungarian corpus, $83 \%$ of the restarting repairs occured in bi- and multisyllabic words. Consequently, although the other languages have fewer restarted words in their corpora than Japanese, we can see similar tendencies in these languages as regards the length of words affected by restarting. Thus cross-linguistically restarting tends to affect longer words.

Let us consider the syntactic class and length of the words in which speakers initiate replacement in the languages studied by Fox et al. (2009). Although the authors do not present their results relating to syntactic class language by language, they claim that replacements are generally of content words in their corpora (Fox et al. 2009: 101). They have not examined the length of words affected by replacement repair in their languages either, but we can find information about this if we compare the data in Table 3.10 (Fox et al. 2009: 82), Table 3.12 (Fox et al. 2009: 84), and on page 63 in their study. While Table 
3.10 displays the site of initiation of replacement repairs initiated in monosyllabic words, Table 3.12 shows the same information regarding words of three or more syllables. Although Fox and her colleagues do not present a similar table for bisyllabic words, the number of the instances of this category involved in replacement repair in the seven languages can be calculated by taking into consideration the two tables mentioned above and the total numbers of replacement repairs in the languages. The word length categories affected by replacement show a similar picture to the one we have seen in the case of restarting repair. $100 \%$ of the replaced words are bi- and multisyllabic in the Indonesian corpus, $87 \%$ of the replacements are initiated in bi- and multisyllabic words in Bikol, $91 \%$ of the replaced words are bi- and multisyllabic in Finnish, and 91\% of the replacements affect bi- and multisyllabic words in the Japanese corpus. There are three languages in the sample of Fox et al. (2009) whose speakers tend to replace monosyllabic words. In Sochiapam Chinantec, only $25 \%$ of the replacements are initiated in bi- and multisyllabic words, but the Sochiapam Chinantec corpus contains only 16 replacement repairs, which is the smallest replacement corpus in the sample. The other two languages are Mandarin and English: while 14\% of the Mandarin replacements are initiated in bi- and multisyllabic words, $37 \%$ of the replaced words are bi- and multisyllabic in the English corpus. Interestingly, of the languages investigated Mandarin and English are the only two in which restarting repair does not tend to affect bi- and multisyllabic words (see above). As far as Hungarian is concerned, $65 \%$ of the replacement repairs are initiated in bi- and multisyllabic words in the Hungarian corpus (see Table 2b in Section 6.2.1). I have explained this relatively low frequency of longer words in the repair operation for example by reference to the frequent article replacement in the corpus (see Section 6.2.2).

All things considered, we can say that restarting (i.e., recycling initiated before recognizable completion) and replacement tend to affect the same categories of word length and syntactic class in the languages examined so far. They tend to be initiated in biand multisyllabic words in Japanese, Finnish, Indonesian, Bikol, and Hungarian, and do not tend to be initiated in bi- and multisyllabic words in English and Mandarin. As to syntactic classes, in Japanese and Hungarian (the only languages in which both restarting and replacement have been examined in this respect), the repair operations tend to be initiated in content words.

I assume that restarting may have the same potential delaying function as recycling initiated after recognizable completion, but its position is different. We have seen that recycling often affects monosyllabic words and function words preceding content words 
(Section 6.2.1). We have also seen that restarting does not support this pattern: it is often initiated in bi- and multisyllabic words and content words (see this section above). I suppose that this difference is due to the different positions of restarting and recycling initiated after recognizable completion: both types of recycling have a delaying function, i.e., they provide the speaker with extra time, but restarting is initiated when the problematic word has already begun. In other words, in the case of restarting, the speaker interrupts the ongoing turn to gain extra time by employing recycling only when s/he has already started the articulation of the problematic word. This may be a potential explanation for the different kinds of words affected by the two types of recycling: while function word recycling initiated after recognizable completion can delay the next content word due, content word recycling initiated before recognizable completion, i.e., the restarting of a content word, can delay the rest of the word. Why might it be necessary to delay only the rest of a word? I assume that in these cases the word turns out to be problematic only when its articulation has already begun. That is, according to my assumption, both types of recycling may be employed to prevent the speaker from producing inappropriate segments, and thus both may be employed to help the speaker in avoiding replacement. The only difference is that while recycling initiated after recognizable completion is used before the problematic, potentially inappropriate word, restarting is initiated when this word has already begun. This means that according to my hypothesis, both restarting and replacement tend to be initiated in potentially inappropriate words. This assumption is supported by the finding that restarting and replacement tend to affect the same word length and syntactic class categories in the languages examined so far.

If this hypothesis is plausible, in languages where function words follow content words there must be more restarting repairs because the speakers do not have the opportunity to gain extra time by recycling function words (initiated after recognizable completion) before the production of content words (which may potentially be more problematic). That is to say, if speakers cannot recycle back to a function word in order to delay a content word, they will be more likely to restart the problematic word just to avoid replacement. The Japanese results of Fox et al. (2009) support this hypothesis: we have seen that in the Japanese language function words tend to follow content words and recycling repairs tend to be initiated prior to recognizable completion (Fox et al. 2009: 80). We can explain this by assuming that if speakers cannot use recycling repair initiated after recognizable completion where they need extra time, they will substitute it with a restarting 
repair just to avoid replacement. This also explains why there are approximately as many recycling repairs relatively to the number of replacements in these languages as in the languages where function words tend to precede content words. The proportions are nearly the same: although the delaying function of function word recycling is missing, there are not fewer recycling repairs and more replacement repairs in Japanese (see Table 16). Hence we can suppose that there is a preference hierarchy among recycling initiated after recognizable completion, restarting, and replacement (cf. Bilmes 1988; Sacks 1995b [1968-1972]). To establish this preference hierarchy, I rely on Bilmes 1988 and Sacks 1995b. Although Sacks never defined his notion of preference (he only showed examples), Bilmes (1988: 163) reconstructed its main aspects, one of which is the principle of ordering. According to this principle, there are situations where the speakers' possible choices are ordered in the following way: "Do $X$, unless you have reason not to, in which case, do $Y$, unless you have reason not to, in which case, do $Z$, and so forth" (Bilmes 1988: 163, emphasis original). I apply Sacks's (1995b) principle of ordering reconstructed by Bilmes (1988) to recycling initiated after recognizable completion, recycling initiated before recognizable completion, and replacement, in the following way: if recycling initiated after recognizable completion is available to delay a problematic word, speakers will use it. If not, they will be more likely to employ a restarting repair (recycling initiated before recognizable completion) than use the repair operation of replacement. Replacement always remains the last resort among the three. ${ }^{40} \mathrm{We}$ can also assume that the ratio of early and late initiations in recycling repairs depends on the typical orders of function and content words in languages, i.e., the exploitability of the delaying function of function word recycling. In other words, while the recycling-replacement ratio is likely to be approximately universally constant, within recycling repairs the ratio of early and late initiations depends on the morpho-syntactic structures of languages. This is in accordance with the previous studies illuminating the strong relationship between grammar and repair (see, e.g., Schegloff 1979; Fox et al. 1996; Rieger 2003; Lerch 2007; Fox et al. 2009; Fox et al. 2010), and points to the interaction between grammar and pragmatics.

\footnotetext{
${ }^{40}$ On the notion of preference, see Section 7.1.
} 


\subsection{Sub-conclusion - Comparing recycling with replacement}

In Chapter 6, I have explored recycling and replacement relative to each other. The starting point for the investigation has been the observation of the first cross-linguistic studies comparing the two repair operations with each other: Fox and her colleagues' (2009, 2010) collections of self-repair instances contain many more recyclings than replacements in all the languages examined in both studies (cf. Fox et al. 2009: 63; Fox et al. 2010: 2490) (Table 1).

Concentrating on the factors examined by the two studies, I have revealed whether Hungarian fits the patterns suggested as universal. I have found that the speakers of the Hungarian corpus recycle back most frequently to monosyllabic function words and tend to replace multisyllabic content words. I have also observed that while in recycling repair syntactic class plays a more important role than word length, in replacement repairs word length plays a more important role than syntactic class. The result regarding function word recycling corroborates the prediction of Fox et al. (2010: 2504), namely, that languages with function words preceding their respective content words will show a preference for recycling back to function words rather than content words so as to delay the next content word due. With respect to site of initiation, Hungarian also fits the cross-linguistic patterns: while recycling tends to be initiated after recognizable completion, replacement is generally initiated before the word is recognizably complete. As speakers initiate repair mainly in monosyllabic words, they tend towards initiation after recognizable completion, but they show no preference for site of initiation in bisyllabic words. The observed frequencies of bisyllabic words by syntactic class, repair type, and site of initiation in the corpus have drawn attention to bisyllabic content words which are recycled before recognizable completion, i.e., restarted. This observation has led to a cross-linguistic comparison of recycling initiated after recognizable completion, restarting, and replacement, which I have carried out using the results of Fox et al. (2009) and Fox et al. (2010), as well as the Hungarian findings. I have realized that while recycling initiated after recognizable completion and restarting tend to affect different categories of word length and syntactic class across languages, we can see similar tendencies as to the length and syntactic class of words affected by restarting and replacement.

I have assumed a preference hierarchy among recycling initiated after recognizable completion, restarting, and replacement: if speakers cannot use recycling initiated after recognizable completion where they need extra time, they will tend to substitute it with a 
restarting repair just to avoid replacement repair. This hypothesis offers a possible explanation not only for the possibly universal preference for recycling over replacement, but for the possibly universally constant recycling-replacement ratio, as well. On the basis of the results of Fox et al. (2009), Fox et al. (2010), and the examination of Hungarian, I assume that the ratio of early and late initiations in recycling repairs depends on the typical orders of function and content words in languages, i.e., the exploitability of the delaying function of function word recycling. This is in accordance with the previous studies which have described how methods of repair are shaped by the linguistic resources of languages, and argued in this way for the relationship between grammar and repair (see, e.g., Fox et al. 1996; Rieger 2003; Lerch 2007; Fox et al. 2009; Fox et al. 2010), and thus between grammar and pragmatics.

Setting up the hypotheses in Chapter 6, I have relied on various direct and indirect sources, which can be divided into two main groups. The first group relating to previous studies involves the quantitative and statistical analyses carried out by Fox et al. (2009) and Fox et al. (2010), and the inferences they made and the conclusions they drew on the basis of their investigations. The second group of sources is made up of my own quantitative and statistical analyses carried out on the Hungarian corpus, and the inferences I have made and the conclusions I have drawn on the basis of these analyses. Finally, I have used my intuition as well, when identifying linguistic phenomena as recycling, replacement, insertion, and aborting in the Hungarian corpus, assuming connections between the functions of recycling and replacement, and setting up a preference hierarchy among recycling initiated after recognizable completion, recycling initiated before recognizable completion, and replacement. In my argumentation leading to the hypothesis, I have also found connections between the data relating to replacement and restarting in the studies of Fox et al. (2009) and Fox et al. (2010) which the authors left undiscussed.

My argumentation has required the conscious integration of the sources listed above. Kertész and Rákosi (2012: 239) emphasize that relying on as many data sources as possible allows us to assign a higher plausibility value to a hypothesis than would be the case when relying on any of these data sources individually. Since in Chapter 6 I have relied on several data sources, I assign a high plausibility value to my statements.

The findings of Chapter 6 pose a new question. Why do speakers tend to avoid replacement cross-linguistically? In Section 6.3, I have regarded the avoidance of replacement and the avoidance of inappropriate segments as similar efforts on the part of speakers. If they tend to avoid replacement cross-linguistically, then they also tend to avoid 
producing inappropriate segments cross-linguistically. Producing inappropriate segments is thus less preferred than employing recycling. Nevertheless, when speakers employ recycling, they still override a preference in talk-in-interaction, namely, the preference for progressivity.

In Chapter 6, I have compared recycling with replacement, which has led to assume a preference hierarchy among recycling initiated after recognizable completion, recycling initiated before recognizable completion (restarting), and replacement. In Chapter 7, I will improve this preference hierarchy model into another one which is able to describe repair operations relative to each other on the basis of one of their inherent properties, namely, that they override the preference for progressivity.

\section{Hypothesis on the preference hierarchy of repair operations}

\subsection{The notion of preference in conversation analysis}

The notion of preference has always been one of the fundamental concepts of conversation analysis. It has been defined as a social/interactional feature of the interactants' orientations to their talk (Schegloff 2007: 61). Its core idea is that speakers follow (often implicit) principles when they act and react in interactional situations (Pomerantz-Heritage 2013: 210). Instead of grasping the speakers' psychological states and their individual attitudes towards their possible actions and the methods of designing their turns, the term preference refers to a ranking of alternatives which is institutionalized (Heritage-Atkinson 1984: 53); in other words, to regularities which speakers observably orient themselves to when taking part in a conversation. We can differentiate between preferences relating to the character of the action a turn implements and preferences affecting the construction of the turn (Schegloff 1988, 2007). The first group involves the attitudes taken towards the success of actions. For instance, it is preferred to accept and dispreferred to refuse an invitation. These kinds of preferences may be in conflict with each other. For example, it is preferred to agree with a compliment, but it is also preferred to avoid self-praise (Pomerantz 1978: 88-89) (see Extract (33) in Section 5.2, in which the speaker uses turnconstructional delaying practices when delivering self-praise). The second group of preferences has to do with the design of the turn. If an invitation is designed in the following way: Don't you want to come to my birthday party?, it is preferred to accept it regarding the character of the action, but the design of the question anticipates the answer No. 
Preference principles work in different domains and involve various types of constraints and orders (Pomerantz-Heritage 2013: 210). They appear when speakers select and interpret referring expressions (see Sacks-Schegloff 1979), produce and interpret initiating and responding actions (see Sacks 1995a (1964-1968), 1995b (1968-1972)), employ repair practices (see Section 3.2), in the turn-taking system (see Stivers-Robinson 2006), and in the progression of action sequences (Pomerantz-Heritage 2013: 210). Let us see what preference means in this last domain.

\subsection{The preference for progressivity}

As was noted, preference principles play an important role in the progression of action sequences (Pomerantz-Heritage 2013: 210). According to Schegloff (2007: 14), most types of organization involve the default relationship between their components such that each component should follow the previous one. He emphasizes that moving from an element to a hearably-next-one (i.e., what is hearable as a/the next one due) with nothing intervening is the embodiment of progressivity (Schegloff 2007: 17). The term progressivity was first used in this sense by Schegloff (1979). It refers to the observation that each component in the organization of interaction generally progresses to the next relevant element immediately after the prior element (Kitzinger 2013: 239). If anything intervenes between one element and the next one due - if anything violate their contiguity -, it will qualify the progressivity of the talk, and will be examined for its importance; in other words, it will influence the understanding of the talk (Schegloff 2007: 15). Examining insertion repair, Schegloff (2008a) notes that when speakers employ this repair operation, the preference for progressivity is violated. He asks: "What sorts of things [...] warrant such an override, warrant such a marked usage?" (Schegloff 2008a, as cited in Wilkinson-Weatherall 2011: 66). This means that there is a general, basic preference for progressivity in talk-ininteraction. Schegloff (2013: 43) argues that the preference for progressivity concerns the overall structural organization of talk, the basic dynamic of which is progressional and directional toward a possible completion. Speakers' orientation to what comes next is organized on two levels. On the macro-level the talk is moved forward by reference to the action; in other words, speakers orient themselves towards the action which is hearable as the next one due. The micro-level concerns the construction of the turn, which means that speakers also orient themselves towards the next relevant element of the construction (Schegloff 2013: 42). 
The preference for progressivity is both an action- and a design-based preference. From a sequential point of view it manifests itself in the rational ordering of turns. This results in an organization in which each turn is connected to the turns on either side of it (Sacks et al. 1974: 722). The concept of nextness is best realized in the minimal unit for sequence construction, which is the adjacency pair. The adjacency pair is composed of two turns produced by two different speakers. These turns are relatively ordered, that is to say, they can be differentiated into first and second pair parts (Schegloff 2007: 13). The adjacency pair is pair-type related: not every first pair part can be properly followed by any second pair part (Schegloff 2007: 13). For instance, the type-fitted response for a question is an answer (Stivers 2013: 192). It is preferred to keep the components of an adjacency pair together. When a turn contains more than one question and thus provides for the relevance of more than one answer as the expected subsequent actions, speakers tend to begin by responding to the last question to preserve the contiguity for at least one adjacency pair (Sacks 1987 [1973]). The preference for maintaining the progressivity of question-answer sequences influences the organization of turn-taking as well. In multiparty conversations, if a selected next speaker fails to provide an answer, and a nonselected recipient is in a position to respond, it is preferable for the latter to provide the answer and thus preserve the progressivity of the sequence (Stivers-Robinson 2006). Within the turn, the preference for progressivity appears in the relationship between syllables and sounds: each sound and syllable should be followed by the next relevant sound and syllable (Schegloff 2007: 14), and the turn progresses from sub-unit to sub-unit by reference to sounds, syllables, and words (Schegloff 2013: 42).

We have defined the domain of repair as the set of practices whereby a speaker interrupts the ongoing course of action to attend to possible trouble in speaking, hearing, or understanding the talk or merely to alter it in some interactionally consequential way without any problems fixed in it (see Section 3.2, cf. Kitzinger 2013: 229 and Schegloff et al. 1977: 361). Kitzinger (2013: 231) points out that whereas self-initiated repair in sameturn interrupts the progressivity of the turn, other-initiated repair interrupts the progressivity of the sequence. When speakers halt the progressivity of the current turn or sequence to attend to possible trouble in speaking, hearing, or understanding the talk or merely to alter it in some interactionally consequential way, they override the preference for progressivity because the maintenance of intersubjectivity (i.e., a world known and held in common among the participants) is more important for them (Schegloff 1992: 
1296). That is, in repair, the principle of intersubjectivity comes into conflict with the principle of progressivity (cf. Heritage 2007).

In Section 3.2, repair operation has been defined as practices whereby a cointeractant interrupts her/his ongoing turn-at-talk to attend to possible trouble in speaking, hearing, or understanding the talk or merely to alter the turn in some interactionally consequential way. Describing ten repair operations, Schegloff (2013: 43) also emphasizes that "in one way or another, [same-turn repairs] intervene to interrupt the progressivity of the talk" (original emphasis). While a co-interactant uses a repair operation, the progressivity of the ongoing turn-at-talk and thus the progressivity of the ongoing course of action is being ${ }^{41}$ suspended: it cannot progress to possible completion from the point of interruption (repair initiation) until the completion of the repair. While repair initiation means a "possible disjunction with the immediately preceding talk" (Schegloff 2000: 207), the repair is completed "when the speaker resumes the talk that had been suspended for the purposes of repair" (Kitzinger 2013: 238). Halting the progressivity of the ongoing course of action is thus an inherent feature of repair, and halting the progressivity of the ongoing turn-at-talk is an inherent feature of repair operations.

Consequently, although we have assumed that recycling is a cross-linguistically more preferred repair operation than replacement, both of them override the preference for progressivity. The preference hierarchy hypothesis proposed has suggested that speakers tend to avoid replacement because they tend to avoid producing inappropriate segments, and producing inappropriate segments is less preferred than employing recycling. I will argue below that recycling and replacement can be differentiated from each other based on how they override the preference for progressivity, in other words, how the turn is being suspended when speakers employ them. After identifying the features of halting the progressivity of the turn in recycling and replacement, I extend this analysis to insertion and aborting so as to see whether these features appear in other repair operations as well.

\subsubsection{Halting the progressivity of the turn by employing recycling}

In this section I will explore exactly what happens when progressivity is being suspended by recycling. Now let us observe what prevents the action from progressing to possible completion when the speaker employs this repair operation. In Extract (57), we can see

\footnotetext{
${ }^{41}$ Here the word being refers to the observation that suspending the talk by employing a repair operation is not limited to the moment when the turn is interrupted, i.e., to repair initiation.
} 
three lines from Extract (36), in which Marcsi employs recycling as a turn-constructional delaying strategy when referring to a rapper's health problem.

(57) (SZTEPSZI2: 725)

$07 \mathrm{M}$ : én ennek

I.NOM this.DAT

tök

örülök

mert

very much

happy am.INDEF

because

'I am so happy about that (the rapper's success) because

08

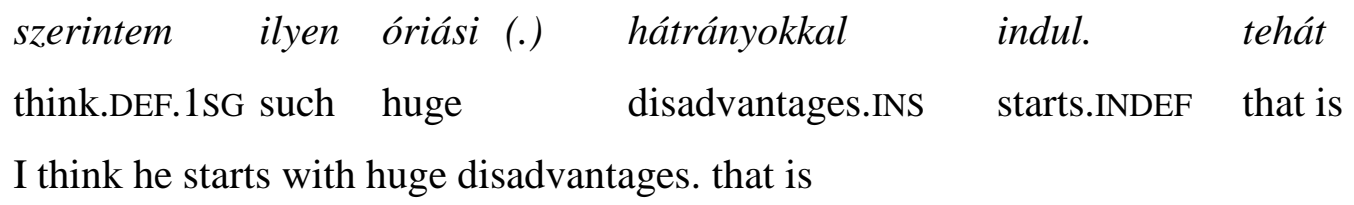

09
baromi
hendikeppel
hogy
hogy hogy olyan
amilyen
enormous
handicap.INS that
that
that kind.NOM.SG
kind.NOM.SG
with an enormous handicap that that that he is like that'

M: I am so happy about that (the rapper's success) because I think he starts with huge disadvantages. that is with an enormous handicap that that that he is like that

In the extract, repair initiation occurs tacitly, without any explicit indication (cf. Kitzinger 2013: 239). At the moment of repair initiation, Marcsi returns to an earlier point of the TCU, and produces the same item again. Since in the example the conjunction hogy 'that' is recycled twice, these steps are repeated, then Marcsi resumes the talk that she has suspended. I argue that recycling suspends the progressivity of the current turn in two respects. On the one hand, returning to an earlier point of the TCU means that from a technological point of view the repair operation is retrospective. The word technological is of great importance here, because in terms of its delaying function recycling is prospective, it operates on upcoming talk when, for example, it is used in a word search (cf. Fox et al. 2009: 74). On the other hand, producing the same item for the second or third time (when it does not express stress or emphasis) means that although the speaker articulates something which moves the turn forward phonetically, this part of speech has the same role in the progression of the action as the first occurrence of the item at issue. The 
progression of the action is similar to when a record needle gets stuck and just plays the same passage over and over again. In this sense, but only in this sense, i.e., from the point of view of progressivity, the second or third occurrence of the same item is redundant. However, since it facilitates attending to possible problems in speaking, hearing, or understanding the talk or merely altering the turn in some interactionally consequential way, producing the same item for the second or third time as a repair operation is necessary in accomplishing the action. One could ask why it is necessary to differentiate between retrospectivity and redundancy when isolating them as the features contributing to halting progressivity in the case of recycling. Their roles in the phenomenon might be understood better if we consider cases in which redundant elements prevent the action from progression by themselves, without involving any retrospective steps. For example, when the speaker uses fillers or hesitation markers, s/he does not go back, but the action still 'gets stuck' (see Extract (28) repeated as Extract (58)).

(58) (bea004f003: 200)

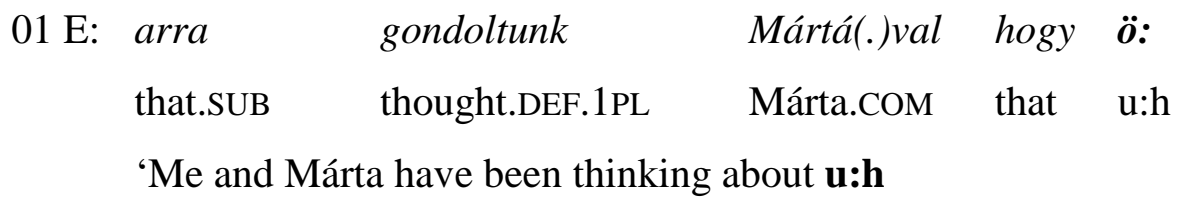

02

\begin{tabular}{llllll} 
szeretnénk & \multicolumn{1}{c}{ Ont } & megkérdezni & hogy & a & karácsonyt \\
like.INDEF.COND.1PL & You.ACC.SG & ask.INF & that & the & Christmas.ACC \\
asking You how (.) & & & & &
\end{tabular}

03

$\begin{array}{lllll}\text { azt (.) hogyan töltötte } O ̈ n ? & \text { meg hogyan } \\ \text { that.ACC } & \text { how } & \text { spent.DEF.3SG You.NOM.SG } & \text { and how }\end{array}$

did You spend Christmas time? and how

04
szokott
Ma- Önöknél zajlani?
(.) az egész
usually do.INDEF.3SG Yo- You.ADE.PL happen.INF
the whole
is it celebrated at Yo- Your place? (.) the whole

$05 \quad$ (.) ünnep?

holiday.NOM

(.) Christmas holiday? 
$06 \mathrm{~T}:$ na jó.

now alright

now it's alright.

$07 \mathrm{~T}$ : akkor kezdjék Maguk!

then begin.DEF.IMP.3PL You.NOM.PL

but You should begin!'

E: Me and Márta have been thinking about u:h asking You how (.) did You spend Christmas time? and how is it celebrated at Yo- Your place? (.) the whole (.) Christmas holiday?

T: now it's alright.

T: but You should begin!

In line 01, Enikö stretches $\ddot{o}$, which is a non-lexical pause filler in Hungarian. Both this stretching and the sequential environment of the phenomenon suggest that it serves as a turn-constructional delaying strategy in the extract. Let us recall that Enikö, a young student, uses the filler before she addresses Tibor, the old man for the first time. Analyzing the example in Section 5.1, I have assumed that there is a formal and hierarchical social relationship between them, which is supported by the replacement employed later, i.e., the less formal form of address Maguknál 'at Your place' is replaced by the more formal Önöknél 'at Your place'. Since using $\ddot{o}$ occurs just before the first time Tibor is addressed (at the end of line 01), it is likely to be the first sign of Enikö's insecurity in addressing the man. In Section 5.2, I have argued that if recycling or practices such as $u h(m), y^{\prime} k n o w$, and silence (and $\ddot{o}$ in Hungarian) are employed solely to delay the next item due so that the speaker can attend to possible trouble in speaking, hearing, or understanding the talk or merely alter the turn in some interactionally consequential way, then we should interpret them as repair and repair operations. Since it alters the turn in some interactionally consequential way, producing $\ddot{o}$ : in the example should be interpreted as repair. Let us see 
how it prevents the action from progressing to possible completion. This time the speaker does not go back but articulates a new element. Although this new element carries the turn forward phonetically, as in the case of recycling, it does not contribute to the progression of the action. In this sense, but again, only in this sense, we can say that although they are necessary for carrying out the action, elements like $\ddot{o}$ are redundant from the point of view of progressivity.

\subsubsection{Halting the progressivity of the turn by employing replacement}

Now let us explore how replacement overrides the preference for progressivity. In Extract (58), Enikő starts the articulation of Maguknál, but cuts it off half-way and replaces it with the other formal Hungarian form of address, Önöknél. How is the turn being suspended in this case? What are the similarities and/or differences relative to recycling?

At the moment of repair initiation the speaker also returns to an earlier point of the TCU (the repair is initiated by a cut-off in the example); therefore, like recycling, from a technological point of view replacement is retrospective. Since in terms of its function replacement changes the preceding talk, we can say that it is retrospective both from a technological and a functional point of view. However, in this case Enikő does not produce the same item again, but substitutes the part of speech between repair initiation and the earlier point she has returned to with a new item. Similarly to producing the same item again, producing an item instead of another one is also redundant from the point of view of progressivity: the new item plays the same role in the TCU as the replaced segment; the action gets stuck. ${ }^{42}$ Nonetheless, unlike a record needle which plays the same passage over and over again, this time the action is 'on the wrong track'. That is, it is not enough that it does not progress to possible completion, it has gone in an inappropriate direction. I will call this third feature of halting progressivity inappropriateness.

Consequently, while recycling is assumed to override the preference for progressivity in two respects (retrospectivity, redundancy), replacement prevents the turn from progressing to possible completion in three (retrospectivity, redundancy, inappropriateness). As halting the progressivity of the ongoing turn is an inherent property of each repair operation, it seems to be an ideal basis on which any two repair operations can be described relative to each other. This assumption makes the extension of the

\footnotetext{
${ }^{42}$ Here again, redundant does not mean unnecessary.
} 
research to further repair operations well-motivated. Below I add insertion and aborting to the operations examined.

\subsubsection{Halting the progressivity of the turn by employing insertion}

Let us consider the insertion in Extract (47), repeated here as Extract (59).

(59) (SZTEPSZI2: 790)

$\begin{array}{lllllllll}01 \text { Á: } & a & \text { média } & \text { nem föltétlenül } & \text { (.) } & \boldsymbol{a} & \text { (.) } & \text { csak } & \boldsymbol{a} \\ & \text { the media.NOM } & \text { not } & \text { necessarily } & & \text { the } & & \text { only the }\end{array}$
'the media is not necessarily (.) guided by (.) only by

02 jóindulat v:ezérli. hogy majd tehetséget faragunk goodwill.NOM guides.DEF that then talent.ACC create.INDEF.1PL goodwill. the intention of making a talented person

03 belö[le

she/he/it.ELA

of somebo[dy

Á: the media is not necessarily (.) guided by (.) only by goodwill. the intention of making a talented person of somebo[dy

In the extract, Ági tries to find out what the leading ethical principle of the Hungarian media is. After the definite article she goes back and inserts csak 'only' into the TCU, which creates a concessive form: goodwill can be one of the leading principles of the Hungarian media. Of the three repair operations examined so far it is here that the retrospectivity feature appears most obviously. Even the description of insertion given by Wilkinson and Weatherall (2011) contains the retrospective step: "speakers halt their talkin-progress to go back and add something else into the turn before resuming" (WilkinsonWeatherall 2011: 65). Insertion thus changes the TCU by adding extra elements into it. Since the speaker goes back but does not change the part of speech between repair 
initiation and the earlier point she has returned to, resuming the talk that had been suspended makes it necessary to have a repeated part in the TCU. Therefore, like recycling, insertion bears the features of redundancy and retrospectivity when overriding the preference for progressivity. The only difference between the technologies of the two repair operations is that insertion adds extra element(s) to the TCU. The progressivity of the turn, however, would not be suspended only by adding extra element(s) to it; the reason for halting progressivity is that these extra element(s) are added afterwards, making it necessary to have a repeated part in the TCU.

\subsubsection{Halting the progressivity of the turn by employing aborting}

In aborting, the speaker casts off the ongoing TCU, and starts the same action in a different way, in a different form, with a different TCU (cf. Laakso-Sorjonen 2010: 1153). In Extract (60), which is five lines from Extract (49), Linda quotes her acquaintances' opinions on the effects of marijuana.

(60) (SZTEPSZI8: 1067)

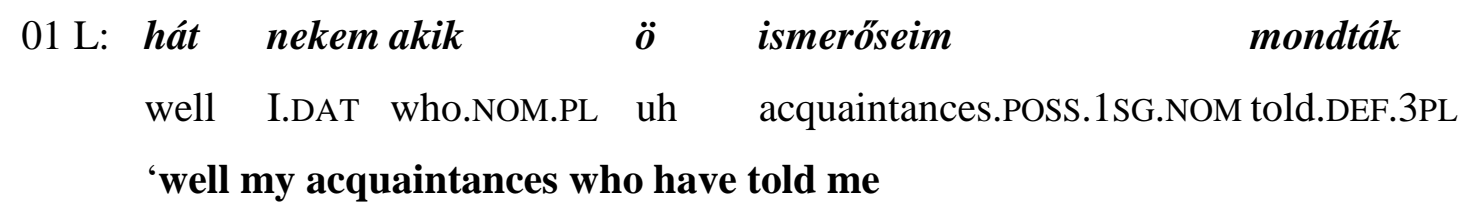

02

$\begin{array}{lllllll}\text { ók } & \text { nem } & \text { nem } & \boldsymbol{e z t} & \text { mondták } & \text { hanem } & \text { inkább } \\ \text { they.NOM } & \text { not } & \text { not } & \text { this.ACC } & \text { told.DEF.3PL but } & \text { rather }\end{array}$
they didn't didn't tell me that but rather

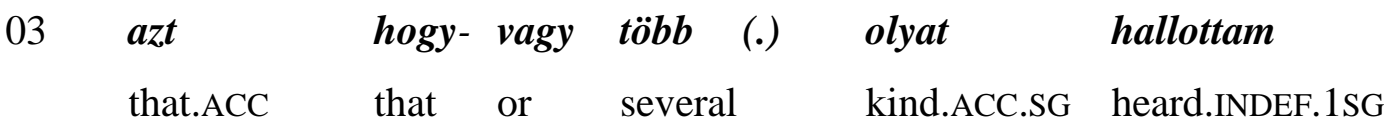
that- or I have heard several (.) opinions like

$\begin{array}{lllll}04 & \text { hogy mondjuk } \quad \text { szar } & \text { volt } & \text { vagy } & \text { vagy } \\ \text { that } \quad \text { so to say } \quad \text { shit.NOM } & \text { was.INDEF.3SG } & \text { or } & \text { or } \\ \text { so to say it felt like shit or or } & & \end{array}$




$\begin{array}{lll}\text { rossz volt } & \text { [utána] } \\ \text { bad } \quad \text { was.INDEF.3SG } & \text { after.POSS.3SG } \\ \text { it felt bad [after it] } & \end{array}$

\section{L: well my acquaintances who have told me they didn't didn't tell me that but rather that- or I have heard several (.) opinions like so to say it felt like shit or or it felt bad [after it]}

In line 01, Linda refers to all of her acquaintances who have told her about their experiences with using marijuana. However, after hogy 'that' in line 03, she casts off the ongoing TCU (this is indicated by a cut-off in the extract), and starts the same action in a different form, restricting the category of referents to 'several opinions'. At the moment of repair initiation she returns to the beginning of the TCU (retrospectivity), and substitutes the part of speech between repair initiation and the earlier point she has returned to, i.e., the whole TCU-so-far with a new TCU which is to implement the same action as the one substituted. As far as the progressivity of the action is concerned, producing a new TCU instead of another one is redundant: the new TCU implements the same action as the replaced TCU had been to implement. Consequently, until the speaker resumes the talk that has been suspended because of the repair, the progression of the activity gets stuck. ${ }^{43}$ Moreover, as in the case of replacement, it is not enough that the action does not progress to possible completion; it has gone in an inappropriate direction. Since aborting can be regarded as replacing a TCU with another TCU, from a technological point of view it does not differ from replacement: it suspends the progressivity of the turn in three respects (retrospectivity, redundancy, inappropriateness).

\subsection{The preference hierarchy of repair operations}

Table 17 displays the respects in which recycling, replacement, insertion, and aborting halt the progressivity of the turn. Although the four repair operations are diverse regarding their possible functions, I have assumed that recycling and insertion, and replacement and

\footnotetext{
${ }^{43}$ Again it is important to emphasize that redundant does not mean unnecessary.
} 
aborting override the preference for progressivity in the same respects. While recycling and insertion violate the preference for progressivity in the respects of redundancy and retrospectivity (two respects), replacement and aborting contain redundant and inappropriate element(s) besides the retrospective step in their technologies, and therefore override the preference for progressivity in the respects of redundancy, retrospectivity, and inappropriateness (in three respects).

\section{Table 17}

The respects in which recycling, replacement, insertion, and aborting suspend the progressivity of the turn

\begin{tabular}{|l|c|c|c|c|}
\hline & Recycling & Insertion & Replacement & Aborting \\
\hline Redundancy & + & + & + & + \\
\hline Retrospectivity & + & + & + & + \\
\hline Inappropriateness & - & - & + & + \\
\hline
\end{tabular}

The starting point of the argumentation of the present section has been the assumption that speakers tend to avoid replacement because they tend to avoid the production of inappropriate segments, and producing inappropriate segments is less preferred than employing recycling. The exploration of recycling and replacement in terms of the way they override the preference for progressivity seems to offer a theoretical basis for this assumption. Producing inappropriate segments and replacing them with new items suspends the progressivity of the turn, i.e., overrides the preference for progressivity in more respects than employing recycling. I suppose that the more respects in which a repair operation overrides the preference for progressivity, the less preferred it will be in the repair mechanism. Since employing replacement prevents the turn from progressing to possible completion in three respects, according to my hypothesis it is less preferred than recycling, which suspends progressivity in only two respects.

To sum up, I assume a preference hierarchy among repair operations. Relying on Sacks's (1995b) principle of ordering reconstructed by Bilmes (1988: 163), I claim that if $\mathrm{X}, \mathrm{Y}$, and $\mathrm{Z}$ are repair operations, and $\mathrm{X}$ overrides the preference for progressivity from one, $\mathrm{Y}$ from two, and $\mathrm{Z}$ in three respects, then speakers will not interrupt the progressivity of the ongoing turn unless they have reason to do so, in which case, they will employ $\mathrm{X}$ unless they have reason not to, in which case, they will employ Y unless they have reason not to, in which case, they will employ $\mathrm{Z}$. 
This hypothesis, which offers a possible explanation for the cross-linguistic difference assumed between the frequency of recycling and replacement, influences the interpretation of the relationship between the principle of intersubjectivity and the principle of progressivity in talk-in-interaction. We have seen that the maintenance of intersubjectivity is built into the procedural organization of interaction (Schegloff 1992: 1299) because the maintenance of the ongoing activity is possible only if there is a world which the interactants know and hold in common (Schegloff 1992: 1296) (see Section 3.2). We have also seen that there is a preference for maintaining the progressivity of the ongoing activity in talk-in-interaction (Sacks 1987 [1973]; Stivers-Robinson 2006; Schegloff 2007, 2013; Kitzinger 2013). In repair, the principle of progressivity comes into conflict with the principle of intersubjectivity (cf. Heritage 2007). In order to restore intersubjectivity, speakers have to override the preference for progressivity when they use the procedural infrastructure of the repair mechanism (Schegloff 1992). These statements imply that there is a one-way relationship between the principle of intersubjectivity and the principle of progressivity, namely, intersubjectivity has an impact on progressivity when the necessity of its restoration makes speakers override the preference for progressivity. The preference hierarchy hypothesis, however, suggests, on the one hand, that speakers tend to make an effort not to violate the preference for progressivity, and, on the other, that before using a repair operation it is possible for them to consider the way it suspends the progressivity of the ongoing turn. That is, although different repair operations aim to solve different problems in interaction, the act of choosing among them is also sensitive to how they override the preference for progressivity. This is possible only if we propose a twoway relationship between intersubjectivity and progressivity: the principle of progressivity also has its impact on that of intersubjectivity. During turn-design, speakers will tend to make an effort to violate the preference for progressivity in the fewest possible respects, which will influence their maintenance of intersubjectivity. They will also tend to make an effort to avoid problems which potentially require repair, and problems which potentially require repair operations overriding the preference for progressivity in several respects. In speakers' choices of repair operations, then, I assume the interaction of the principle of intersubjectivity manifesting itself in the functions of repair operations and the principle of progressivity manifesting itself in the way they suspend the progressivity of the turn. 


\subsection{Testing the preference hierarchy hypothesis}

At first sight, counting the occurrences of the particular repair operations in the corpus seems to be a reliable empirical test for the hypothesis. Since insertion, like recycling, is assumed to be more preferred than aborting and replacement, it is also expected to be more frequent in the corpus. The corpus used in the second phase of the research (see Chapter 4) contains 790 recycling repairs, 171 replacement repairs, 146 aborting repairs, and 139 insertion repairs. This does not meet our previous expectations. However, considering the hypothesis again, we will realize that it does not imply that the insertion-aborting ratio should be the same as the recycling-replacement ratio. If the corpus simply contained more repair operations which override the preference for progressivity in only two respects, and fewer repair operations preventing the turn from progressing in three respects, it would already support our previous assumption. In order to carry out this examination, however, we should take into account not only four, but all repair operation types in the corpus. That is to say, on the one hand, we do not know how the other six repair operation types described by Schegloff (2013) override the preference for progressivity, and, on the other hand, we do not know how the turn is being suspended when speakers employ repair operations which have not yet been recognized and described in the conversation analytic literature (Schegloff 2013: 68). From this it follows that we have to find another method to test the hypothesis.

Schegloff (2007: 15) notes that if something intervenes between an element and the next one due, i.e., qualifies the progressivity of the talk, it will be examined for its importance, in other words, will influence the understanding of the talk. Drew et al. (2013: 92) point out that self-repair affords us access to the work of turn-design, i.e., to speakers' orientations as to how they should construct the turn the best to make it appropriate for its sequential environment, for the action they intend it to do, and for the recipient to whom it is addressed. Self-repair thus shows us the alternative versions of the turn, the version which is initially selected and then rejected, and the subsequent version in favor of which the previous one is rejected. This means that each self-repair changes the turn in some way. Whereas the initially selected and then rejected version of the turn constitutes the input, the subsequent version in favor of which the previous one is rejected can be regarded as the output of the self-repair. The input of a replacement repair in this way is the turn-version which contains the replaced segment but does not contain the segment substituting for the old one, while its output is the turn-version which contains the new segment but does not 
contain the old one which is substituted. Similarly, in the case of aborting, the input is the turn-version which contains the replaced TCU-so-far but does not contain the new TCU substituting for the old one, while its output is the turn-version which contains the new TCU but does not contain the old one which is substituted. The input of insertion repair is the turn-version without the inserted segment, and its output is the turn-version which contains the inserted material as well. Considering recycling, it seems to be obvious that its input is the turn-version containing only the first occurrence of the repeated segment. In order to find out how it changes the turn, in other words, what its output will be, as in the case of the other repair operations, we have to examine how the turn is constructed in a better way if the speaker employs it. That is to say, the output of every repair operation is the turn-version which is more appropriate for its sequential environment, for the action it is designed to perform, and for the recipient to whom it is addressed. We know that recycling may change the turn at the emergence of overlapping talk to deal with possible problems caused by simultaneous talk (Schegloff 2013; cf. Schegloff 1987), at the emergence of inattentiveness in order to elicit gaze from recipients (Goodwin 1980), or as a device for delaying the next item due e.g. when the speaker needs time to select the appropriate next word or choose between alternatives (Fox et al. 2009; Jefferson 1974). In these cases, the turn-version which is more appropriate for its sequential environment, for the action it is designed to perform, and for the recipient to whom it is addressed is the one which helps the speaker in accomplishing the aims listed above. That is to say, the output of recycling repair is the turn-version which 1) is able to treat problems caused by the possibly compromised hearing of the talk (cf. Schegloff 2009: 386), and/or 2) is able to elicit gaze from recipients, and/or 3) is able to gain extra time for the speaker. Consequently, the output of recycling repair is the turn-version which contains each subsequent occurrence of the repeated segment.

Hence I argue that each self-repair phenomenon changes the turn in some way to make it more appropriate for its sequential environment, and/or the action it is designed to perform, and/or the recipient to whom it is addressed. Let us see what happens if the speaker employs more than one self-repair in the same turn when carrying out the same action. In Extract (61), the self-repairs employed while carrying out the same action address the same problem. This phenomenon is called multiple self-repair in the conversation analytic literature (Schegloff 1979: 278). In the extract, Ági tells Zsuzsi and Marcsi that once she met and talked to the star of a Hungarian reality show in a pub. This man belongs to the gypsy ethnic minority, which is always recognizable in his manner of 
speaking in the show. In the pub, where there were no cameras, he gave himself away: he revealed that the events of his reality show are prearranged.

(61) (SZTEPSZI2: 803)

$\begin{array}{rlllll}01 \mathrm{~A}: & \text { és } & \text { akkor } & \text { elkezdett } & \text { velünk } & \text { beszélgetni, és akkor } \\ & \text { and then started.INDEF.3SG } & \text { we.COM } & \text { talk.INF } & \text { and then }\end{array}$
'and then he started talking to us, and then

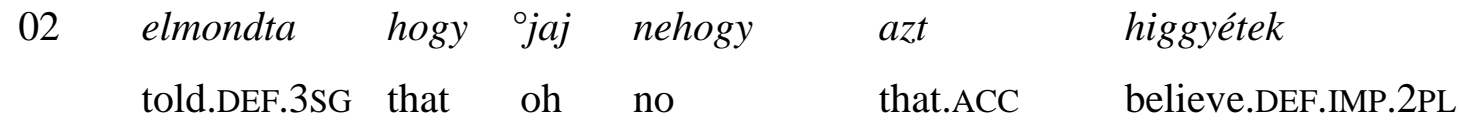
he told us that ${ }^{\circ} \mathrm{oh}$, you shouldn’t believe it at all.

03 má. meg van tervezve az egész. fel fogok at all PVB is.INDEF prearranged the whole PVB will.INDEF.1SG the whole show is prearranged. I will have a

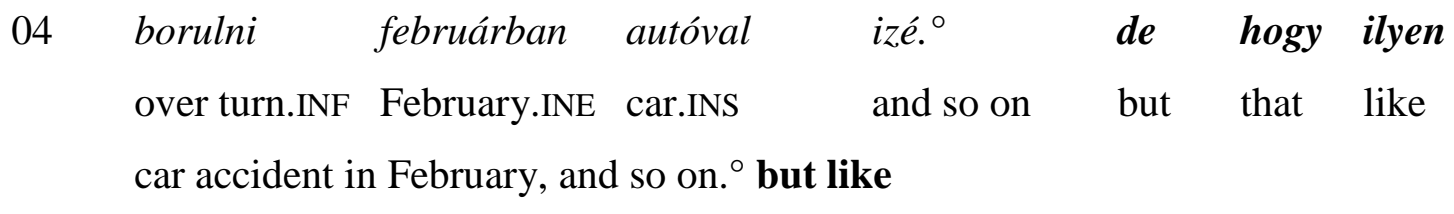

05 egész norm-tehát hogy $\ddot{o} \quad$ (.) $\quad$ nem:
quite norm- that is that uh $\quad$ nem: hasz-
quite norm- that is, uh (.) he didn't u:mm didn't use-

06
nem volt
akcentusa:
not was.INDEF.3SG
accent.POSS.3SG.NOM
didn't have an accent'

Á: $\quad$ and then he started talking to us, and then he told us that ${ }^{\circ}$ oh, you shouldn't believe it at all. the whole show is prearranged. I will have a car accident in February, and so on. ${ }^{\circ}$ but like quite norm- that is, uh (.) he didn't u:mm didn't use- didn't have an accent 
When Ági tells the others about the deception behind the reality show, she lowers her voice (her quieter talk is between degree signs in lines 02-04), which suggests that she is giving them some secret, inside information. In line 05 , she breaks off (de hogy ilyen egész norm'but like quite norm-'). After the cut-off, she starts anew with the explainer tehát 'that is', which supports the analysis of this phenomenon as aborting repair: Ági starts another TCU but does the same action (tehát hogy ö (.) nem: hm: nem: hasz- nem volt akcentusa: 'that is, uh (.) he didn't u:mm didn't use- didn't have an accent'). The new TCU, which contains several hesitancy markers and a recycling (nem: hm: nem: 'didn't u:mm didn't'), is closed by a replacement: Ági breaks off again, and replaces the segment nem: hasz- 'didn't use-' with the segment nem volt akcentusa 'didn't have an accent'. Why does Ági employ this multiple self-repair when designing this TCU? In order to find a potential answer to this question, we should examine the action the TCU implements. Ági tells the others that the famous man in the pub did not speak in the way he usually does in the show; in other words, his manner of speaking (e.g., his pronunciation) did not show that he was a gypsy. As she has to distinguish between the gypsies' manner of speaking and the non-gypsies' manner of speaking, Ági may disprefer and tries to avoid discriminative, offensive language, which makes her employ multiple self-repair. The first turn-version she selects so as to refer to the man's manner of speaking is cut off at the beginning of line 05 . It is very likely that the cut-off is in the word normális ('normal'). ${ }^{44}$ As this adjective is quite offensive, Ági may not want to take responsibility for it, and tries to find another solution, which will be the output of an aborting repair. This time she selects a negative construction (tehát hogy $\ddot{o}$ (.) nem: 'that is, uh (.) he didn't'), then repeats the negative (nem: m: nem: 'didn't u:mm didn't'). The output of the aborting repair thus will be the input of another repair operation, namely, a recycling repair. According to the argumentation presented above, the output of recycling contains each subsequent occurrence of the repeated segment, which means that the output of the recycling employed by Ági is tehát hogy ö (.) nem: m: nem: hasz- 'that is, uh (.) he didn't u:mm didn't use-'. We can see that even this turn-version is cut off: Ági replaces nem: hasz- 'didn't use-' with nem volt akcentusa: 'didn't have an accent'. Hence the output of the recycling is the input of a replacement, which is the last repair operation in Ági's multiple self-repair: its output is the final turnversion (tehát hogy ö (.) nem: hm: nem volt akcentusa: 'that is, uh (.) he didn't u:mm

\footnotetext{
${ }^{44}$ The only other Hungarian words starting with norm- and not being the derivations of norma 'norm' are normann 'Norman' and Normandia 'Normandy'. Neither of these fit into the sequential environment of the extract.
} 
didn't have an accent'). This extract indicates that aborting, recycling, and replacement may fulfil one and the same task in one and the same turn and thus one and the same action: all repair operations used by Ági are to avoid offensive language when she refers to the man's manner of speaking in the pub.

As each repair operation employed in a multiple self-repair changes the turn in some way to bring it closer to the most appropriate turn-design, we can assume that the repair operations following one another in a multiple self-repair are not independent of one another because the different turn-versions they generate will be interconnected: the output of the first repair operation will be the input of the second one, the output of the second one will be the input of the third one, the output of the third one will be the input of the fourth one, and so on until the speaker designs the final turn-version.

If every self-repair changes the turn in some way to make it more appropriate for its sequential environment, for the action it is designed to perform, and for the recipient to whom it is addressed, it does not matter whether or not they address the same trouble. If more than one self-repair is employed while carrying out the same action, the repair operations following one another will not be independent of one another; the different turnversions they generate will be interconnected in the same way as in the case of multiple self-repairs explicated above. Extract (13) in Section 3.1 has represented how turns are fashioned out of turn-constructional units and how these turn-constructional units embody actions. Now let us consider the analysis of a few lines from the same extract (as Extract (62)) from another point of view. Extract (62) displays different repair operations which are employed while carrying out the same action, but which address different problems. Cili and Anna talk about Christmas. Anna is raising the question of when a couple who have been going out with each other for some time should decide to spend Christmas together.

(62) (bea003n001)
$01 \mathrm{C}$ : bövül
a család
még jobban.
bigger becomes.INDEF
the family.NOM
even more
'the family becomes even bigger.
$02 \mathrm{~A}$ : hát igen. de ez is olyan nehéz hogy igazából well yes but this.NOM also so difficult that actually well yes. but actually it is also so difficult (to decide)




$\begin{array}{lllll}\text { amikormár } & \text { valaki: } & \text { hosszabb } & \text { ideje } & \text { együtt } \\ \text { when already } & \text { somebody.NOM } & \text { longer } & \text { time.ABL } & \text { together }\end{array}$

when somebody: has been going out with somebody for a longer time

04

$\begin{array}{llllll}\text { van } & \text { valakivel } & \text { hogy } & \text { hogy } & \text { mikor jön } & \boldsymbol{a z} \\ \text { is.INDEF } & \text { somebody.COM } & \text { that } & \text { that } & \text { when comes.INDEF that }\end{array}$

that that when the time

05

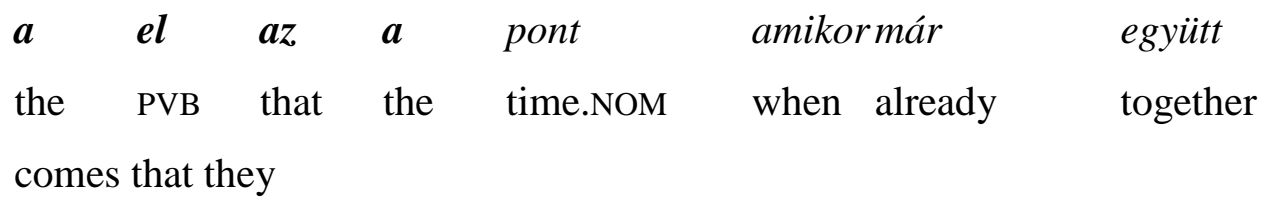

06 is karácsonyoznak

also Christmas spend.INDEF.3PL

also spend Christmas together'

$\mathrm{C}$ : the family becomes even bigger.

(0.3)

A: well yes. but actually it is also so difficult (to decide) when somebody: has been going out with somebody for a longer time that that when the time comes that they also spend Christmas together

The first action in the extract is a telling in line 01 by Cili (cf. Schegloff 2007: 7). The second action is Anna's response in line 02, which constitutes the first TCU of her turn. The second unit in Anna's turn implements a problem-raising (as we have seen in Extract (13) in Section 3.1). She is wondering when the time comes for a couple to spend Christmas together. The TCU implementing this action is extended twice and contains two self-repairs which orient towards different problems. First, in line 04, Anna recycles the conjunction hogy 'that'. This is a function word occurring at the beginning of clauses in Hungarian (cf. Lerch 2007: 127). As the recycling of conjunctions and relative pronouns may indicate a clause search process in Hungarian (see Section 6.3), it is well-motivated to analyze this phenomenon as the repair operation of recycling (see Section 5.2). While the 
input of this recycling is de ez is olyan nehéz hogy igazából amikor már valaki: hosszabb ideje együtt van valakivel hogy 'but actually it is also so difficult (to decide) when somebody: has been going out with somebody for a longer time that', its output is de ez is olyan nehéz hogy igazából amikor már valaki: hosszabb ideje együtt van valakivel hogy hogy 'but actually it is also so difficult (to decide) when somebody: has been going out with somebody for a longer time that that'. The output of the recycling will be the input of another repair operation, namely, an insertion repair in Anna's turn. With the conjunction hogy 'that' she starts a subordinate clause: hogy mikor jön az a (hogy 'that' mikor 'when' jön 'comes' $a z$ 'that (demonstrative determiner)' $a$ 'the'). After the demonstrative determiner $a z$ 'that' and the definite article $a$ 'the' which introduce a noun phrase in Hungarian, she interrupts the progressivity of the turn and inserts the verbal prefix $e l$ into it. The verbal prefix, which is usually written together with the verb as a prefix+verb unit, is a subtype of verb modifiers in Hungarian (É. Kiss 2002: 57). The difference between jön 'come' and eljön 'come' is that eljön 'come' carries an additional meaning: its agent is expected to come. In the present case, it emphasizes that the time when a couple decides to spend Christmas together does not come unexpectedly but is an ordinary event in a developing relationship. Since interrogative phrases have an inherent [+focus] feature (É. Kiss 2002: 90), and the focus and the verb are required to be adjacent in the Hungarian sentence (É. Kiss 2002: 84), in the clause Anna starts, the prefix el should come after the verb which it modifies (mikor jön el az a pont 'when the time (which is to be expected) comes'). However, since Anna has already pronounced the demonstrative determiner $a z$ 'that' and the definite article $a$ 'the' introducing the noun phrase az a pont 'the time', she has to go back and insert the prefix afterwards. ${ }^{45}$ The output of this insertion repair is therefore de ez is olyan nehéz hogy igazából amikor már valaki: hosszabb ideje együtt van valakivel hogy hogy mikor jön el az a 'but actually it is also so difficult (to decide) when somebody: has been going out with somebody for a longer time that that when the (time) comes'.

The analysis of Extract (62) also makes it plausible that if more than one self-repair is employed while carrying out the same action, the repair operations following one another will not be independent of one another: the different turn-versions they generate will be interconnected. If the output of the first repair operation is the input of the second

\footnotetext{
${ }^{45}$ This case suggests that the possibilities for locating the initiation of insertion repair in the TCU depend on the morpho-syntactic structure of the language involved. The exploration of this interesting issue requires further studies.
} 
one, that is, the second repair operation changes the turn which has been changed by the first one, and so on till the end of the action, then if more than one repair operation is employed while carrying out the same action, each choice of repair operation will have an effect on the next choice. In speakers' choices of repair operations I have assumed the interaction of the principle of intersubjectivity manifesting itself in the functions of repair operations and the principle of progressivity manifesting itself in the way they suspend the progressivity of the turn, i.e., a two-way relationship between intersubjectivity and progressivity. I have assumed that when designing their turns, speakers will tend to make an effort to violate the preference for progressivity in the fewest possible respects, which will influence their maintenance of intersubjectivity. They will also tend to make an effort to avoid problems which potentially require repair, and problems which potentially require repair operations overriding the preference for progressivity in several respects. In the speakers' choices of repair operations, then, I hypothesize the following tendencies in the order of repair operations employed while carrying out the same action:

[1] [a] They tend to violate the preference for progressivity in at least as many respects as the immediately previous repair operation in the action.

[1] [b] They tend to violate the preference for progressivity in at most as many respects as the immediately next repair operation in the action. ${ }^{46}$

[2] [a] If [1] is satisfied, of two repair operations violating the preference for progressivity in different number of respects, the next one after any repair operations tends to be the one which violates the preference for progressivity in fewer respects.

[2] [b] If [1] is satisfied, of two repair operations violating the preference for progressivity in different number of respects, the previous one before any repair operations tends to be the one which violates the preference for progressivity in more respects. ${ }^{47}$

As we can see, it is assumed that speakers tend to select first the repair operations violating the preference for progressivity in fewer respects. As Table 17 has shown, while recycling and insertion violate the preference for progressivity in the respects of redundancy and retrospectivity (two respects), replacement and aborting contain redundant and inappropriate element(s) besides the retrospective step in their technologies, therefore override the preference for progressivity in the respects of redundancy, retrospectivity, and

\footnotetext{
${ }^{46}[1][\mathrm{b}]$ is the inverse restatement of [1] [a] with the purpose of making it easier to test.

47 [2] [b] is the inverse restatement of [2] [a] with the purpose of making it easier to test.
} 
inappropriateness (in three respects). [1] means that in actions where more than one repair operation is employed, a repair operation is more likely to be followed by an operation which violates the preference for progressivity in the same or higher number of respects, than by an operation which violates the preference at issue in fewer respects. For example, [1] means that a recycling/insertion is more likely to be followed by a recycling/insertion or a replacement/aborting than an operation which violates the preference for progressivity in only one respect. ${ }^{48}$ [2] means that if [1] is satisfied, a repair operation is more likely to be followed by a repair operation which violates the preference for progressivity in the same number of respects, than by a repair operation which violates the preference at issue in more respects. For example, a recycling/insertion is more likely to be followed by another recycling/insertion than by a replacement/aborting.

On the basis of this argumentation, the hypothesis on the preference hierarchy of repair operations becomes testable taking into consideration only the four repair operation types under investigation. We have to examine all cases in the corpus which meet the following criteria: 1) more than one repair operation is employed while carrying out the same action, and 2) these repair operations are recycling(s), replacement(s), insertion(s), or aborting(s), or any combination of these, and 3) there are no other repair operation types employed while carrying out the action.

In order to test [1] and [2], we should consider the orders of repair operations in the actions which satisfy 1), 2), and 3). I will do this by considering the repair operations following one another in twos, that is, for example, if we find an insertion $\rightarrow$ aborting $\rightarrow$ replacement order in an action, I will take into account the following pairs: insertion $\rightarrow$ aborting, aborting $\rightarrow$ replacement.

Now we have two repair operation categories, namely, the one involving the operations which violate the preference for progressivity in two respects (redundancy, retrospectivity) and the one involving the operations which violate the preference at issue in three respects (redundancy, retrospectivity, inappropriateness). While recycling and insertion belong to the first category $(\mathrm{C} 1)$, replacement and aborting belong to the second (C2). For these two categories, [1] means that in actions satisfying 1), 2), and 3), a repair operation violating the preference for progressivity in three respects is more likely to be followed by a repair operation which also violates the preference at issue in three respects,

\footnotetext{
${ }^{48}$ Although I have not examined repair operations like this, in Section 7.2.1 I have referred to a possible analysis of the fillers such as $\ddot{o}$ : as repair operations violating the preference for progressivity in only one respect, namely, the respect of redundancy (see Extract (58)). This classification, however, requires further studies.
} 
than by an operation which violates it only in two respects. That is, a replacement or an aborting (C2) is more likely to be followed by another replacement or aborting (C2) than by a recycling or an insertion (C1). Similarly for our two categories, [2] means that if [1] is satisfied, a repair operation violating the preference for progressivity in two respects is more likely to be followed by a repair operation which also violates the preference at issue in two respects, than by an operation which violates it in three respects. That is, a recycling or an insertion $(\mathrm{C} 1)$ is more likely to be followed by another recycling or insertion $(\mathrm{C} 1)$ than by a replacement or an aborting $(\mathrm{C} 2)$.

Table 18 shows the pairs of repair operations identified in the corpus following the criteria established above. Since both recycling and insertion violate the preference for progressivity in two respects, and both replacement and aborting do so in three, I treat the four repair operations as two categories: recycling/ insertion: $\mathrm{C} 1$; replacement/ aborting: $\mathrm{C} 2$.

Table 18

Repair operation pairs in the actions satisfying criteria 1), 2), and 3)

\begin{tabular}{|l|c|c|}
\hline 1. recycling/ insertion $\rightarrow$ recycling/ insertion & $\mathrm{C} 1 \rightarrow \mathrm{C} 1$ & 262 \\
\hline 2. recycling/ insertion $\rightarrow$ replacement/ aborting & $\mathrm{C} 1 \rightarrow \mathrm{C} 2$ & 73 \\
\hline 3. replacement/ aborting $\rightarrow$ replacement/ aborting & $\mathrm{C} 2 \rightarrow \mathrm{C} 2$ & 35 \\
\hline 4. replacement/ aborting $\rightarrow$ recycling/ insertion & $\mathrm{C} 2 \rightarrow \mathrm{C} 1$ & 46 \\
\hline Total & & 416 \\
\hline
\end{tabular}

To be sure that these values do not come from the relative frequencies of the four repair operations in the corpus, we have to consider the results in relation to the whole corpus. However, even without taking into account the occurrences of the two categories in the whole corpus as well, we can already get usable information when we compare $\mathrm{C} 1 \rightarrow \mathrm{C} 2$ (recycling/ insertion $\rightarrow$ replacement/ aborting) (line 2 in Table 18) and C2 $\rightarrow \mathrm{C} 1$ (replacement/ aborting $\rightarrow$ recycling/ insertion) (line 4 in Table 18). It can already be seen that while there are 73 recycling/ insertion $\rightarrow$ replacement/ aborting pairs in the actions satisfying 1), 2), and 3), the number of replacement/ aborting $\rightarrow$ recycling/ insertion pairs in these actions is only 46. This means that it is more probable that a repair operation overriding the preference for progressivity in two respects is followed by a repair operation overriding the preference for progressivity in three, than vice versa. Since $\mathrm{C} 1 \rightarrow \mathrm{C} 2$ satifies 
the tendency assumed in hypothesis [1] but $\mathrm{C} 2 \rightarrow \mathrm{C} 1$ does not, this observation suggests that hypothesis [1] may be plausible. In order to acquire more reliable data, we should take into consideration the occurrences of the two categories $(\mathrm{C} 1$ and $\mathrm{C} 2)$ in the whole corpus as well.

To consider the results in relation to the whole corpus, I compare two fractions. The numerator and denominator of the first fraction form a minimal pair with each other, and show the repair operation pairs belonging to the relevant categories in the actions which satisfy 1), 2), and 3) (e.g., (A) in Figure 1). The second fraction contains all the occurrences of the repair operations under investigation belonging to the relevant categories in the corpus (not only in the actions satisfying 1), 2), and 3) (e.g., (B) in Figure $1)$.

\section{Figure 1}

A method for testing the preference hierarchy hypothesis
(A)
$\underline{\mathrm{C} 1 \rightarrow \mathrm{C} 1}$
(B)
$\underline{\mathrm{C} 1}$
$\mathrm{C} 1 \rightarrow \mathrm{C} 2$
$\mathrm{C} 2$

If we want to know which category ( $\mathrm{C} 1$ (recycling/ insertion) or $\mathrm{C} 2$ (replacement/ aborting)) follows more frequently after a certain category (e.g., C1 (recycling/ insertion)) in the actions satisfying 1), 2), and 3), we have to consider the ratio represented by the fraction in (A). While the numerator of this fraction contains the number of the repair operation pairs both members of which belong to the first category $(\mathrm{C} 1)$, its denominator shows the number of the repair operation pairs the first member of which belongs to $\mathrm{C} 1$, and the second member of which belongs to $\mathrm{C} 2$. If the value of (A) is greater than 1 (the degree of the numerator is greater than the degree of the denominator), then this means that in the actions satisfying 1), 2), and 3), a repair operation belonging to $\mathrm{C} 1$ (recycling or insertion) is more frequently followed by another repair operation belonging to $\mathrm{C} 1$ (recycling or insertion) than one which belongs to C2 (replacement or aborting). If the value of (A) is smaller than 1 (the degree of the numerator is smaller than the degree of the denominator), then this means that in the actions satisfying 1), 2), and 3), a repair operation belonging to $\mathrm{C} 1$ (recycling or insertion) is more frequently followed by an operation belonging to $\mathrm{C} 2$ (replacement or aborting) than one which belongs to $\mathrm{C} 1$ (recycling or insertion). In order to consider the value of (A) in relation to the whole corpus, we should 
compare the ratio in (A) with the ratio in (B). Whereas the numerator of (B) contains all the occurrences of the repair operations under investigation belonging to $\mathrm{C} 1$ in the corpus (not only in the actions satisfying the criteria 1), 2), and 3)), the denominator of (B) contains all the occurrences of the relevant repair operations belonging to $\mathrm{C} 2$ in the corpus (not only in the actions satisfying the criteria 1), 2), and 3)). If the value of (B) is greater than 1 , then the corpus contains more instances of the repair operations under investigation belonging to $\mathrm{C} 1$ than ones belonging to $\mathrm{C} 2$. If, for example, $\mathrm{C} 1 \rightarrow \mathrm{C} 1>\mathrm{C} 1 \rightarrow \mathrm{C} 2$ (rec./ins. $\rightarrow$ rec./ins. $>$ rec./ins. $\rightarrow$ repl./ab. (i.e. the value of $(\mathrm{A})$ is greater than 1$)$, and $(\mathrm{A})>(\mathrm{B})$, then we can say that in the actions satifying 1), 2), and 3), a repair operation belonging to $\mathrm{C} 1$ (recycling or insertion) is more frequently followed by another repair operation belonging to $\mathrm{C} 1$ (recycling or insertion) than one which belongs to $\mathrm{C} 2$ (replacement or aborting), and this does not come from the frequency of their occurrences in the corpus.

Table 19 includes all the possible minimal pairs testing [1] and [2] in the way described above (left side), and the fractions belonging to them which contain the relevant repair operations belonging to $\mathrm{C} 1$ and $\mathrm{C} 2$ in the corpus (right side). Table 20 shows the values belonging to Table 19.

Table 19

The patterns testing the preference hierarchy hypothesis

\begin{tabular}{|l|l|l|}
\hline$[1][\mathrm{a}]$ & $\frac{\mathrm{C} 1 \rightarrow \mathrm{C} 1}{\mathrm{C} 2 \rightarrow \mathrm{C} 1}$ & $\frac{\mathrm{C} 1}{\mathrm{C} 2}$ \\
\hline$[1][\mathrm{b}]$ & $\frac{\mathrm{C} 2 \rightarrow \mathrm{C} 1}{\mathrm{C} 2 \rightarrow \mathrm{C} 2}$ & $\frac{\mathrm{C} 1}{\mathrm{C} 2}$ \\
\hline$[2][\mathrm{a}]$ & $\frac{\mathrm{C} 1 \rightarrow \mathrm{C} 1}{\mathrm{C} 1 \rightarrow \mathrm{C} 2}$ & $\frac{\mathrm{C} 1}{\mathrm{C} 2}$ \\
\hline$[2][\mathrm{b}]$ & $\frac{\mathrm{C} 1 \rightarrow \mathrm{C} 2}{\mathrm{C} 2 \rightarrow \mathrm{C} 2}$ & $\frac{\mathrm{C} 1}{\mathrm{C} 2}$ \\
\hline
\end{tabular}

Table 20

The values belonging to Table 19

\begin{tabular}{|c|c|c|c|c|c|c|}
\hline [1][a] & $\frac{\text { rec./ ins. }(\mathbf{C 1}) \rightarrow \text { rec./ ins. }(\mathbf{C 1})}{\text { repl./ ab. }(\mathbf{C 2}) \rightarrow \text { rec./ ins. }(\mathbf{C 1})}$ & $\frac{262}{46}$ & 5.69 & $\frac{\text { rec./ ins.(C1) }}{\text { repl./ ab.(C2) }}$ & $\frac{929}{317}$ & 2.93 \\
\hline$[1][\mathrm{b}]$ & $\frac{\text { repl./ab.(C2) } \rightarrow \text { rec./ ins.(C1) }}{\text { repl./ab.(C2) } \rightarrow \text { repl./ ab.(C2) }}$ & $\frac{46}{35}$ & 1.31 & $\frac{\text { rec./ ins.(C1) }}{\text { repl./ ab.(C2) }}$ & $\frac{929}{317}$ & 2.93 \\
\hline$[2][a]$ & $\begin{array}{l}\text { rec./ ins. }(\mathbf{C 1}) \rightarrow \text { rec./ ins. }(\mathbf{C 1}) \\
\text { rec./ ins. }(\mathbf{C 1}) \rightarrow \text { repl./ ab.(C2) }\end{array}$ & $\frac{262}{73}$ & 3.58 & $\frac{\text { rec./ ins.(C1) }}{\text { repl./ ab.(C2) }}$ & $\frac{929}{317}$ & 2.93 \\
\hline
\end{tabular}




\begin{tabular}{|c|c|c|c|c|c|c|}
\hline$[2][\mathrm{b}]$ & $\frac{\text { rec./ins.(C1) } \rightarrow \text { repl./ ab.(C2) }}{\text { repl./ab.(C2) } \rightarrow \text { repl./ ab.(C2) }}$ & $\frac{73}{35}$ & 2.09 & $\frac{\text { rec./ ins.(C1) }}{\text { repl./ ab.(C2) }}$ & $\frac{929}{317}$ & 2.93 \\
\hline
\end{tabular}

To make the figures on the left and the right side comparable, the ratios have been turned into decimals. On the left side of [1] [a], we can see that a recycling or an insertion is much more frequently preceded by another recycling or insertion than by a replacement or an aborting: there are 5.69 times more recycling/ insertion $\rightarrow$ recycling/ insertion pairs than replacement/ aborting $\rightarrow$ recycling/ insertion pairs in the actions satisfying 1), 2), and 3). We can find only 2.93 times more recycling/ insertion repairs than replacement/ aborting repairs in the corpus, that is, the occurrences of the relevant repair operations in the corpus do not warrant such a great difference between the recycling/ insertion $\rightarrow$ recycling/ insertion pairs and the replacement/ aborting $\rightarrow$ recycling/ insertion pairs in the actions at issue. Therefore, a recycling or an insertion is more likely to be preceded by another recycling or insertion than by a replacement or an aborting, and this does not follow from their frequencies in the corpus. According to [1] [b], however, the pattern previously supposed to be less probable (replacement/ aborting $\rightarrow$ recycling/ insertion) is more frequent than the pattern assumed to be more probable (replacement/ aborting $\rightarrow$ replacement/ aborting). A replacement or an aborting is more likely to be followed by a recycling or an insertion than by another replacement or aborting. Nevertheless, if we compare this result with the numbers of the relevant repair operations in the corpus, we will realize that the difference between the occurrences of recycling/ insertion and replacement/ aborting in the corpus would warrant a much greater difference between the numerator and denominator of [1] [b]. Whereas there are 2.93 times more recycling/ insertion repairs than replacement/ aborting repairs in the corpus, we can find only 1.31 times as many replacement/ aborting $\rightarrow$ recycling/ insertion pairs than replacement/ aborting $\rightarrow$ replacement/ aborting pairs in the actions satisfying 1), 2), and 3). Consequently, the values in [1] [b] are not against the hypothesis, in other words, they do not make it implausible. As seen in [2][a], there are 3.58 times more recycling/ insertion $\rightarrow$ recycling/ insertion pairs than recycling/ insertion $\rightarrow$ replacement/ aborting pairs in the relevant actions. Comparing this result with the occurrences of the repair operations under investigation in the corpus, we realize that the corpus does not warrant the difference between the recycling/ insertion $\rightarrow$ recycling/ insertion pairs and the recycling/ insertion $\rightarrow$ replacement/ aborting pairs in the actions at issue. A recycling or an insertion is thus more likely to be followed by another recycling or insertion than by a replacement or an 
aborting, and this does not follow from their frequencies in the corpus. As in the case of testing [1] [b], in [2] [b], the pattern supposed to be less probable (recycling/ insertion $\rightarrow$ replacement/ aborting) is more frequent than the pattern assumed to be more probable (replacement/ aborting $\rightarrow$ replacement/ aborting). A replacement or an aborting is thus more likely to be preceded by a recycling or an insertion than by another replacement or aborting. However, if we compare this result with the numbers of the relevant repair operations in the corpus again, we will also realize that the difference between the occurrences of recycling/ insertion and replacement/ aborting in the corpus would warrant a greater difference between the numerator and denominator of [2] [b]. While there are 2.93 times more recycling/ insertion repairs than replacement/ aborting repairs in the corpus, we can find only 2.09 times more recycling/ insertion $\rightarrow$ replacement/ aborting pairs than replacement/ aborting $\rightarrow$ replacement/ aborting pairs in the actions satisfying 1), 2), and 3). Consequently, like in the case of [1] [b], we can say that the values in [2] [b] do not make the preference hierarchy hypothesis of repair operations implausible.

\subsection{Sub-conclusion - Hypothesis on the preference hierarchy of repair operations}

My argumentation in Chapter 6, which led to the setting up of a preference hierarchy among recycling initiated after recognizable completion, restarting, and replacement, has taken us closer to finding a potential explanation for the research question of the thesis, namely, why there is a cross-linguistic difference between the frequencies of recycling and replacement. The starting point of Chapter 7 has been the finding that speakers tend to avoid replacement because they tend to avoid producing inappropriate segments, and therefore, producing inappropriate segments is less preferred than employing the repair operation of recycling.

In order to find an answer to the question why it is less preferred to produce inappropriate segments than to employ recycling, in Chapter 7 I have added insertion and aborting to the repair operations under investigation, and examined the four operations in a larger corpus (see Chapter 4). The focus of this exploration has been on the ways recycling, replacement, insertion, and aborting suspend the progressivity of the ongoing action and thus violate the preference for progressivity. In other words, in order to move forwards in my argumentation, I have found it necessary to use new data sources and new methodological norms. For this reason, I have extended the p-context of the research, and started a new argumentation cycle, during which I have examined the repair operations 
from a different perspective (Kertész-Rákosi 2012: 134-153, 2014: 32-34; this thesis: Section 2.3.1). Since the conceptual apparatus of conversation analysis has proved to be insufficient by itself to describe the ways the four repair operations halt progressivity, I have introduced retrospectivity, redundancy, and inappropriateness as the respects in which the four repair operations violate the preference for progressivity. On the basis of this examination, I have proposed a model which can describe repair operations relative to each other. I have argued that the fewer respects there are in which a repair operation overrides the preference for progressivity, the more preferred it will be in the repair mechanism.

The preference hierarchy hypothesis has made it necessary to reconsider the relationship between intersubjectivity and progressivity. In Section 7.3, claiming that the principle of maintaining progressivity also has an impact on the principle of maintaining intersubjectivity (and not only vice versa), I have proposed a two-way relationship between intersubjectivity and progressivity. I have supposed that when they design their turns, speakers tend to make an effort to violate the preference for progressivity in the fewest possible respects, and this influences their maintenance of intersubjectivity. They also tend to make an effort to avoid problems which potentially require repair, and problems which potentially require repair operations overriding the preference for progressivity in several respects.

On the basis of data from previous research (Schegloff 1979, 1987, 2007, 2009, 2013; Drew et al. 2013; Goodwin 1980; Fox et al. 2009; Jefferson 1974), the qualitative analysis of extracts from the Hungarian corpus (during which I have also used statements from previous research), and my intuition, I have hypothesized that in a case where more than one self-repair is employed while carrying out the same action, the repair operations following one another will not be independent of one another, but the preference hierarchy assumed among them influences their order. During this argumentation cycle, then, I have developed the original hypothesis on the preference hierarchy of repair operations into another, already testable hypothesis. I have worked out the testing method, then applied it to the Hungarian corpus. The quantitative analysis of the possible orders of the four repair operations within the actions has supported the hypothesis.

\section{Conclusion - The results of the research and future directions}

In this thesis I have attempted to find a potential explanation for the difference between the frequency of recycling and replacement, which seems to be cross-linguistic (Fox et al. 
2009; Fox et al. 2010). The general aims of the thesis have been as follows: 1) to examine recycling and replacement repairs relative to each other in Hungarian conversations, and make a comparison with the languages so far investigated in this respect, and 2) to propose a model able to describe repair operations relative to each other. I have reached my proposed explanation for the difference between the frequencies of recycling and replacement by setting up a preference hierarchy model describing recycling, insertion, replacement, and aborting relative to each other. I have worked out this model by applying Kertész and Rákosi's p-model of plausible argumentation (Kertész-Rákosi 2012, 2014). I have built the metatheoretical issues into my object theoretical discussion, which has made my object theoretical results more reliable for the following reasons:

1. I have relied on a wide spectrum of data (statements originating from direct sources) as well as statements obtained as the conclusions of plausible inferences (statements originating from indirect sources). These direct and indirect sources can be divided into two main groups. The first group relates to previous studies, and involves their qualitative, quantitative, and statistical analyses based on the corpora of their languages examined, as well as the inferences they made and the conclusions they drew on the basis of their investigations. I have also obtained data from previous studies by finding connections between some pieces of their data which they left uncovered. The second group of sources I have used is comprised of my own qualitative, quantitative, and statistical analyses carried out on the Hungarian corpus, and the inferences I have made and the conclusions I have drawn on the basis of these analyses. I have used more types of statistical analyses the results of which have reinforced each other. Finally, I have used my intuition as well. These sources have been consciously integrated in the course of the research.

2. This metatheoretical approach has also made my problem solving more effective. When I have faced p-inconsistency (informational overdetermination), I have retrospectively re-evaluated the p-context (i.e., the previously accepted hypotheses, data, data sources, and methodological norms) from different perspectives, and treated the p-problems with the help of the problem-solving strategies offered by the p-model. Setting up the preference hierarchy hypothesis of repair operations in this way has not been linear, but cyclic and prismatic: cyclic, because the p-context has been retrospectively re-evaluated again and again, and prismatic, because this re-evaluation has been carried out from different perspectives. From this it follows 
that my argumentation has left open the possibility of more alternative solutions and further argumentation cycles.

My object theoretical findings which I have obtained in the way described above are the following:

1. I have found it plausible that repair operations are in the domain of same-turn selfrepair.

2. I have defined repair operations as practices whereby a co-interactant interrupts her/his ongoing turn-at-talk to attend to possible trouble in speaking, hearing, or understanding the talk or merely to alter the turn in some interactionally consequential way without any problems fixed in it.

3. I have argued for the repair operation status of recycling when it is employed solely to delay the next item due so that the speaker can attend to possible trouble in speaking, hearing, or understanding the talk or alter the turn in some interactionally consequential way without any problems fixed in it (Fox et al. 2009: 75).

4. I have proposed that if the practices such as $u h(m), y^{\prime} k n o w$, and silence are employed solely to delay the next item due so that the speaker can attend to possible trouble in speaking, hearing, or understanding the talk or alter the turn in some interactionally consequential way without any problems fixed in it, then they should be regarded as repair operations.

5. I have found that the speakers of the Hungarian corpus tend to recycle back to monosyllabic function words, and in the recycling repairs of the corpus syntactic class plays a more important role than word length.

6. My results concerning function word recycling in Hungarian support the prediction of Fox et al. (2010: 2504), who suggest that languages with function words preceding their respective content words will show a preference for recycling back to function words rather than content words.

7. I have found that the speakers of the Hungarian corpus tend to employ replacement repair in multisyllabic content words, and in the replacement repairs of the corpus word length plays a more important role than syntactic class. This may be due to the rich system of inflectional and derivational morphology of the language.

8. With respect to site of initiation, Hungarian fits the patterns suggested as universal by Fox et al. (2009): while recycling tends to be initiated after recognizable 
completion, replacement is generally initiated before the word is recognizably complete. As speakers initiate repair mainly in monosyllabic words, they tend towards initiation after recognizable completion, but they show no preference for site of initiation in bisyllabic words, where restarting repairs contribute to early repair initiations in the Hungarian corpus.

9. I have assumed that in the languages where speakers tend to use function word recycling to delay the next content word due and replacement repair to replace content words, the function of recycling repair and the function of replacement repair may not be independent of each other. Recycling in these languages may serve as a device for avoiding the repair operation of replacement. The study of Fox et al. (2010) and my result regarding Hungarian have supported this assumption. Fox et al. (2010) have found that the speakers of their three languages tend to use function word recycling to delay the next content word due and replacement repair to replace content words. Since in the replacement repairs of the Hungarian corpus word length plays a more important role than syntactic class, my finding that most of the function word recyclings in the Hungarian corpus happen before multisyllabic words, has also made the hypothesis plausible.

10. According to my assumption, both restarting repair and recycling repair initiated after recognizable completion may be employed to prevent the speaker from producing inappropriate segments, and thus both of them may be employed to help the speaker in avoiding replacement. The only difference is that while recycling initiated after recognizable completion is used before the problematic word, restarting is initiated when the problematic word has already begun. This is supported by the finding that restarting and replacement tend to affect the same word length and syntactic class categories in the languages examined so far.

11. I have assumed a preference hierarchy among recycling initiated after recognizable completion, restarting, and replacement: if speakers cannot use recycling initiated after recognizable completion where they need extra time, they will tend to substitute it with a restarting repair just to avoid replacement. This hypothesis offers a possible explanation not only for the possibly universal preference for recycling over replacement, but for the possibly universally constant recycling replacement ratio as well. On the basis of the results of Fox et al. (2009), Fox et al. (2010), and the examination of Hungarian, I assume that the ratio of early and late initiations in recycling repairs depends on the typical orders of function and content 
words in the languages, i.e., the exploitability of the delaying function of function word recycling. This is in accordance with the previous studies which have described how the methods of repair are shaped by the linguistic resources of languages, and argued in this way for the relationship between grammar and repair (see, e.g., Fox et al. 1996; Rieger 2003; Lerch 2007; Fox et al. 2009; Fox et al. 2010).

12. I have introduced retrospectivity, redundancy, and inappropriateness as the respects in which the repair operations of recycling, replacement, insertion, and aborting may violate the preference for progressivity, and I have proposed a model which can describe repair operations relative to each other. I have argued that the fewer respects in which a repair operation overrides the preference for progressivity, the more preferred it will be in the repair mechanism.

13. Since the preference hierarchy hypothesis of repair operations offers a possible explanation for the cross-linguistic difference assumed between the frequency of recycling and replacement, it proposes a candidate answer for the main research question of the thesis. It also influences the interpretation of the relationship between the principle of intersubjectivity and the principle of progressivity in talkin-interaction. Saying that the principle of maintaining progressivity also has an impact on the principle of maintaining intersubjectivity (not only vice versa), it supposes a two-way relationship between intersubjectivity and progressivity.

14. I have elaborated a testing method for the hypothesis, which was based on the subhypothesis that in a case in which more than one self-repair is employed while carrying out the same action, the repair operations following one another will not be independent of one another. The analysis of the Hungarian corpus with this method has made the hypothesis on the preference hierarchy of repair operations plausible.

Summarizing the object theoretical results of the thesis, we can conclude that the speakers' possible choices of repair operations relating to self-repair depend on at least three factors: the function of repair operations, the number of respects in which they override the preference for progressivity, and the morpho-syntactic structure of the language used by the speaker. This is in accordance with the previous studies illuminating the strong relationship between grammar and repair (see, e.g., Schegloff 1979; Fox et al. 
1996; Rieger 2003; Lerch 2007; Fox et al. 2009; Fox et al. 2010), and further supports the research highlighting the interaction between grammar and pragmatics.

The features of redundancy, retrospectivity, and inappropriateness do not belong to the four repair operations per se but to the property of halting the progressivity of the turn. Therefore, in order to test the hypothesis in a direct way, i.e., to see the frequencies of the different categories in the corpus, and to see whether there are more categories (more respects in which the preference for progressivity can be violated), we should examine the other six repair operations as well (deleting, searching, parenthesizing, sequence-jumping, reformatting, and reordering) (see Schegloff 2013). This could be the next step of the study. Moreover, in order to see even more clearly, we sould take into consideration all the phenomena halting the progressivity of the turn. In this way, it would be possible to recognize new repair operations which have not been described in the literature yet (cf. Schegloff 2013: 68), and also phenomena where the progressivity of the turn is suspended without repair occurring. Furthermore, since the repair operations of deleting, searching, parenthesizing, sequence-jumping, reformatting, and reordering has not been investigated in Hungarian so far, the analysis should be expanded to the interactional import of the six repair operations, the techniques employed accomplishing them, as well as the potential relationship between the structure of the language and their usage.

\section{References}

Austin, John L. 1962. How to do Things with Words. Cambridge, MA: Harvard University Press.

Austin, John L. 1979. Philosophical Papers. Oxford and New York: Oxford University Press.

Bilmes, Jack 1988. The concept of preference in conversation analysis. Language in Society 17: 161-181.

Blackmer, Elizabeth - Janet Mitton 1991. Theories of monitoring and the timing of repairs in spontaneous speech. Cognition 39: 173-194.

Bolden, Galina B. - Jenny Mandelbaum - Sue Wilkinson 2012. Pursuing a response by repairing an indexical reference. Research on Language and Social Interaction 45(2): $137-155$.

Bóna, Judit 2006. A megakadásjelenségek akusztikai és percepciós sajátosságai [The acoustic and perceptional characteristics of disfluency phenomena]. In Mária Gósy 
(Ed.) Beszédkutatás 2006 [Speech Research 2006]. Budapest: MTA Nyelvtudományi Intézet. 101-114.

Boomer, Donald S. - John D. M. Laver 1968. Slips of the tounge. British Journal of Disorders of Communication 3: 2-11.

Clark, Herbert H. - Thomas Wasow 1998. Repeating words in spontaneous speech. Cognitive Psychology 37: 201-242.

Clayman, Steven E. 2013. Turn-Constructional Units and the Transition Relevance Place. In Jack Sidnell - Tanya Stivers (Eds.) The Handbook of Conversation Analysis. Oxford: Wiley-Blackwell. 150-166.

Cutler, Anne 1988. The perfect speech error. In Larry M. Hyman - Charles N. Li (Eds.) Language, Speech and Mind: Studies in Honor of Victoria A. Fromkin. London: Croom Helm. 209-223.

Drew, Paul 1997. 'Open' class repair initiators in response to sequential sources of troubles in conversation. Journal of Pragmatics 28: 69-101.

Drew, Paul 2013. Turn design. In Jack Sidnell - Tanya Stivers (Eds.) The Handbook of Conversation Analysis. Oxford: Wiley-Blackwell. 131-149.

Drew, Paul - Traci Walker - Richard Ogden 2013. Self-repair and action construction. In Makoto Hayashi - Geoffrey Raymond - Jack Sidnell (Eds.) Conversational Repair and Human Understanding. Cambridge: Cambridge University Press. 71-94.

Egbert, Maria M. 1996. Context sensitivity in conversation analysis: Eye gaze and the German repair initiator 'bitte'. Language in Society 25(4): 587-612.

Egbert, Maria M. 2004. Other-initiated repair and membership categorization: Some conversational events that trigger linguistic and regional membership categorization. Journal of Pragmatics 36: 1467-1498.

É. Kiss, Katalin 2002. The Syntax of Hungarian. Cambridge: Cambridge University Press. Fabulya, Márta 2007. Izé, hogyhívják, hogymondjam. Javítást kezdeményező lexikális kitöltőelemek [Lexical fillers initiating self-repair sequences in Hungarian]. Magyar Nyelvör [Hungarian Purist] 131: 324-342.

Fox, Barbara A. - Makoto Hayashi - Robert Jasperson 1996. Resources and repair: A cross-linguistic study of syntax and repair. In Elinor Ochs - Emanuel A. Schegloff Sandra A. Thompson (Eds.) Interaction and Grammar. Cambridge: Cambridge University Press. 185-237.

Fox, Barbara A. - Fay Wouk - Makoto Hayashi - Steven Fincke - Liang Tao - MarjaLeena Sorjonen - Minna Laakso - Wilfrido Flores Hernandez 2009. A cross- 
linguistic investigation of the site of initiation in same-turn self-repair. In Jack Sidnell (Ed.) Conversation Analysis: Comparative Perspectives. Cambridge: Cambridge University Press. 60-103.

Fox, Barbara A. - Yael Maschler - Susanne Uhmann 2010. A cross-linguistic study of self-repair: Evidence from English, German, and Hebrew. Journal of Pragmatics 42: $2487-2505$.

Fromkin, Victoria A. (Ed.) 1973. Speech Errors as Linguistic Evidence. The Hague Paris: Mouton.

Goodwin, Charles 1980. Restarts, pauses, and the achievement of a state of mutual gaze at turn-beginning. Sociological Inquiry 50: 272-302.

Goodwin, Charles 1981. Conversational Organization: Interaction Between Speakers and Hearers. New York: Academic Press.

Goodwin, Marjorie Harness 1983. Aggravated correction and disagreement in children's conversations. Journal of Pragmatics 7: 657-677.

Gósy, Mária 2003. A spontán beszédben előforduló megakadásjelenségek gyakorisága és összefüggései [Co-occurrence and frequency of disfluencies in Hungarian spontaneous speech]. Magyar Nyelvör [Hungarian Purist] 127: 257-277.

Gósy, Mária 2004. A spontán magyar beszéd megakadásainak hallás alapú gyüjteménye [An audition-based collection of spontaneous Hungarian speech disfluencies]. In Mária Gósy (Ed.) Beszédkutatás 2004 [Speech Research 2004]. Budapest: MTA Nyelvtudományi Intézet. 6-18.

Gósy, Mária 2005. Pszicholingvisztika [Psycholinguistics]. Budapest: Osiris Kiadó.

Gósy, Mária 2008. Magyar spontánbeszéd-adatbázis - BEA [A Hungarian spontaneous speech database - BEA]. In Mária Gósy (Ed.) Beszédkutatás 2008 [Speech Research 2008]. Budapest: MTA Nyelvtudományi Intézet. 194-208.

Gósy, Mária 2012. Multifunkcionális beszélt nyelvi adatbázis - BEA [A multifunctional spontaneous speech database - BEA]. In Gábor Prószéky - Tamás Váradi (Eds.) Általános Nyelvészeti Tanulmányok XXIV. Nyelvtechnológiai Kutatások [Studies in General Linguistics XXIV. Language Technology Research]. Budapest: Akadémiai Kiadó. 329-349.

Grice, Paul 1989. Studies in the Way of Words. Cambridge, Massachusetts, London, England: Harvard University Press.

Guimaraes, Estefania 2007. Talking About Violence: Women Reporting Abuse in Brazil. Unpublished PhD Dissertation, UK: University of York. 
Gyarmathy, Dorottya 2006. A beszédpercepciós és beszédprodukciós folyamat összefüggései a megakadásjelenségek tükrében [The correlations of speech perception and speech production in the light of disfluency phenomena]. In Pál Heltai (Ed.) MANYE XVI. Tanulmánykötet [Volume of Studies] 3/2. Gödöllő: Szent István Egyetemi Kiadó. 449-455.

Gyarmathy, Dorottya 2007. Az alkohol hatása a spontán beszédprodukcióra [The effect of alcohol on spontaneous speech production]. In Mária Gósy (Ed.) Beszédkutatás 2007 [Speech Research 2007]. Budapest: MTA Nyelvtudományi Intézet. 108-121.

Gyarmathy, Dorottya 2009. A beszélő bizonytalanságának jelzései: ismétlések és újraindítások [The cues of speakers' uncertainty: Repetitions and restarts]. In Mária Gósy (Ed.) Beszédkutatás 2009 [Speech Research 2009]. Budapest: MTA Nyelvtudományi Intézet. 196-216.

Gyarmathy, Dorottya 2012a. Kétarcú újraindítás [Double-faced restart]. In Alexandra

Markó (Ed.) Beszédtudomány [Speech Science]. Budapest: ELTE Bölcsészettudományi Kar, MTA Nyelvtudományi Intézet. 50-67.

Gyarmathy, Dorottya 2012b. Strategies of disfluency repairs in spontaneous speech. The Phonetician 2011-I/II 103/104: 88-96.

Gyarmathy, Dorottya - Gósy Mária 2014. The characteristics of sublexical errors in spontaneous speech. In Susanne Fuchs - Martine Grice - Anne Hermes - Leonardo Lancia - Doris Mücke (Eds.) Proceedings of the 10th International Seminar on Speech Production. 166-169.

Have, Paul ten 1990. Methodological issues in conversation analysis. Bulletin de Méthodologie Sociologique 27: 23-51.

Hayashi, Makoto 2003. Language and the body as resources for collaborative action: A study of word searches in Japanese conversation. Research on Language and Social Interaction 36(2): 109-141.

Heritage, John 1984. Garfinkel and Ethnomethodology. Cambridge: Polity Press.

Heritage, John 2007. Intersubjectivity and progressivity in person (and place) reference. In Nicholas J. Enfield - Tanya Stivers (Eds.) Person Reference in Interaction: Linguistic, Cultural, and Social Perspectives. Cambridge: Cambridge University Press. 255-280.

Heritage, John - J. Maxwell Atkinson 1984. Preference organization. In J. Maxwell Atkinson - John Heritage (Eds.) Structures of Social Action: Studies in Conversation Analysis. Cambridge: Cambridge University Press. 53-56. 
Horváth, Viktória 2004. Megakadásjelenségek a párbeszédekben [Speech disfluencies in dialogues]. In Mária Gósy (Ed.) Beszédkutatás 2004 [Speech Research 2004]. Budapest: MTA Nyelvtudományi Intézet. 187-199.

Horváth, Viktória 2007. Vannak-e „női” és „férfi” megakadásjelenségek a spontán beszédben? [Are there gender-based differences in disfluency phenomena?] Magyar Nyelvör [Hungarian Purist] 131: 315-323.

Huszár, Ágnes 2005. A Gondolattól a Szóig. A Beszéd Folyamata a Nyelvbotlások Tükrében [From Thought to Word. The Process of Speech in the Light of the Slips of the Tongue]. Budapest: Tinta Kiadó.

Jasperson, Robert 1998. Repair After Cut-off. PhD Dissertation, University of Colorado: Boulder.

Jefferson, Gail 1972. Side sequences. In David Sudnow (Ed.) Studies in Social Interaction. New York: Free Press. 294-338.

Jefferson, Gail 1974. Error correction as an interactional resource. Language in Society 3: 181-199.

Jefferson, Gail 1987. On exposed and embedded correction in conversation. In Graham Button - John R. E. Lee (Eds.) Talk and Social Organisation. Clevedon, UK: Multilingual Matters. 86-100.

Jefferson, Gail 2004. Glossary of transcript symbols with an introduction. In Gene H. Lerner (Ed.) Conversation Analysis: Studies from the First Generation. Amsterdam: John Benjamins. 13-31.

Jurafsky, Daniel - Alan Bell - Eric Fosler-Lussier - Cynthia Girand - William Raymond 1998. Reduction of English function words in switchboard. Proceedings of the International Conference on Spoken Language Processing 7. Sydney. 3111-3114.

Kenesei, István 2000. Szavak, szófajok, toldalékok [Words, word classes, affixes]. In Ferenc Kiefer (Ed.) Strukturális Magyar Nyelvtan 3. [Structural Hungarian Grammar 3.] Budapest: Akadémiai Kiadó. 75-136.

Kertész, András - Rákosi Csilla 2012. Data and Evidence in Linguistics: A Plausible Argumentation Model. Cambridge: Cambridge University Press.

Kertész, András - Rákosi Csilla 2014. The Evidential Basis of Linguistic Argumentation. Amsterdam, Philadelphia: John Benjamins Publishing Company.

Kim, Kyu-Hyun 1993. Other-initiated repair sequences in Korean conversation as interactional resources. In Soonja Choi (Ed.) Japanese/Korean Linguistics III. Center for the Study of Language and Information: Leland Stanford Junior University. 3-18. 
Kim, Kyu-Hyun 2001. Confirming intersubjectivity through retroactive elaboration: Organization of phrasal units in other-initiated repair sequences in Korean conversation. In Margret Selting - Elizabeth Couper-Kuhlen (Eds.) Studies in Interactional Linguistics. Amsterdam: John Benjamins. 345-372.

Kitzinger, Celia 2013. Repair. In Jack Sidnell - Tanya Stivers (Eds.) The Handbook of Conversation Analysis. Oxford: Wiley-Blackwell. 229-256.

Kolk, Herman - Albert Postma 1997. Stuttering as a covert repair phenomena. In Richard F. Curlee - Gerald M. Siegel (Eds.) Nature and Treatment of Stuttering: New Directions. Needham Heights, Massachusetts: Allye and Bacon 182-203.

Laakso, Minna - Marja-Leena Sorjonen 2010. Cut-off or particle - Devices for initiating self-repair in conversation. Journal of Pragmatics 42: 1151-1172.

Labov, William 1972. Sociolinguistic patterns. Philadelphia: University of Pennsylvania Press.

Lehmann, Christian 2004. Data in linguistics. The Linguistic Review 21: 175-210.

Lerch, Ágnes 2007. Az ismétlés mint az önjavítás eszköze a magyarban [Repetition as a means of self-repair in Hungarian]. In Tamás Gecső - Csilla Sárdi (Eds.) Nyelvelmélet - nyelvhasználat [Language Theory and Language Use]. Budapest: Tinta Könyvkiadó. 123-130.

Lerner, Gene H. 2013. On the place of hesitating in delicate formulations: A turnconstructional infrastructure for collaborative indiscretion. In Makoto Hayashi Geoffrey Raymond - Jack Sidnell (Eds.) Conversational Repair and Human Understanding. Cambridge: Cambridge University Press. 95-134.

Levelt, Willem J. M. 1983. Monitoring and self-repair in speech. Cognition 14: 41-104.

Levelt, Willem J. M. 1989. Speaking. From Intention to Articulation. Cambridge, MA: MIT Press.

Levinson, Stephen 2013. Action formation and ascription. In Jack Sidnell - Tanya Stivers (Eds.) The Handbook of Conversation Analysis. Oxford: Wiley-Blackwell. 103-130.

Luke, Kang-Kwong - Wei Zhang 2010. Insertion as a self-repair device and its interactional motivations in Chinese conversation. Chinese Language and Discourse 1: $153-182$.

Maheux-Pelletier, Genevieve - Andrea Golato 2008. Repair in membership categorization in French. Language in Society 37(5): 689-712.

Markó, Alexandra 2004. Megakadások vizsgálata különféle monologikus szövegekben [The examination of speech disfluencies in various monologic texts]. In Mária Gósy 
(Ed.) Beszédkutatás 2004 [Speech Research 2004]. Budapest: MTA Nyelvtudományi Intézet. 209-222.

Markó, Alexandra 2006. A megakadásjelenségek hatása a beszédészlelésre [The effect of disfluency phenomena on speech perception]. Alkalmazott Nyelvtudomány [Applied Linguistics] VI/1-2. 103-117.

Moerman, Michael 1977. The preference for self-correction in a Thai conversational corpus. Language 53(4): 872-882.

Mondada, Lorenza 2013. The conversation analytic approach to data collection. In Jack Sidnell - Tanya Stivers (Eds.) The Handbook of Conversation Analysis. Oxford: Wiley-Blackwell. 32-56.

Moravcsik, Edith A. 1969. Determination. Working Papers on Language Universals 1. Stanford University, CA: Committee on Linguistics.

Németh, Zsuzsanna 2007-2008. A forduló (beszédlépés) kiterjesztésének grammatikája a magyarban [The grammatics of turn-expansion in Hungarian]. Nyelvtudomány III-IV [Linguistics III-IV]: 149-183.

Németh, Zsuzsanna 2012a. Az ismétlés és a csere interakciós funkciói magyar nyelvü spontán társalgásokban [The interactional functions of recycling and replacement repairs in spontaneous Hungarian conversations]. In Mária Gósy (Ed.) Beszédkutatás 2012 [Speech Research 2012]. Budapest: MTA Nyelvtudományi Intézet. 154-167.

Németh, Zsuzsanna 2012b. Recycling and replacement self-repairs in spontaneous Hungarian conversations. In Balázs Surányi - Diána Varga (Eds.) Proceedings of the First Central-European Conference for Postgraduate Students. Piliscsaba: Pázmány Péter Catholic University. 211-224.

Németh, Zsuzsanna 2012c. Recycling and replacement repairs as self-initiated same-turn self-repair strategies in Hungarian. Journal of Pragmatics 44: 2022-2034.

Németh, Zsuzsanna 2013. A javításkezdeményezés helye és a javítási műveletek a magyarban [The site of repair initiation and repair operations in Hungarian]. In Zsuzsanna Gécseg (Ed.) LingDok 12. Szeged: JATEPress. 177-198.

Németh, Zsuzsanna 2014. A javítási mủveletek jelöltségi hipotézise [The markedness hypothesis of repair operations]. Jelentés és Nyelvhasználat 1: 29-54.

Nooteboom, Sieb G. 1980. Speaking and unspeaking: Detection and correction of phonological and lexical errors in spontaneous speech. In Victoria A. Fromkin (Ed.) Errors in Linguistic Performance: Slips of the Tongue, Ear, Pen, and Hand. New York: Academic Press. 87-96. 
Nooteboom, Sieb G. 2005. Lexical bias revisited: Detecting, rejecting and repairing speech errors in inner speech. Speech Communication 47: 43-58.

Pérez, Elvira - Julio Santiago - Alfonso Palma - Padraig G. O’Seaghdha 2007. Perceptual bias in speech error data collection: Insights from Spanish speech errors. Journal of Psycholinguistic Research 36: 20 -235.

Pomerantz, Anita 1978. Compliment responses: Notes on the co-operation of multiple constraints. In Jim Schenkein (Ed.) Studies in the Organization of Conversational Interaction. New York: Academic Press. 79-112.

Pomerantz, Anita 1986. Extreme case formulations: A way of legitimizing claims. Human Studies 9(2-3): 219-229.

Pomerantz, Anita - John Heritage 2013. Preference. In Jack Sidnell - Tanya Stivers (Eds.) The Handbook of Conversation Analysis. Oxford: Wiley-Blackwell. 210-228.

Postma, Albert 2000. Detection of errors during speech production: A review of speech monitoring models. Cognition 77: 97-131.

Postma, Albert - Herman H. J. Kolk - Dirk-Jan Povel 1990. On the relation between speech errors, disfluencies and self-repairs. Language and Speech 33: 19-29.

Poulisse, Nanda 1999. Slips of the Tongue. Speech Errors in First and Second Language Production. Amsterdam: John Benjamins.

Rieger, Caroline L. 2003. Repetitions as self-repair strategies in English and German conversations. Journal of Pragmatics 35: 47-69.

Robinson, Jeffrey D. 2006. Managing trouble responsibility and relationships during conversational repair. Communication Monographs 73(2): 137-161.

Sacks, Harvey 1987 [1973]. On the preferences for agreement and contiguity in sequences in conversation. In Graham Button - John R. E. Lee (Eds.) Talk and Social Organisation. Clevedon, UK: Multilingual Matters. 54-69.

Sacks, Harvey 1995a [1964-1968]. Lectures on Conversation 1. Oxford: Blackwell.

Sacks, Harvey 1995b [1968-1972]. Lectures on Conversation 2. Oxford: Blackwell.

Sacks, Harvey - Emanuel A. Schegloff - Gail Jefferson 1974. A simplest systematics for the organization of turn-taking for conversation. Language 50: 696-735.

Sacks, Harvey - Emanuel A. Schegloff 1979. Two preferences in the organization of reference to persons in conversation and their interaction. In George Psathas (Ed.) Everyday Language: Studies in Ethnomethodology. New York: Irvington Publishers. $15-21$. 
Schegloff, Emanuel A. 1979. The relevance of repair to syntax-for-conversation. In Talmy Givón (Ed.) Syntax and Semantics XII. New York: Academic Press. 261-286.

Schegloff, Emanuel A. 1987. Recycled turn beginnings, a precise repair mechanism in conversation's turn-taking organization. In Graham Button - John R. E. Lee (Eds.) Talk and Social Organisation. Clevedon, UK: Multilingual Matters. 70-85.

Schegloff, Emanuel A. 1988. On an actual virtual servo-mechanism for guessing bad news: A single case conjecture. Social Problems 35(4): 442-457.

Schegloff, Emanuel A. 1992. Repair after next turn: The last structurally provided place for the defense of intersubjectivity in conversation. American Journal of Sociology 95: $1295-1345$.

Schegloff, Emanuel A. 1993. Reflections on quantification in the study of conversation. Research on Language and Social Interaction 26(1): 99-128.

Schegloff, Emanuel A. 1996. Confirming allusions: Toward an empirical account of action. American Journal of Sociology 102(1): 161-216.

Schegloff, Emanuel A. 1997a. Third turn repair. In Gregory R. Guy - Crawford Feagin Deborah Schiffrin - John Baugh (Eds.) Towards a Social Science of Language: Papers in Honour of William Labov II. Amsterdam: John Benjamins. 31-40.

Schegloff, Emanuel A. 1997b. Practices and actions: Boundary cases of other-initiated repair. Discourse Processes 23(3): 499-545.

Schegloff, Emanuel A. 2000. When 'others' initiate repair. Applied Linguistics 21: 205243.

Schegloff, Emanuel A. 2007. Sequence Organization in Interaction: A Primer in Conversation Analysis. Cambridge: Cambridge University Press.

Schegloff, Emanuel A. 2008a. Ten Operations in Self-initiated, Same-Turn Repair. Paper presented at the conference on repair and intersubjectivity in talk and social interaction, University of Toronto.

Schegloff, Emanuel A. 2008b. Self-initiated, Same-Turn Repair: Three Core Topics. Paper presented at the workshop on repair and intersubjectivity in talk and social interaction, University of Toronto.

Schegloff, Emanuel A. 2009. One perspective on Conversation Analysis: Comparative Perspectives. In Jack Sidnell (Ed.) Conversation Analysis: Comparative Perspectives. Cambridge: Cambridge University Press. 357-406. 
Schegloff, Emanuel A. 2013. Ten operations in self-initiated, same-turn repair. In Makoto Hayashi - Geoffrey Raymond - Jack Sidnell (Eds.) Conversational Repair and Human Understanding. Cambridge: Cambridge University Press. 41-70.

Schegloff, Emanuel A. - Gail Jefferson - Harvey Sacks 1977. The preference for selfcorrection in the organization of repair in conversation. Language 53: 361-382.

Schenkein, Jim 1978. Sketch of an analytic mentality for the study of conversational interaction. In Jim Schenkein (Ed.) Studies in the Organization of Conversational Interaction. New York: Academic Press. 1-6.

Schirm, Anita 2011. A diskurzusjelölök funkciói: a hát, az -e és a vajon elemek története és jelenkori szinkrón státusa alapján [The functions of discourse markers: on the basis of the history and present status of the elements 'hát', '-e', and 'vajon']. PhDdissertation. Szeged: University of Szeged. http://doktori.bibl.uszeged.hu/759/1/schirm_anita_doktori_disszertacio.pdf

Searle, John R. 1969. Speech Acts. Cambridge: Cambridge University Press.

Searle, John R. 1975. Indirect speech acts. In Peter Cole - Jerry L. Morgan (Eds.) Syntax and Semantics III. New York: Academic Press. 59-82.

Searle, John R. 1976. The classification of illocutionary acts. Language in Society 5: 1-24.

Searle, John R. - Daniel Vanderveken 1985. Foundations of Illocutionary Logic. Cambridge: Cambridge University Press.

Selkirk, Elisabeth 2008. The prosodic structure of function words. In John J. McCarthy (Ed.) Optimality Theory in Phonology: A Reader. Oxford: Blackwell. 464-482.

Shriberg, Elizabeth 2001. To 'errr' is human: Ecology and acoustics of speech disfluencies. Journal of the International Phonetic Association 31: 153-169.

Sidnell, Jack 2008. Alternate and complementary perspectives on language and social life: The organization of repair in two Caribbean communities. Journal of Sociolinguistics 12(4): 477-503.

Sidnell, Jack - Tanya Stivers (Eds.) 2013. The Handbook of Conversation Analysis. Oxford: Wiley-Blackwell.

Stivers, Tanya 2005. Modified repeats: One method for asserting primary rights from second position. Research on Language and Social Interaction 38(2): 131-158.

Stivers, Tanya 2011. Morality and question design: 'Of course' as contesting a presupposition of askability. In Tanya Stivers - Lorenza Mondada - Jakob Steensig (Eds.) The Morality of Knowledge in Conversation. Cambridge: Cambridge University Press. 82-106. 
Stivers, Tanya 2013. Sequence Organization. In Jack Sidnell - Tanya Stivers (Eds.) The Handbook of Conversation Analysis. Oxford: Wiley-Blackwell. 191-209.

Stivers, Tanya - Jeffrey D. Robinson 2006. A preference for progressivity in interaction. Language in Society 35: 367-392.

Stivers, Tanya - Jack Sidnell 2013. Introduction. In Jack Sidnell - Tanya Stivers (Eds.) The Handbook of Conversation Analysis. Oxford: Wiley-Blackwell. 1-8.

Svennevig, Jan 2008. Trying the easiest solution first in other-initiation of repair. Journal of Pragmatics 40(2): 333-348.

Szabó, Tamás Péter 2012. „Kirakunk táblákat, hogy csúnyán beszélni tilos”. A javítás mint gyakorlat és mint téma diákok és tanáraik metanyelvében [Repair as Communication Practice - Repair as Discourse Topic. A Multi-Faceted Investigation of Hungarian School Metalanguage]. Dunajská Streda: Gramma.

Szili, Katalin 2004. A bókra adott válaszok pragmatikája. Adalékok a szerénység nyelvi megnyilvánulásához a magyar nyelvben [The pragmatics of replies to compliments: Data on the manifestation of the principle of modesty in Hungarian]. Magyar Nyelvör [Hungarian Purist] 128: 265-285.

Szili, Katalin 2010. The linguistic forms of modesty in the Hungarian language or the pragmatics of compliment response. In Iwona Witczak-Plisiecka (Ed.) Pragmatic Perspectives on Language and Linguistics. Cambridge: Cambridge Scholars Publishing. 149-164.

Whitehead, Kevin A. 2009. 'Categorizing the Categorizer': The management of racial common sense in interaction. Social Psychology Quarterly 72: 325-342.

Wilkinson, Sue - Ann Weatherall 2011. Insertion repair. Research on Language and Social Interaction 44: 65-91.

Wouk, Fay 2005. The syntax of repair in Indonesian. Discourse Studies 7(2): 237-258.

$\mathrm{Wu}$, Ruey-Jiuan Regina 2006. Initiating repair and beyond: The use of two repeatformatted repair initiations in Mandarin conversation. Discourse Processes 41(1): 67-109.

\section{Appendix}

\section{Transcription conventions (Jefferson 2004)}

Falling terminal contour 
, Continuing contour (incomplete)

? Strongly rising terminal contour

- $\quad$ Abrupt halt

[] Overlapping speech

$=$ Latching (contiguous stretches of talk)

(0.7) Pause measured in tenths of a second

(.) Pause timed less than 0.2 seconds

_ Stress on the word/syllable/sound

: $\quad$ Lengthening of previous sound

CAPS Increase in volume

$\circ \circ$ Decrease in volume

$\uparrow \downarrow \quad$ Significant rise or fall in intonation

$>$ Faster than surrounding talk

$<$ Slower than surrounding talk

.hhh Audible inhalation

( ) Unintelligible speech

(( )) Comments, e.g., quality of speech

\section{Glossary}

1 first person

2 second person

3 third person

ABL ablative

ACC accusative

ADE adessive

ADER affix deriving an adjective

ALL allative

CAUS causative

COM comitative

COND conditional

DAT dative

DEF definite

DEL delative 
ELA elative

GEN genitive

ILL illative

IMP imperative

INE inessive

INF infinitive

INS instrumental

NDER suffix deriving a noun

NEG negation, negative

NOM nominative

PL plural

POSS possessive

PTCP participle

PVB preverb (verbal prefix)

SG singular

SUB sublative

SUP superessive

TERM terminative

\section{Acknowledgements}

My special thanks are due to my supervisor Enikö Németh T. for her constant encouragement and help. I also would like to thank the two referees of the first version of the thesis Enikő Tóth and Tamás Péter Szabó for their insightful comments and constructive criticism. I am very grateful to Csilla Rákosi, Márta Maleczki, George O’Neal, Mária Gósy, and the participants of the Pragmatics Research Seminar (Doctoral School of Theoretical Linguistics, University of Szeged), as well as the anonymous reviewers of my previous submissions on the topic for their useful comments and suggestions. I am indebted to Ágnes Lerch, who was my first supervisor and with whom I have made the recordings of the SZTEPSZI corpus. I thank Gábor Orosz, Dezső Németh, Zsolt Turi, Márk Kékesi, Karolina Janacsek, and Réka Dudok for supporting me in carrying out the statistical analyses of the thesis. I am also grateful to the Institute of Psychology, University of Szeged for making possible to record and code one of the two 
corpora, and Mária Gósy for putting the other corpus at my disposal. Finally, I also thank George Seel for improving my English. 